\title{
ECGLESIASTIGUS \\ THE FRAGMENTS
}

HITHERTO RECOVERED

OF THE HEBREW TEXT

IN FACSIMILE 


\title{
FACSIMILES OF THE FRAGMENTS
}

\author{
HITHERTO RECOVERED OF \\ THE BOOK OF ECCLESIASTICUS \\ IN HEBREW
}

OXFORD

UNIVERSITY PRESS

LONDON : HENRY FROWDE
CAMBRIDGE

UNIVERSITY PRESS

LONDON: C. J. CI.AY \& SONS

$M \mathrm{D} \mathrm{CCCCI}$ 


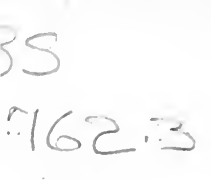

901

OXFORD: HOKACE HAKT
PRITTKK TO THE LXNERSITY

THE LIBRARY

Crintity Colles: toronio, - Can. 


\section{EXPLANATORY NOTE}

TH: fragments of the Hebrew Ecclesiasticus have been edited as follow: :-

\section{MS. A.}

(a) $8 \mathrm{pp}$. belonging to the Taylor-Schechter collection in the University

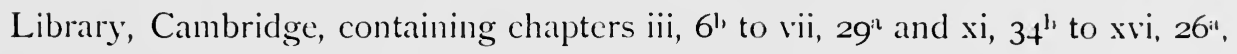
edited by Schechter and Taylor in 'The Wisdom of Ben Sira,' Cambridge, I8s9.

(b) $+\mathrm{pp}$. belonging to E. N. Adler, containing chapters vii, 29 to $x \mathrm{ii}, \mathrm{I}+$, edited by' him in the 'Jewish Quarterly Review' for April, 1900, pp. 466 sqq.

\section{MS. B.}

(c) I 4 pp. belonging to the Taylor-Schechter collection, containing chapters xxx, I t to xxxi, I ; xxxii, I to xxxiii, 3 ; xxxv, in to xxxvi, 26 ; xxxiii, 27 to xxxviii, $27^{\text {h }}$; xlix, $12^{\mathrm{c}}$ to the end, edited with $(a)$.

(d) $4 \mathrm{pp}$. in the British Muscum, containing chapters xxxi, 12 to xxxi, 31 ; xxxvi, 24 to xxxvii, 26, edited by G. Margoliouth in the 'Jewish Quarterly' Revicw' for October, 1899, pp. I sqq.

(e) 2 pp. (the first leaf found) belonging to Mrs. Lewis and Mrs. Gibson, containing chapters xxxix, $\mathrm{I}^{\mathrm{c}}$ to $\mathrm{xl}, 8$, edited by Schechter in the 'Expositor' for July, I896, pp. I sqq., and afterwards with $(f)$.

(f) $18 \mathrm{pp}$. in the Bodleian Library, Oxford, containing chapters $\mathrm{xl}, 9$ 
to xlix, I I, edited together with $(c)$ by Cowley and Neubauer in 'The Original Hebrew of a portion of Ecclesiasticus,' Oxford, 1897.

MS. C.

(g) $4 \mathrm{pp}$. belonging to the Taylor-Schechter collection, containing chapters iv, 23, 30, 31; v, 4-7", 9-13+; $\mathrm{xxv}, 8, \mathrm{I3}, \mathrm{I7}-24$; $\mathrm{xxvi}, \mathrm{I}, 2^{\mathrm{a}}$, edited by Schechter in the 'Jewish Quarterly Review' for April, I900, pp. 456 sqq.

(h) $2 \mathrm{pp}$. in the library of the Consistoire israćlite (Paris), containing chapters vi, I8", 19, 28, 35; vii, I, 4, 6al', I7, 20, 21, 23-25, edited by I. Lévi in the 'Rerue des Études Juives' for Janvier-Mars, 1900, pp. I sqq.

(i) 2 pp. belonging to M. Gaster, containing chapters xviii, $3^{\mathrm{l}}$ to $\mathrm{xix}, 3^{\mathrm{l}}$; xx, 5-7, 13; xxxvii, 19, 22, 24, 26, edited by him in the 'Jewish Quarterly Reriew' for July, I900, pp. 688 sqq.

\section{MS. D.}

(k) 2 pp. in the library of the Consistoire israélite (Paris), containing chapters xxxvi, 29 to xxxviii, $\mathrm{I}^{\mathrm{a}}$, edited with $(h)$.

The chapters and verses are numbered in accordance with Swete's Greek text. 


\section{CONTENTS}

\section{AND ORDER OF THE FRAGMENTS}

MS. A :-

Ecclus. iil, $6^{b}-i v$, Io

iv, $10^{c}-v, 10^{n}$

v, $10^{b}-v i, 30$

vi, 3 I-vii, $29^{\text {a }}$

vii, $29^{\mathrm{n}}-\mathrm{ix}, 2^{\mathrm{a}}$

ix, $2^{n}-x, 12^{a}$

Ecclus. $\mathrm{xxx}, \mathrm{II}-\mathrm{xxx}, 24^{\mathrm{h}}$

$\mathrm{xxx}, 2 t^{\mathrm{c}}-\mathrm{xxxi}$, I I

xxxi, I2 - xxxi, 21

xxxi, $22^{c}-x x x i, 3^{I}$

xxxii, I $^{b}-x x x i i, 3^{1}$

xxxii, I4-xxxiii, 3

xxxv, II-Xxxi, $26^{\prime}$

xxxvi, I-xxxvi, 26

xxxvi, 2+一xxxvii, 9

xxxvii, I I - xxxvii, 26

xxxvii, $27-x x x v i i i, 12$

xxxviii, 13 - xxxviii, 27

xxxix, $15^{\mathrm{c}}-\mathrm{xxxix}, 28$

xxxix, 29-xl, 8

$\mathrm{xl}, 9-\mathrm{xl}, 26^{\mathrm{h}}$

$x \mathrm{l}, 26^{\mathrm{c}}-\mathrm{xli}, 9^{\mathrm{a}}$

xli, 9-xli, 22

xlii, $\mathbf{I}-\mathrm{xlii}$, I I

xlii, 1 I $\mathrm{e}-\mathrm{xlii}, 23$

MS. C :-

Ecclus. iv, 23, 30, 31; v, $+-v, 7^{\text {b }}$

$\mathrm{v}, 7^{\mathrm{c}} ; \mathrm{v}, 9-\mathrm{v}, \mathrm{13}+$

vi, $18^{\text {b }}, 19,28,35$; vii, $1,+, 6^{\text {n }}$

vii, 6 ${ }^{\mathrm{b}}, 17,20,21,23-25$

MS. D:-

MS. B :-

\author{
Ecclus. $x, 12^{n}-x i$, 10 \\ xi, I I-xii, I + \\ xi, $34^{\prime \prime}-x$ iii, $6^{\text {b }}$ \\ xiii, $7^{b}-x i v, I^{b}$ \\ xiv, $11^{b}-x v, 19^{a}$ \\ $x v, 19^{b}-x v i, 26^{3}$
}

Ecclus. xlii, 2+-xliii, $17^{1}$

xliii, $17^{\mathrm{c}}-\mathrm{xliii}, 33$

xliv, $\mathrm{I}-\mathrm{xliv}$, 16

xliv, I $7-x l v,+$

xlv, 5-xlv; 13

xlv, If-xlv, $23^{\text {a }}$

xlv, $23^{\text {b }}-x$ lvi, $6^{1}$

xlvi, $6 \mathrm{e}-\mathrm{xlvi}, \mathrm{i} 8$

xlvi, 19-xlvii, по

xlvii, I I - xlvii, $23^{\text {l }}$

xlvii, $23^{\mathrm{c}}-\mathrm{xlviii,} 12$

xlviii, $12^{\mathrm{c}}-\mathrm{xlviii,} 22^{1}$

xlviii, $24-x l i x, 11$

xlix, $12^{\mathrm{c}}-1$, 10

l, II $-1,22^{1}$

l, $22^{\mathrm{c}}-\mathrm{li}, 5$

li, $6^{\text {h }}-\mathrm{li}, 12+$

li, $12+-\mathrm{li}, 20$

li, 2 I to the end

Ecclus. xviii, $3^{1^{b}}-x i x, 3^{b} ; x x, 5,6$ $\mathrm{xx}, 7$; xxxvii, 19, 22, 24, 26 ; $\mathrm{xx}, \mathrm{I} 3$ $\mathrm{xxv}, 8,13,17-20^{2}$

$\mathrm{xxv}, 20^{\mathrm{b}}-2+$; xxvi, I, $2^{\text {it }}$

Ecclus. xxxvii, $12^{b}-x x x v i i i, I^{a}$

Ecclus. xxxvi, 29-xxxvii, $\mathbf{2}^{\mathrm{a}}$ 



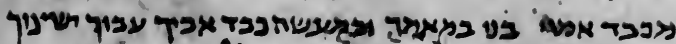

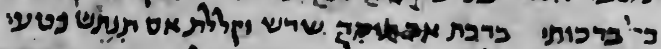

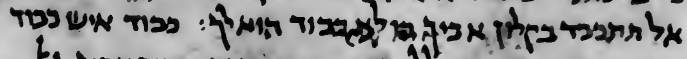

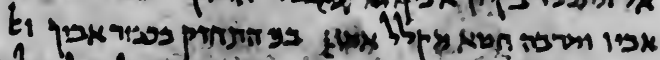

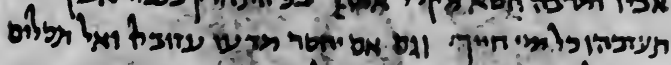

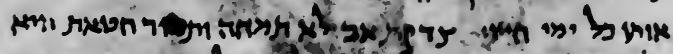

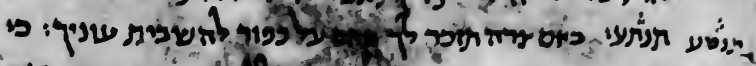
'T4

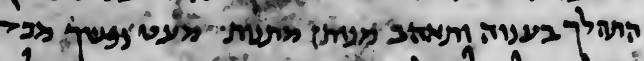

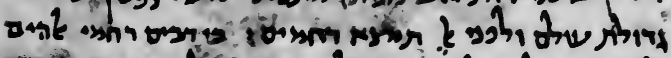

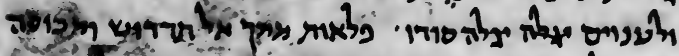

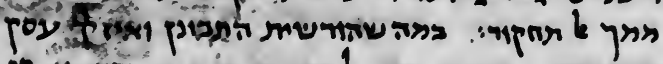

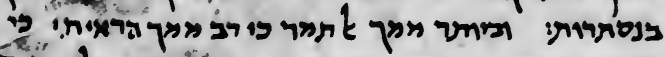

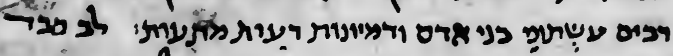

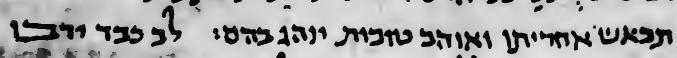

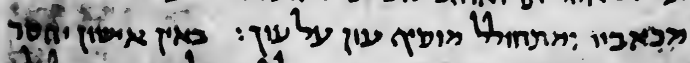

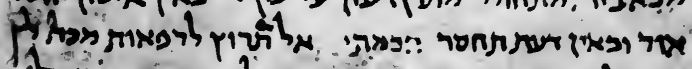

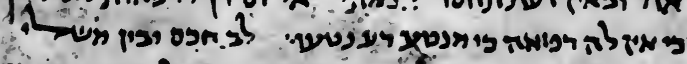

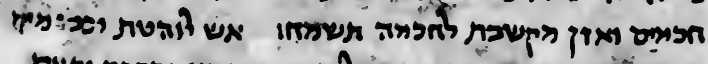
si

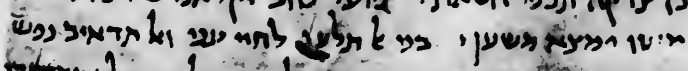

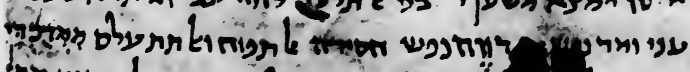

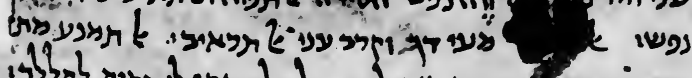

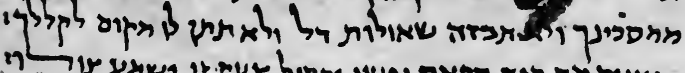

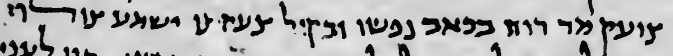

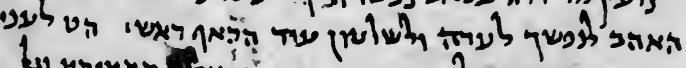

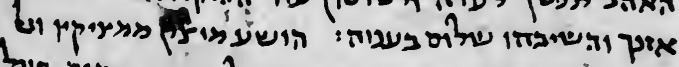

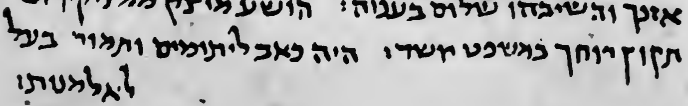





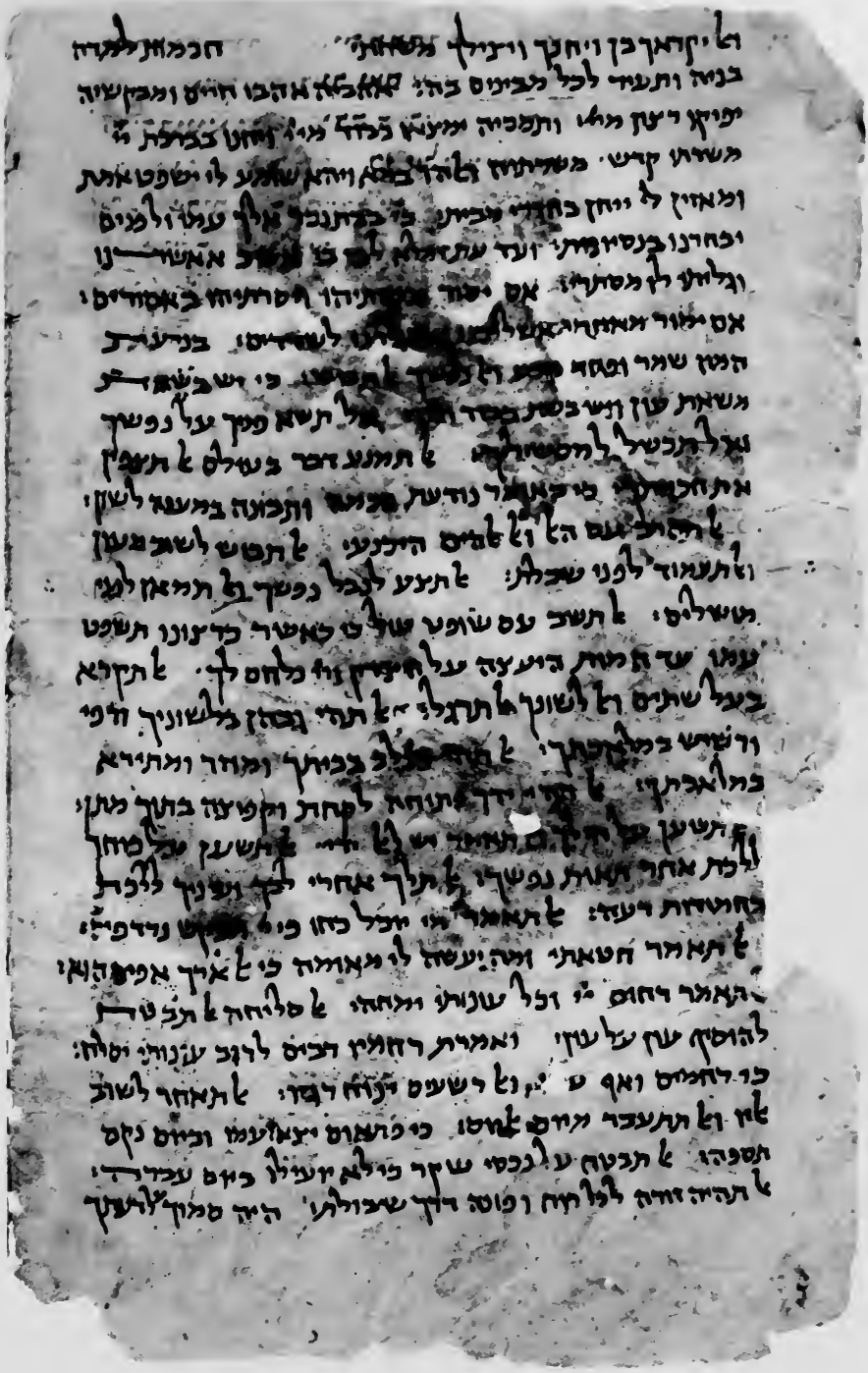

MS. A. Ecclus. iv, $10^{c}-v, 10^{a}$ 



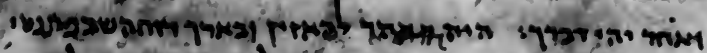

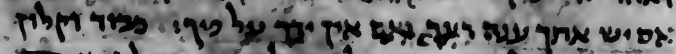

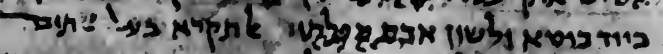

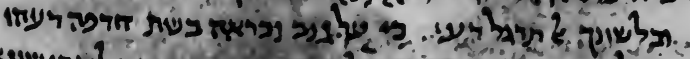

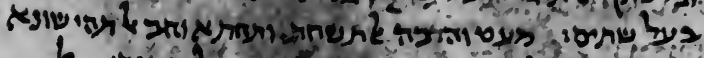

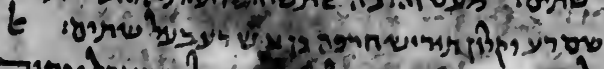

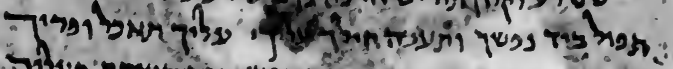

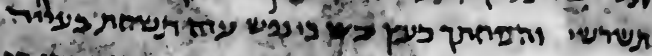

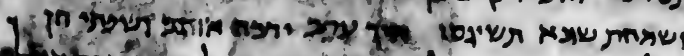

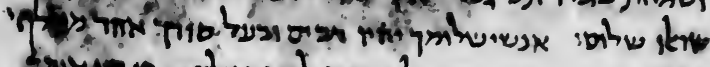

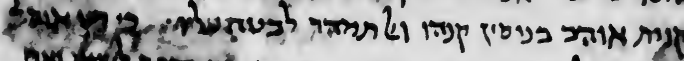

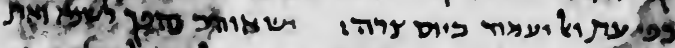

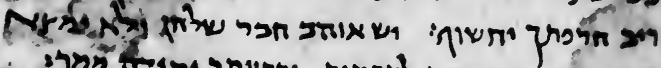

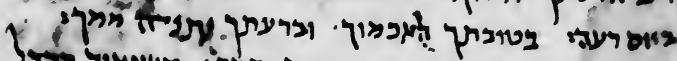

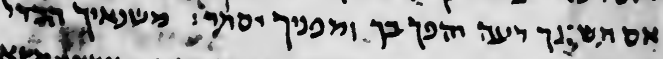

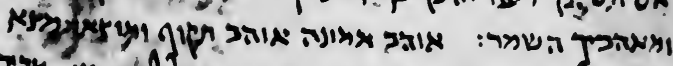

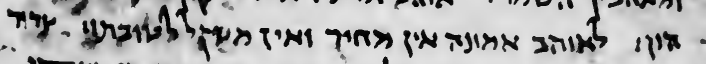

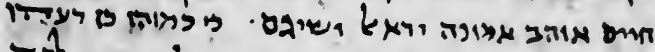

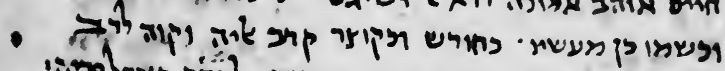
'ingloner - Non

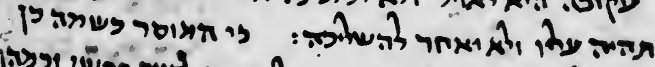

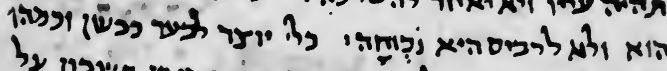

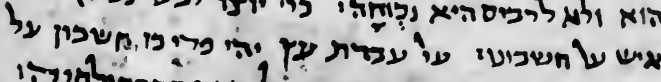

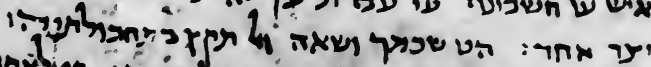

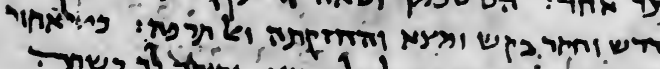

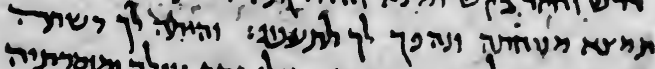

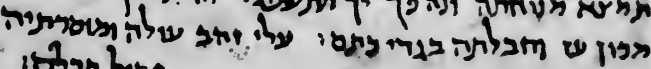
ishers bers

\section{n)}

MS. A. Ecclus. v, $10^{h}-v i, 3^{\circ}$ 



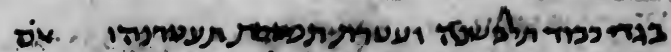

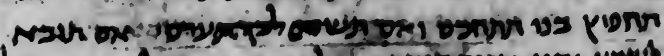

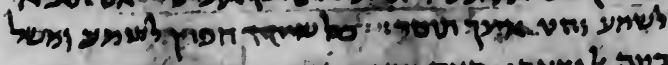

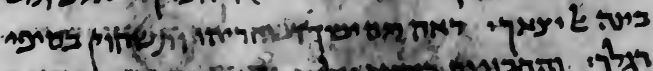

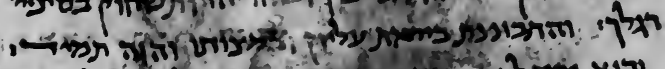

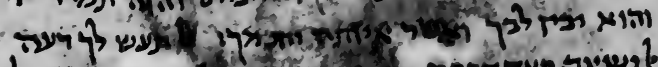

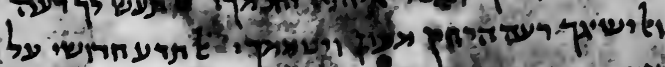

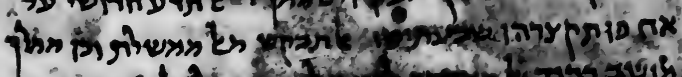

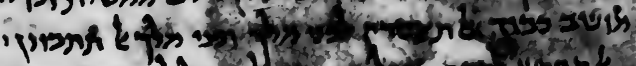

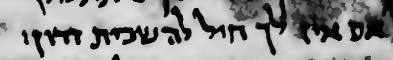

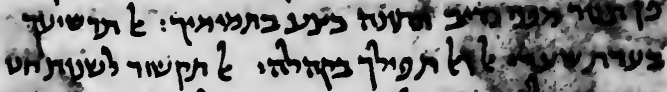

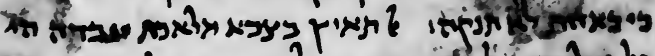
a

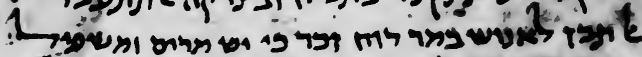

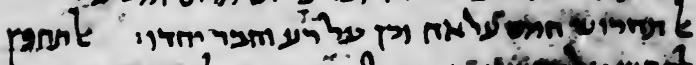

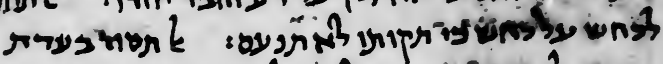

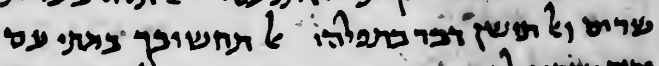

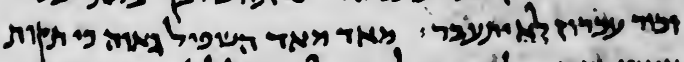

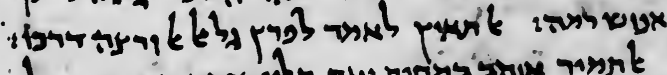

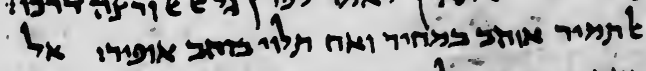

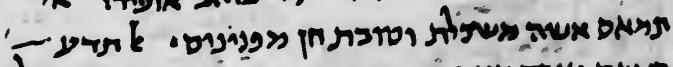

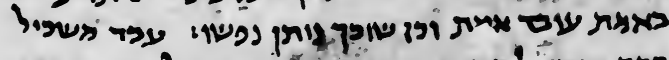

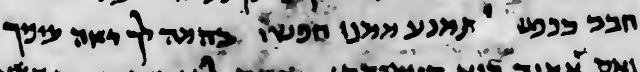

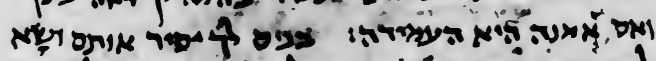

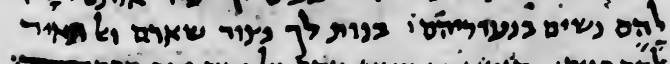

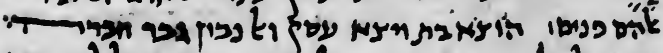
a.ph 


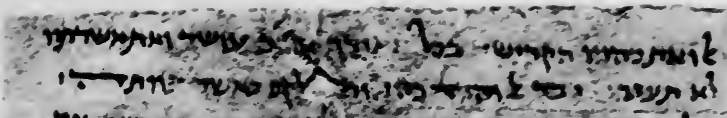

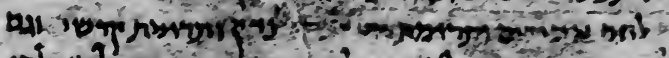

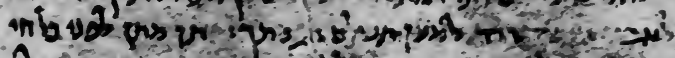

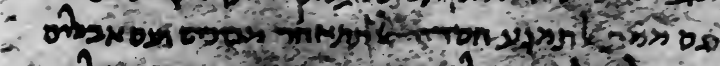

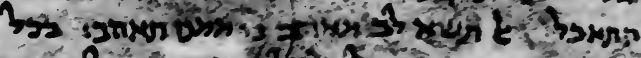

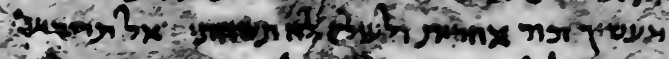

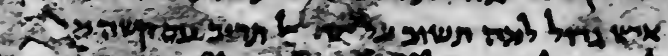

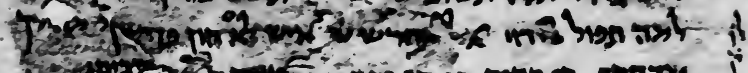

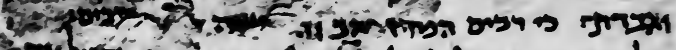
(a)

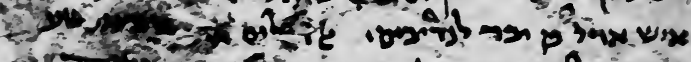

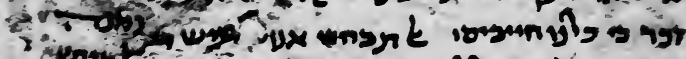

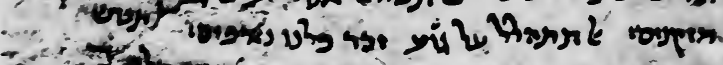

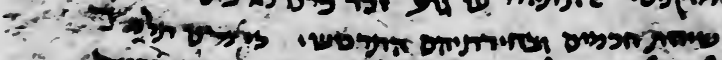

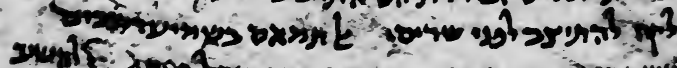

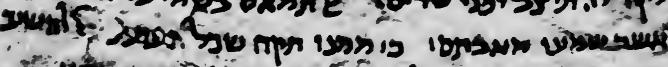

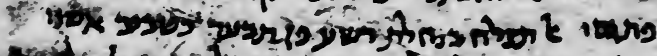

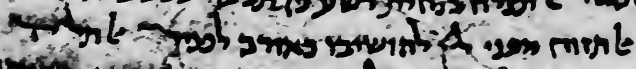

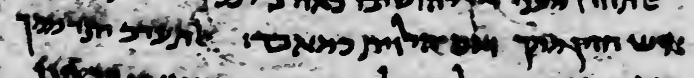

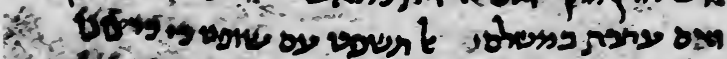

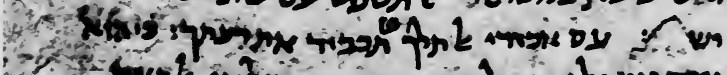

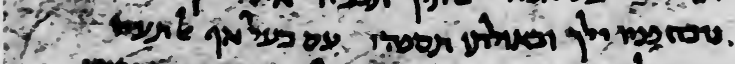

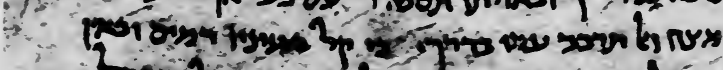

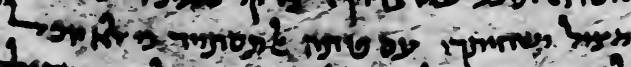

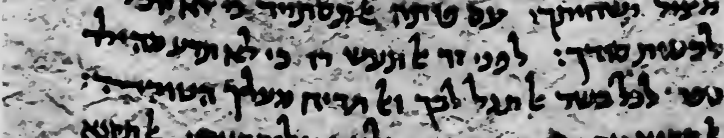

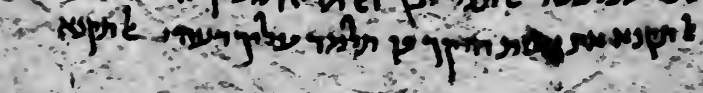

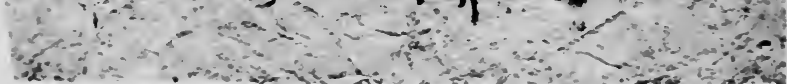




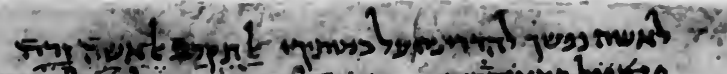

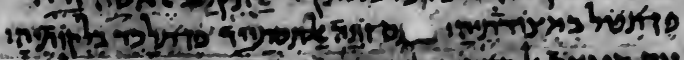

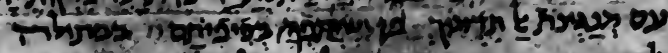

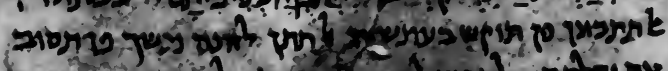

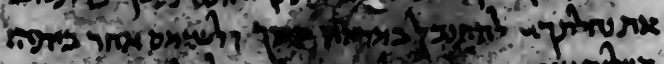

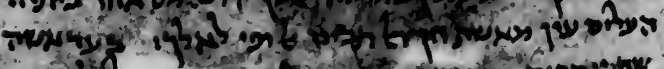

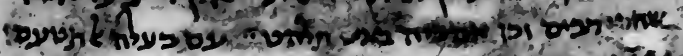

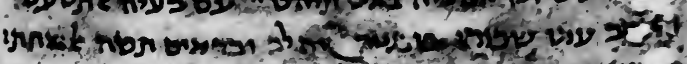

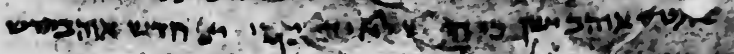

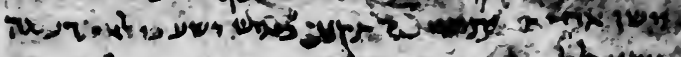

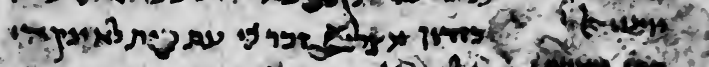

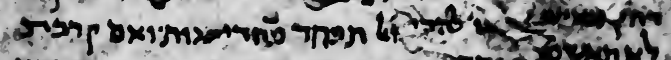

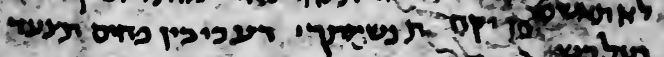

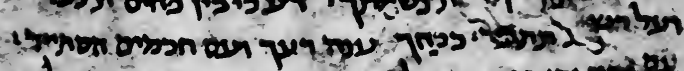

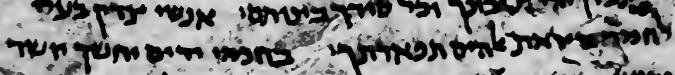

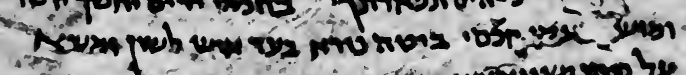

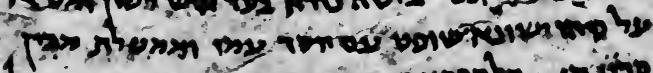

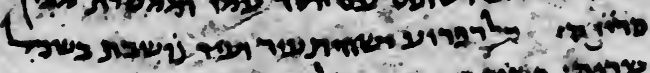

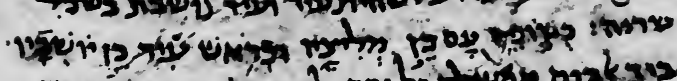

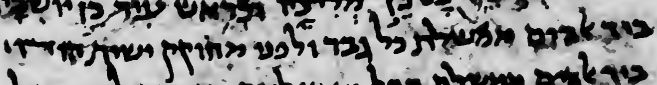

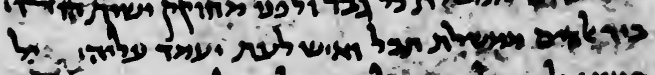

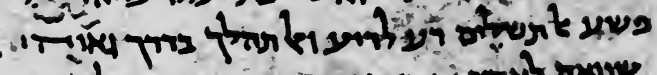

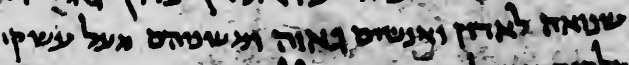

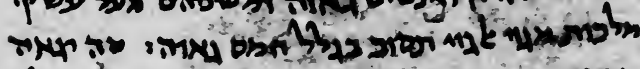

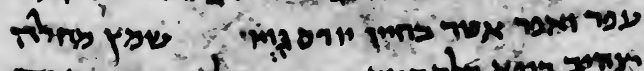

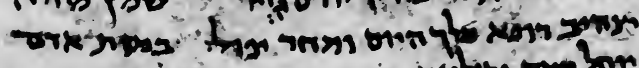

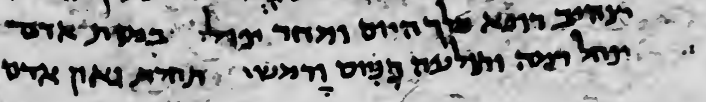
$\therefore$ ( 


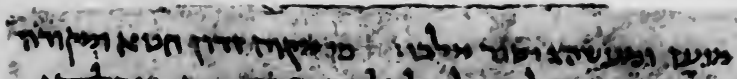

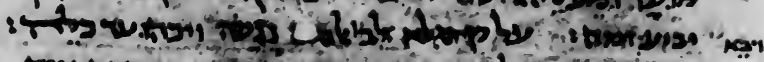

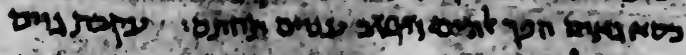

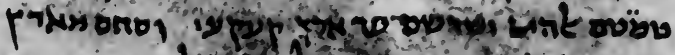

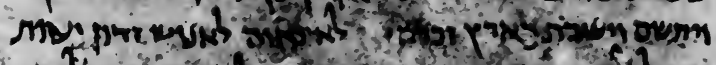

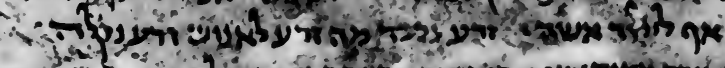

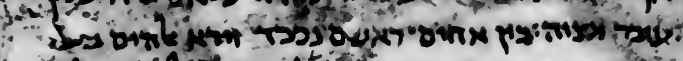

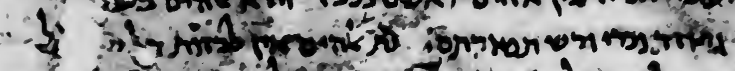

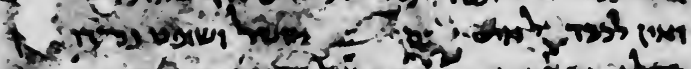

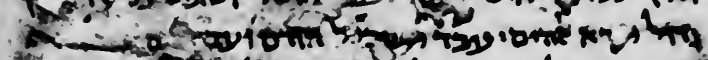

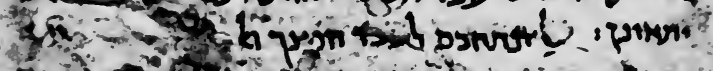

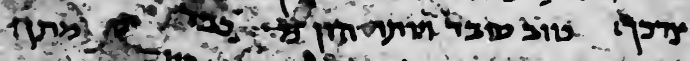

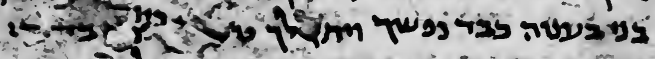

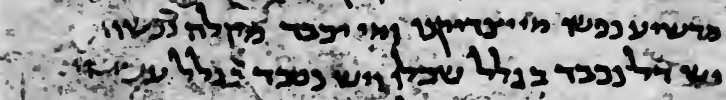

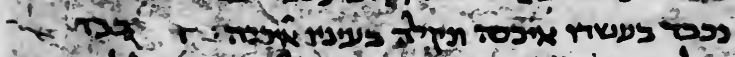

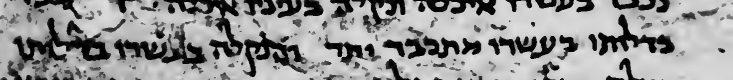

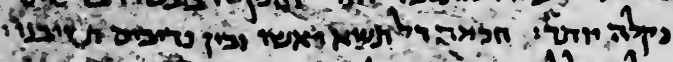

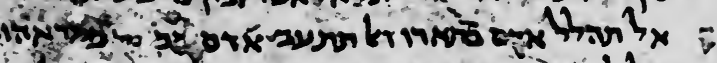

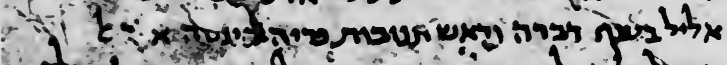

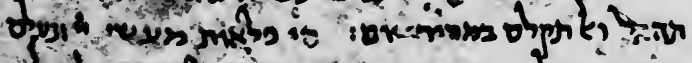

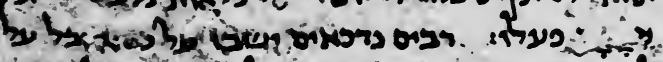

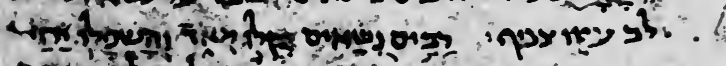

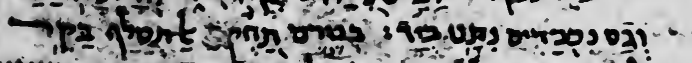
ע\%

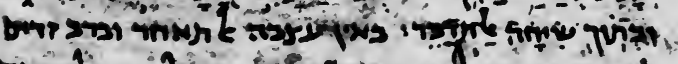

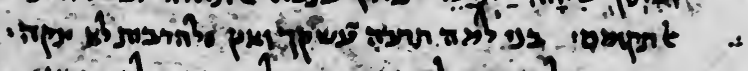

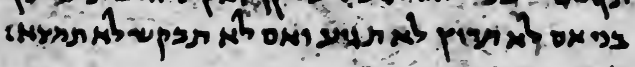




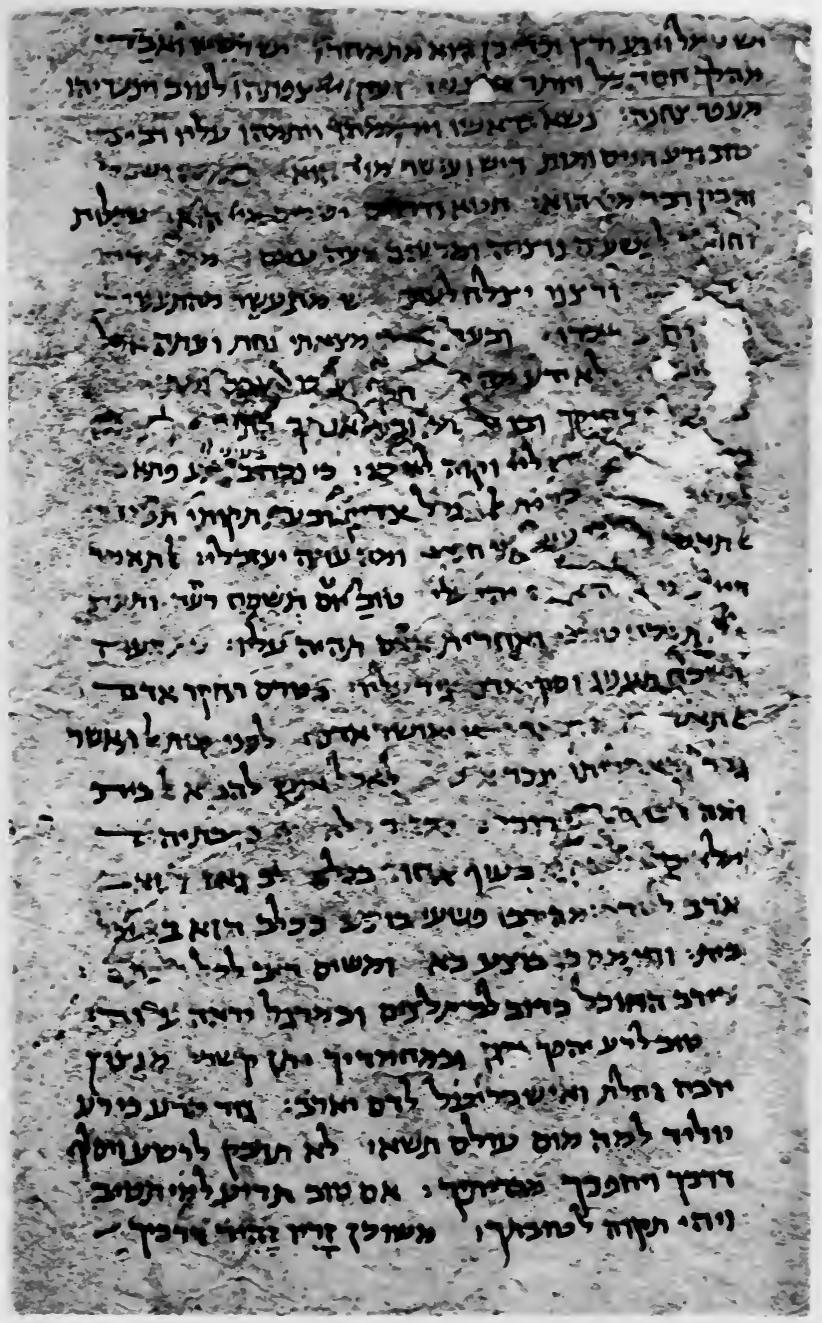

NS. A. Ecclus. xi, $1-x i i, 1+$ 


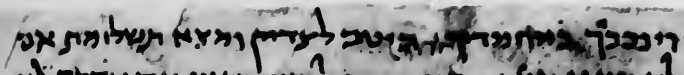

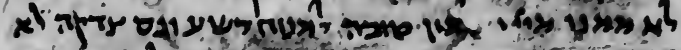
ע'A ת ה

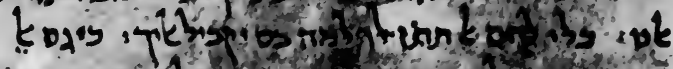

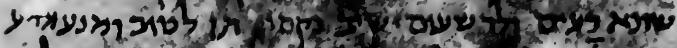

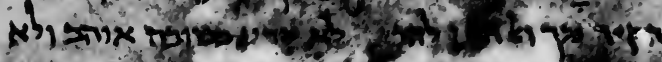

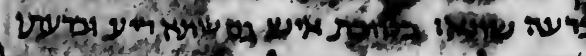

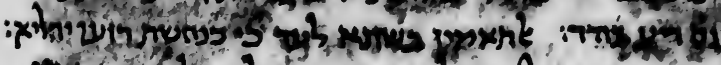

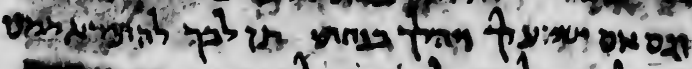

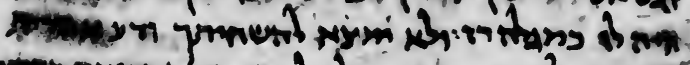

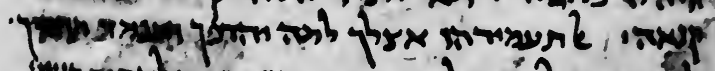

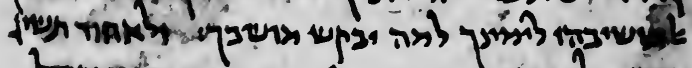

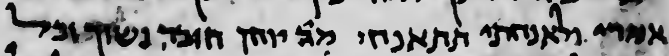

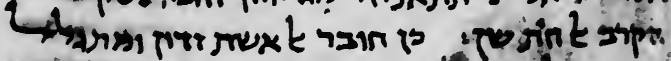
mis the was

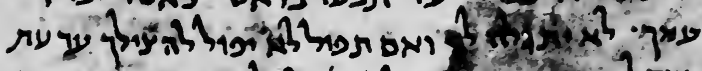

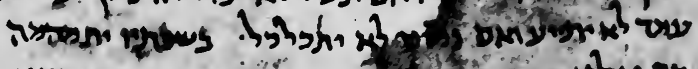

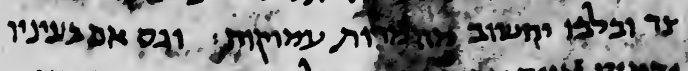

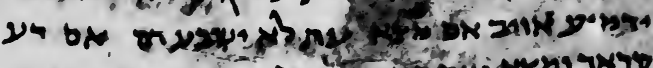

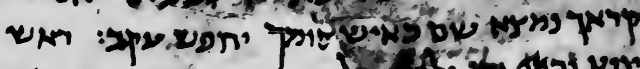

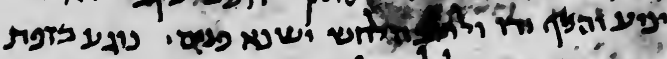

$$
\text { ת }
$$

-

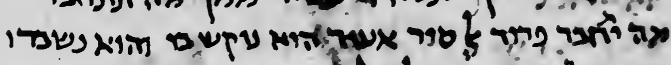

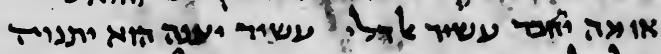

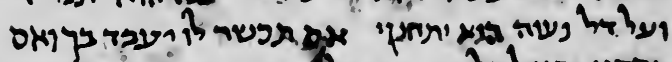

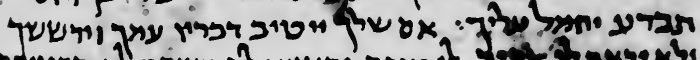

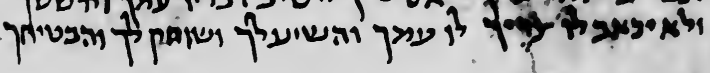




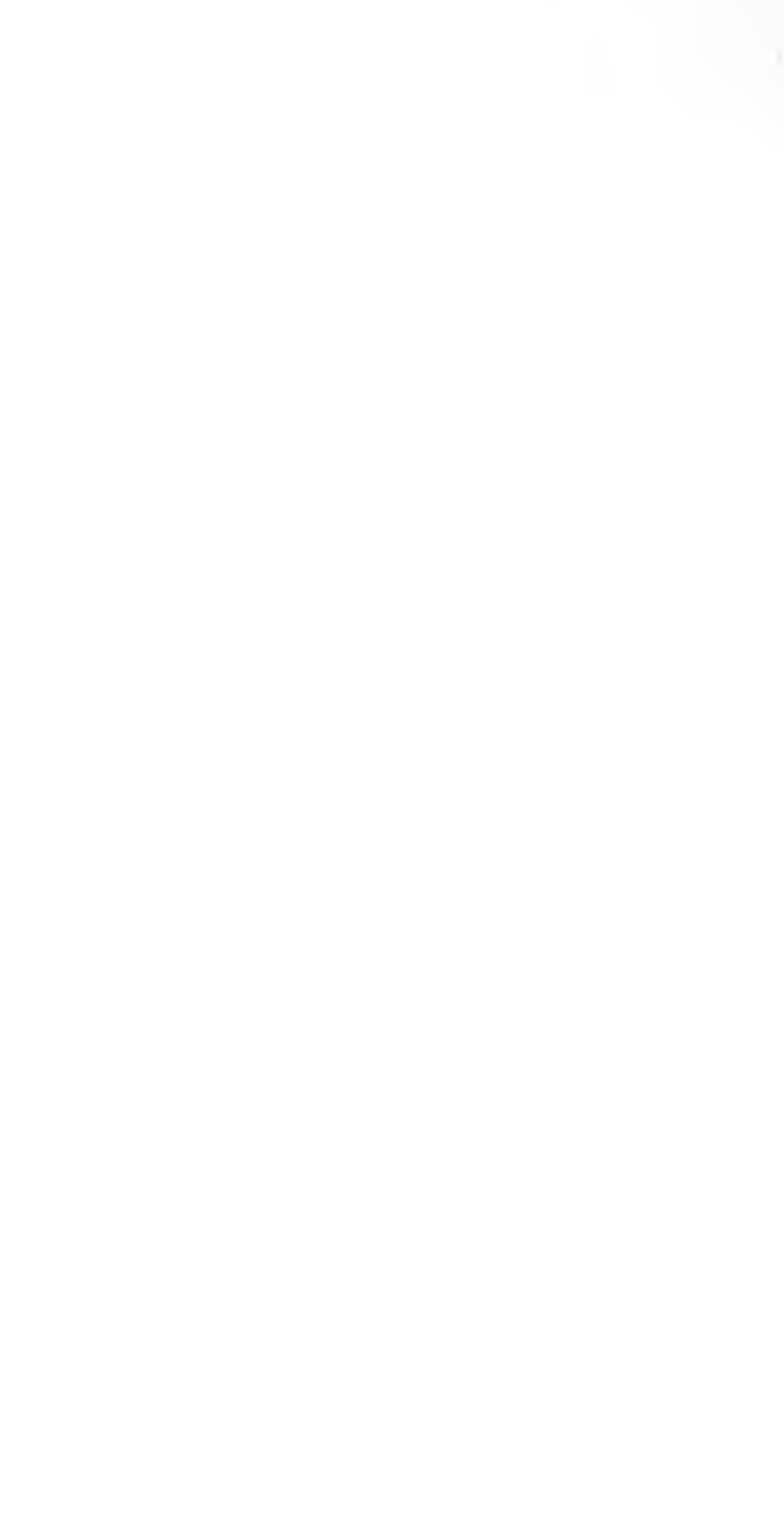




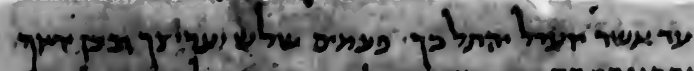

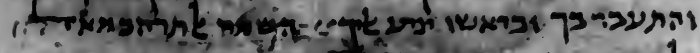

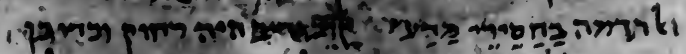

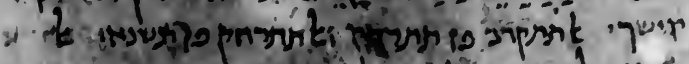

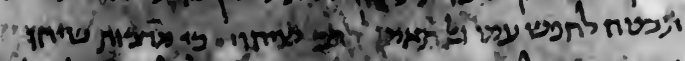

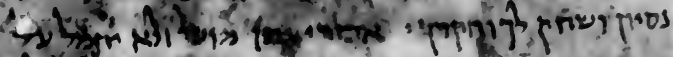

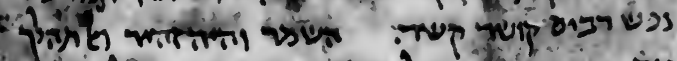

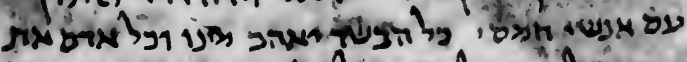

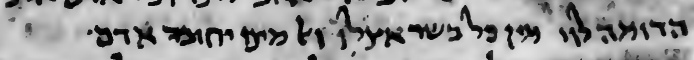

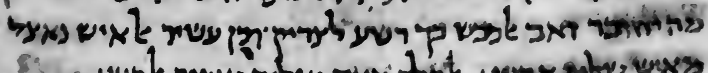

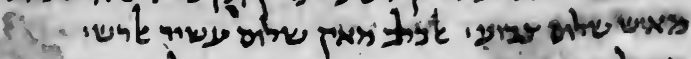

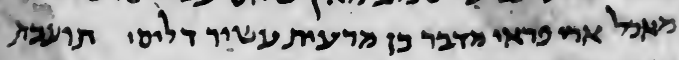

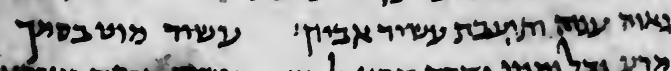

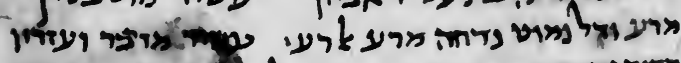

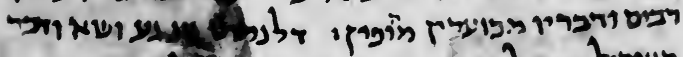

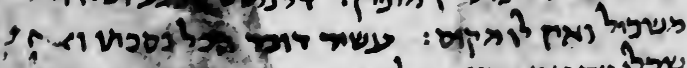

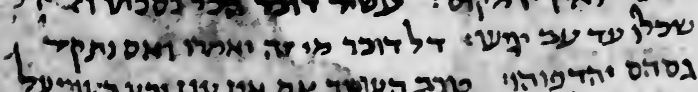
Sy

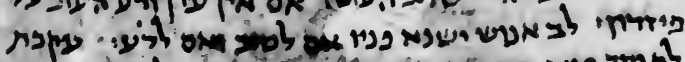

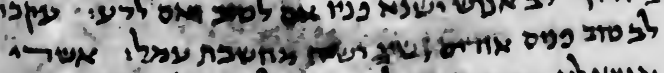

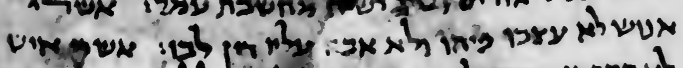

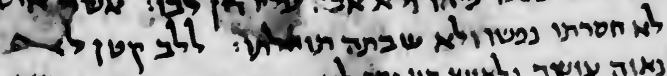

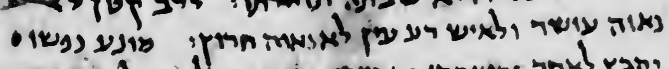

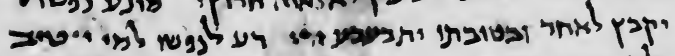

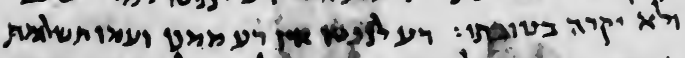

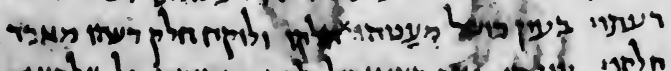

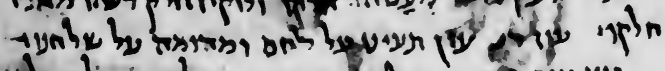

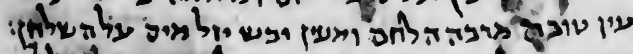

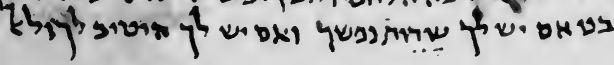

MS. A. Ecclus. xiii, $7^{b}-x i v, y^{b}$ 



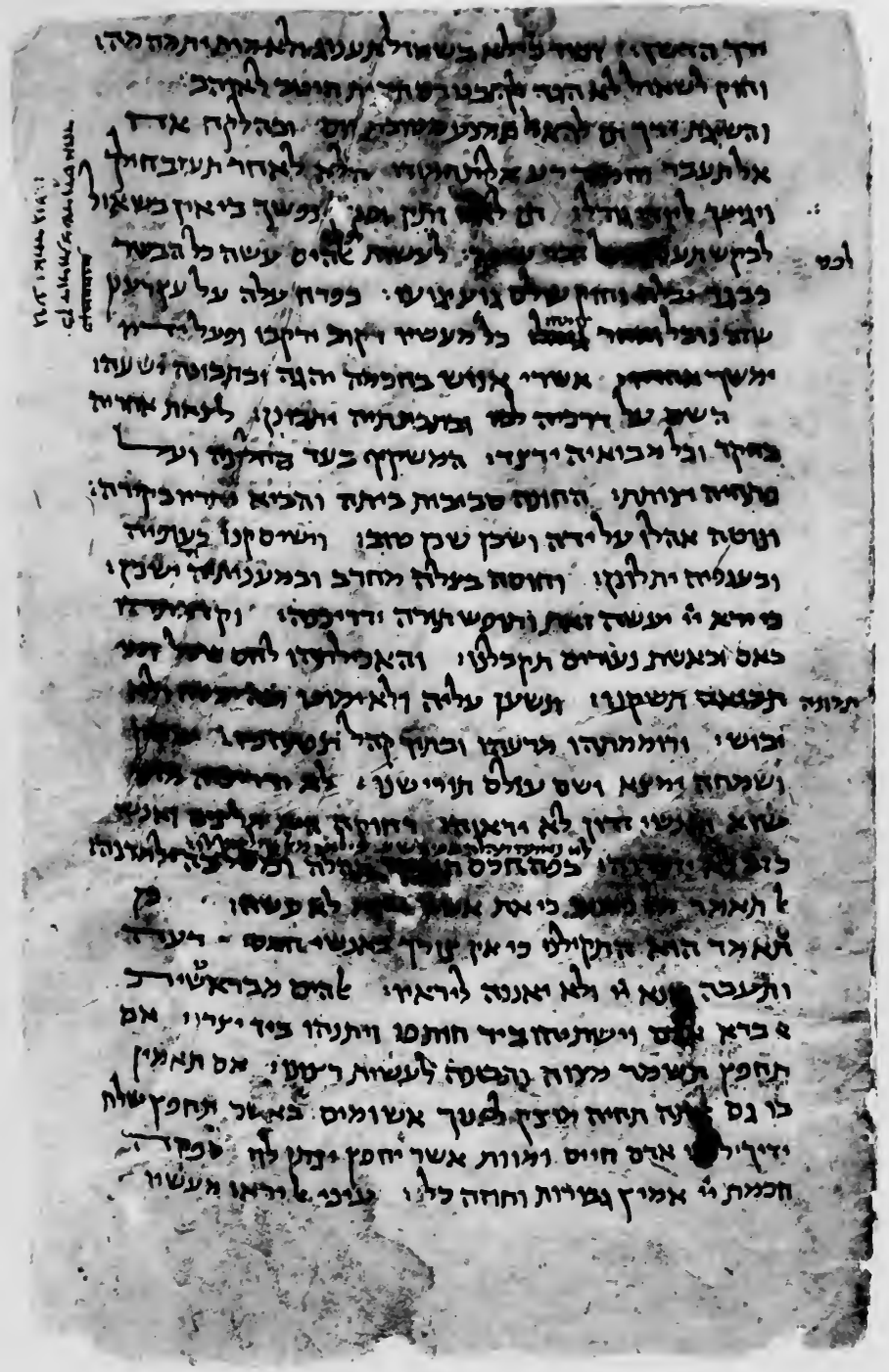

MS. A. Ecclus. xiv, $\mathrm{II}^{\mathrm{b}}-\mathrm{xv}, 19^{n}$ 



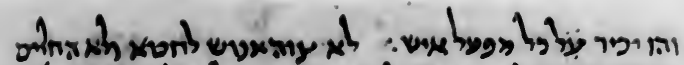

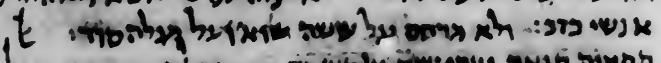

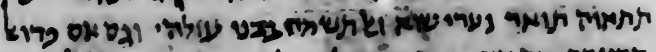

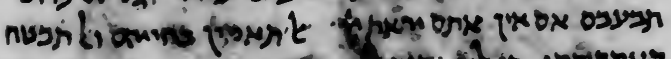

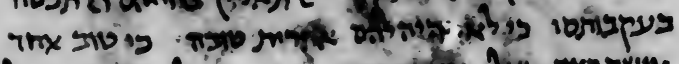

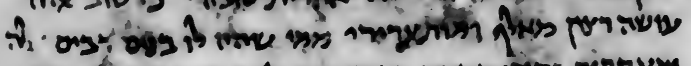
mow il

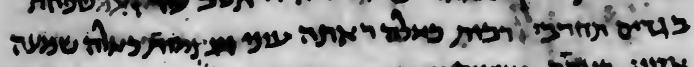
ith לח

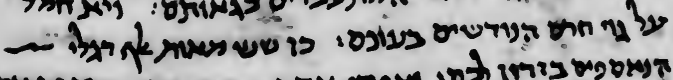

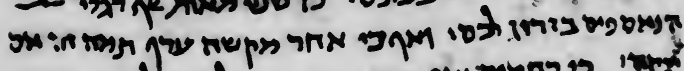

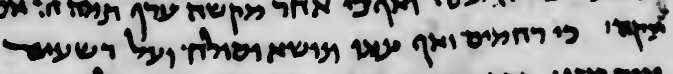

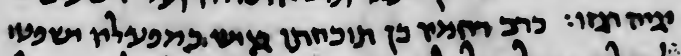

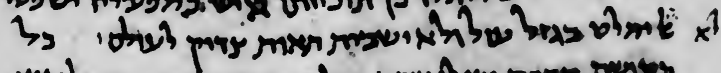

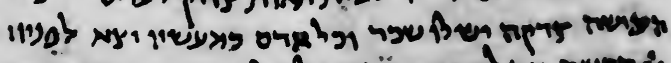

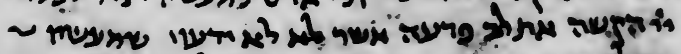

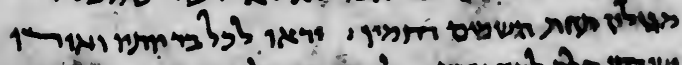

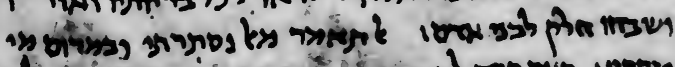

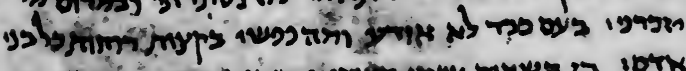

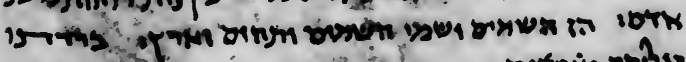

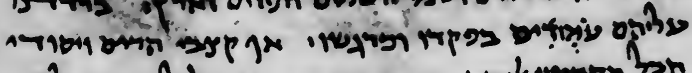

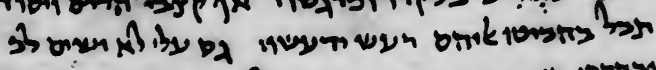

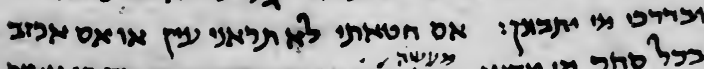

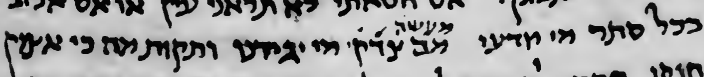

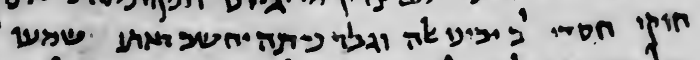

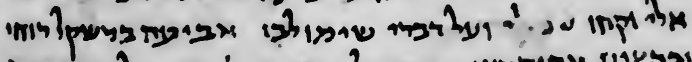

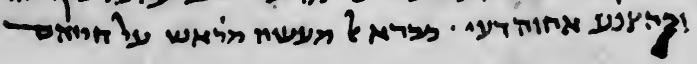

MS. A. Ecclus. $x v, 19^{b}-x v i, 26^{n}$ 



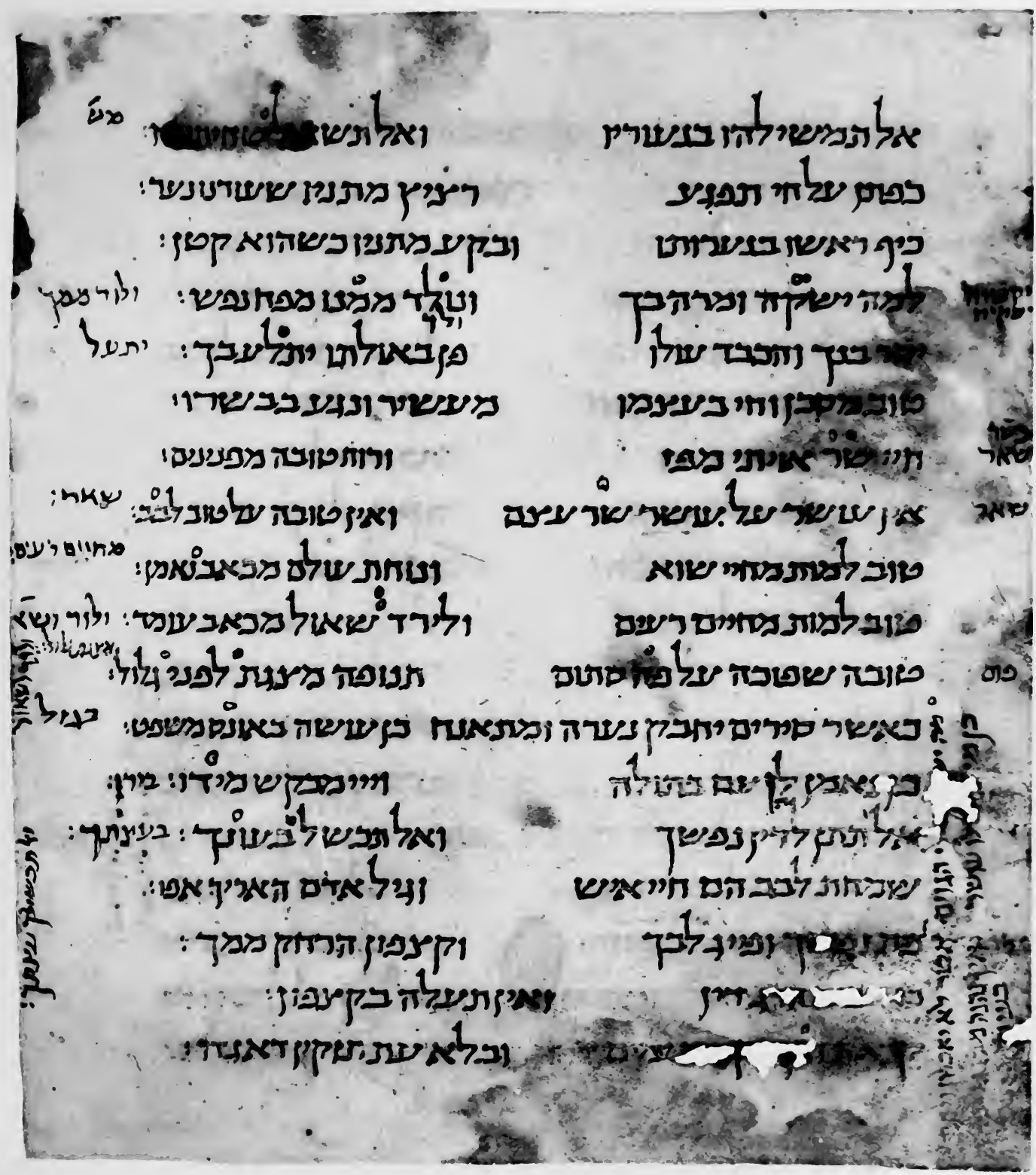

MS. B. Ecclus. $\mathrm{xxx}, \mathrm{I} I-\mathrm{xxx}, 2 t^{\mathrm{b}}$ 


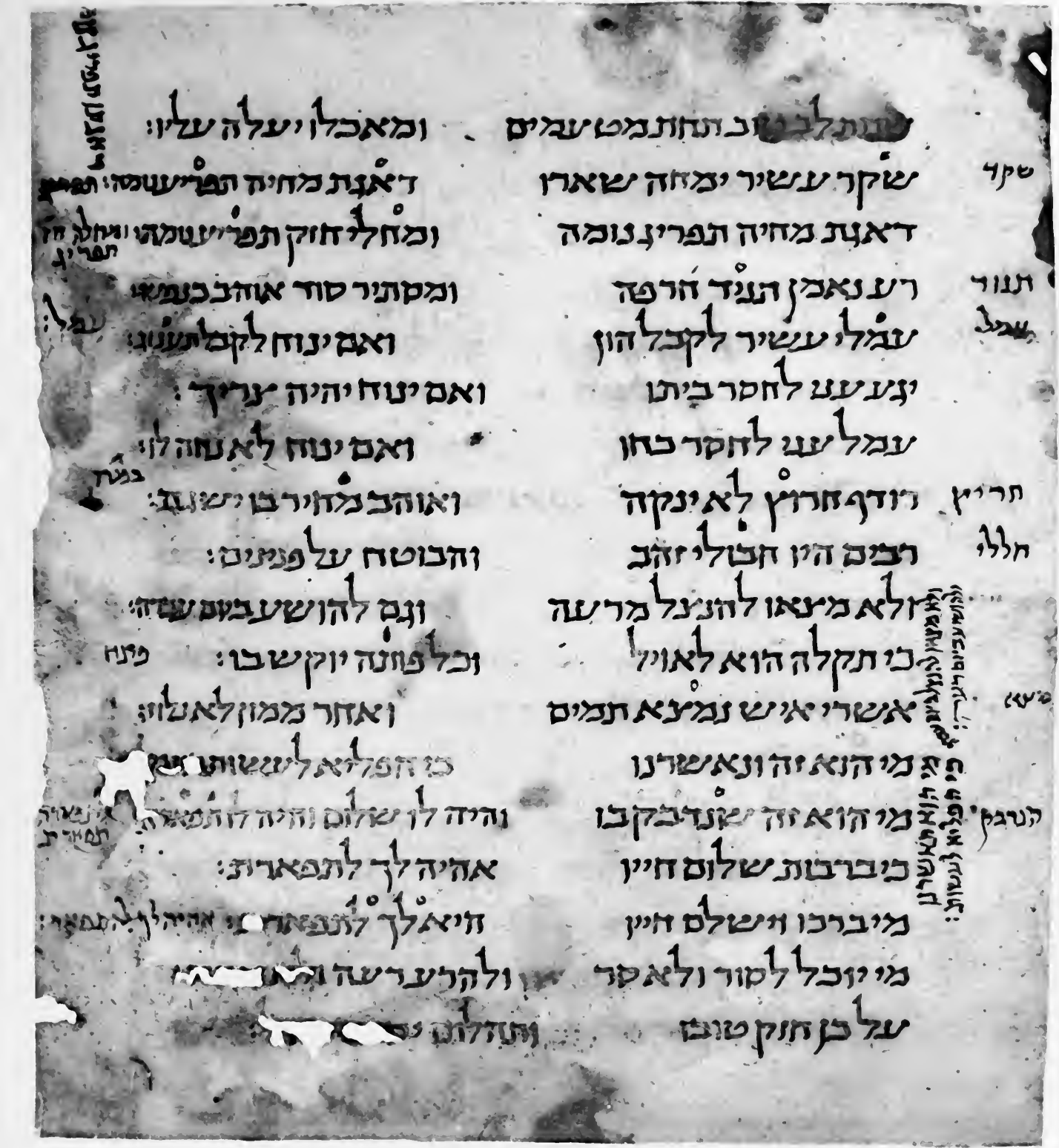





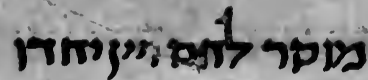

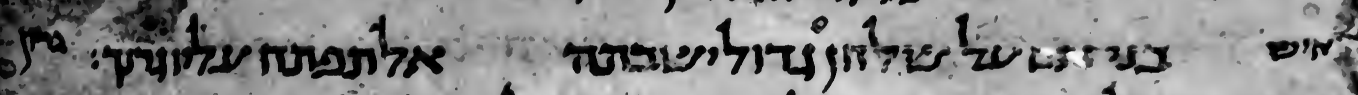

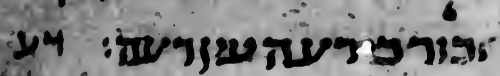

:אר

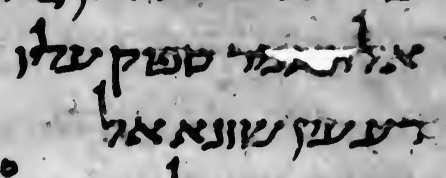

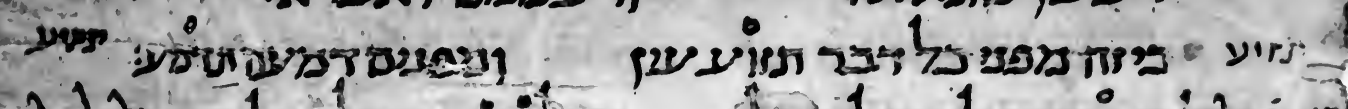

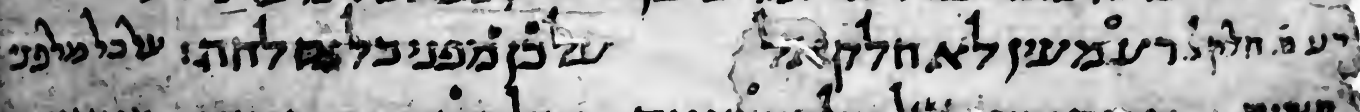

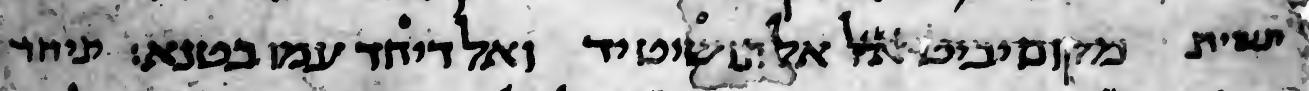

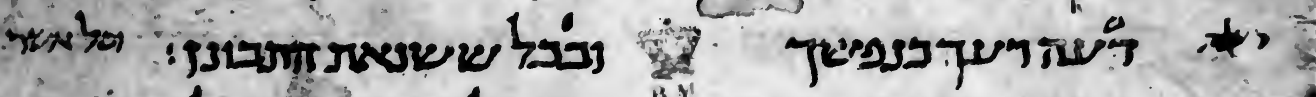

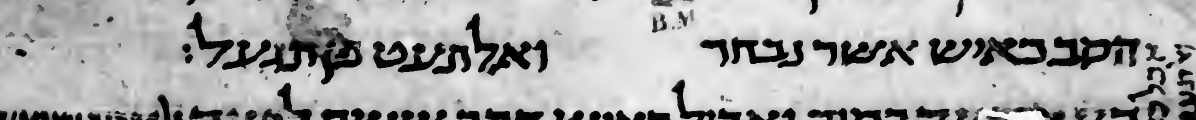

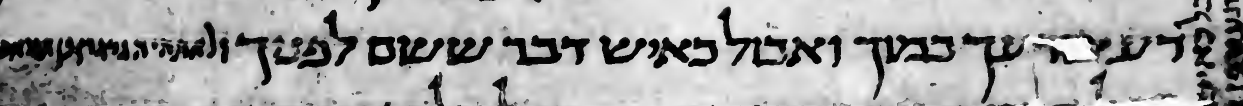

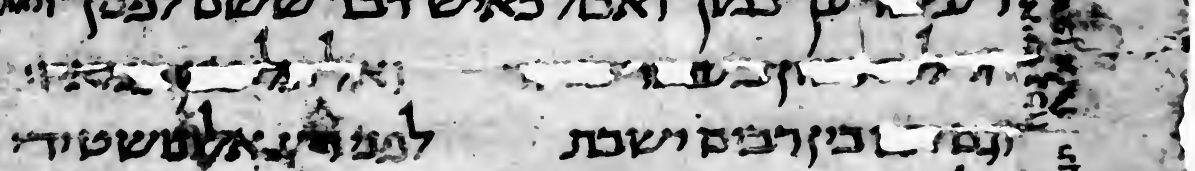

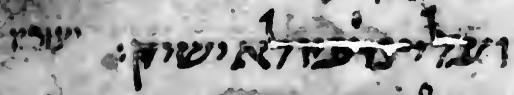

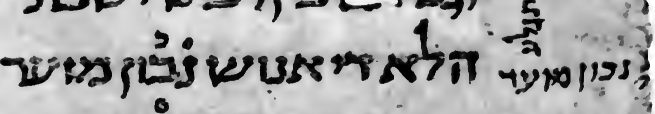

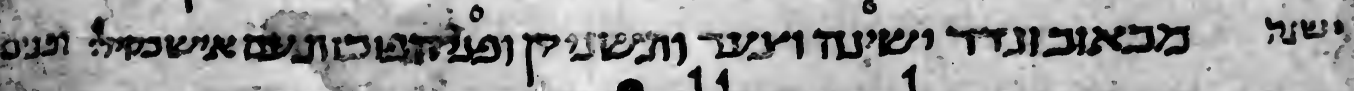

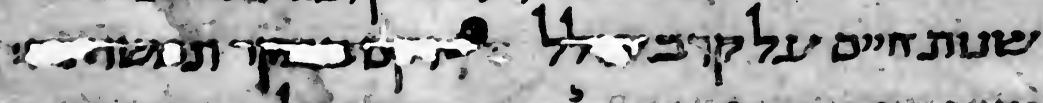

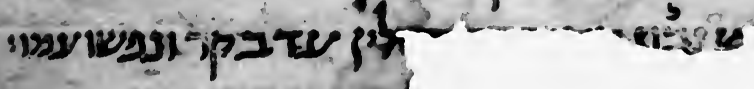

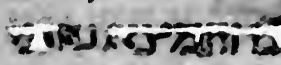

MS. B. Ecclus, $x x x i, 12-x x x i, 21$ 


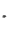




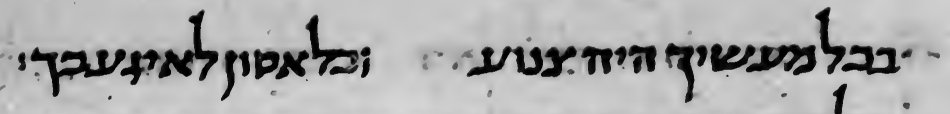

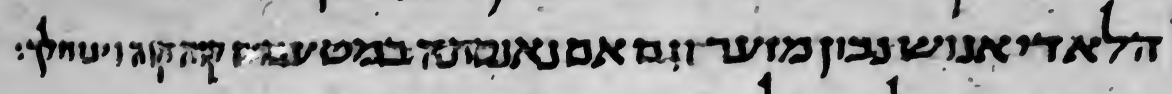
1

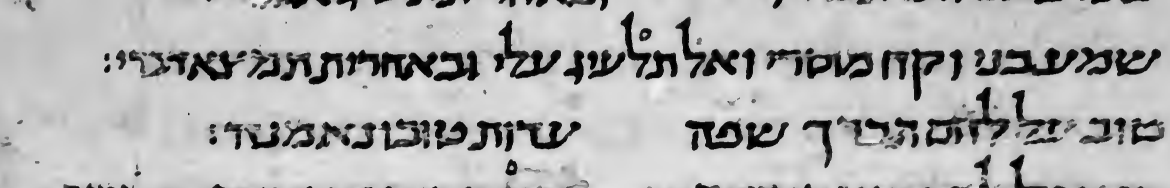

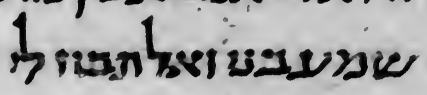
תים

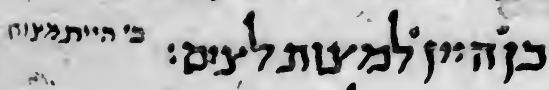

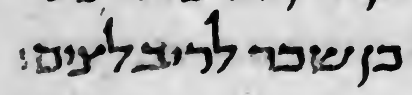

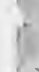

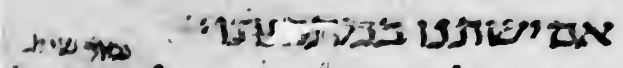

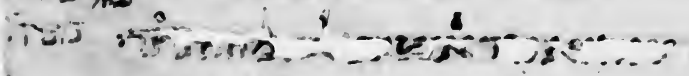

(

תעx :

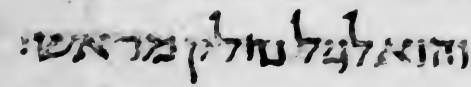

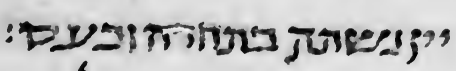

: ino : :

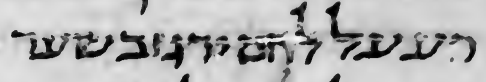

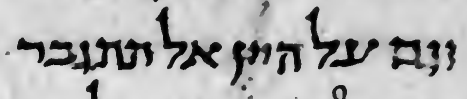

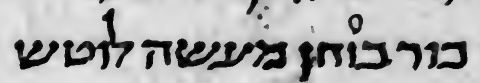

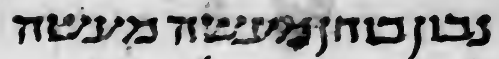

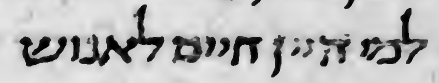

$$
\text { : }
$$

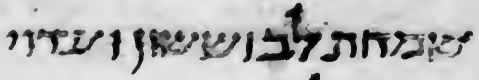

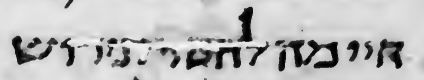

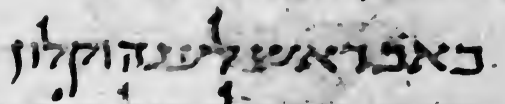
es fon תל 
1000

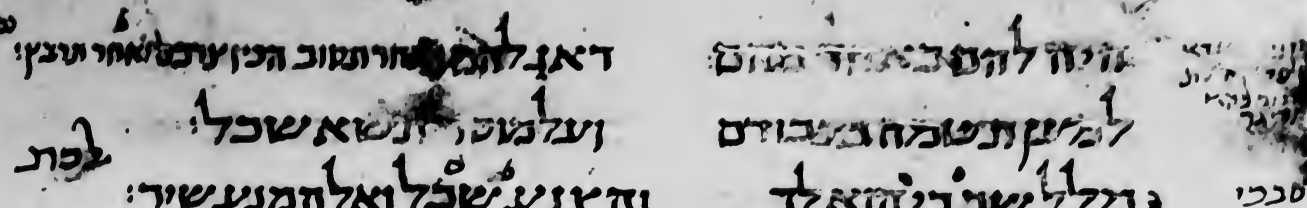

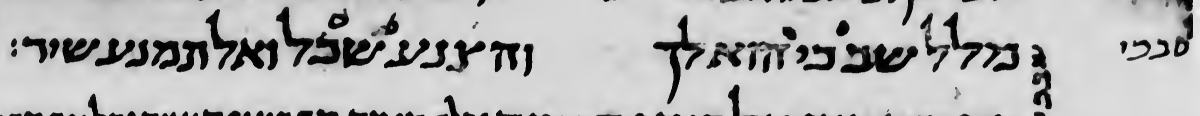

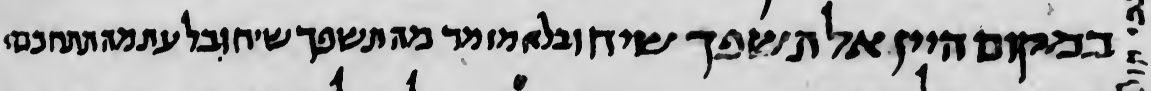

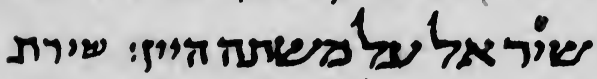

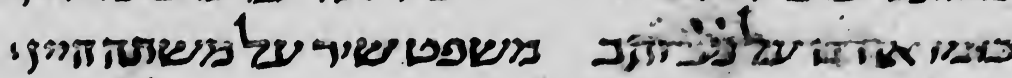

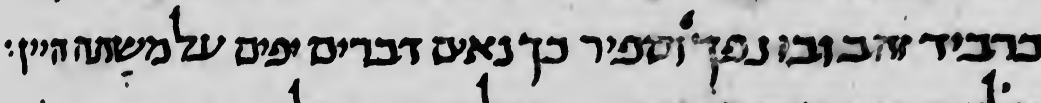

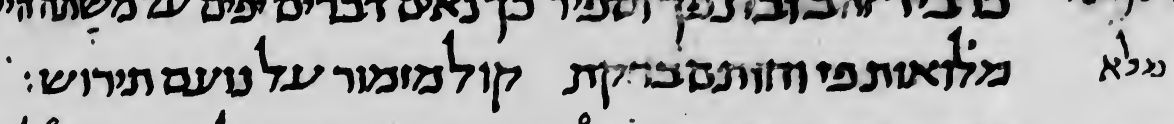

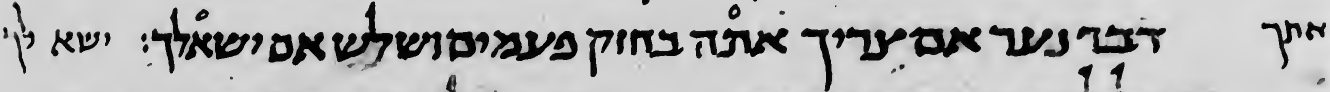

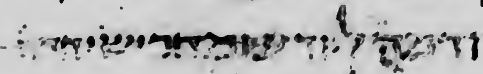
ואיריט

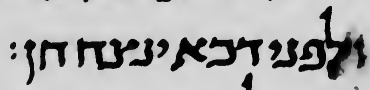

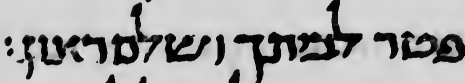

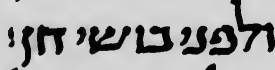
: 477 और

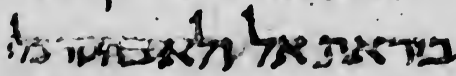

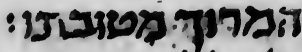

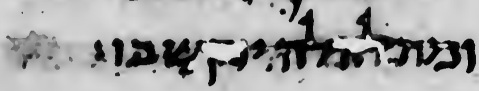

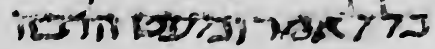
ext 59040:5. 



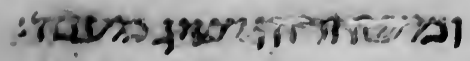

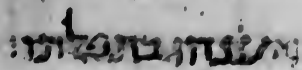

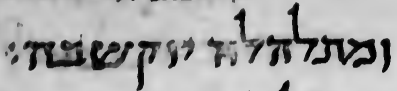

:Neyig gessomingri!

ומד

inis

tivess

:

ז

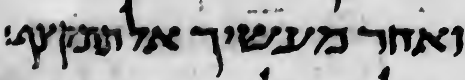

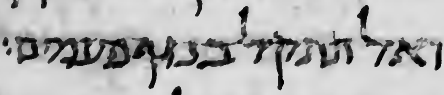

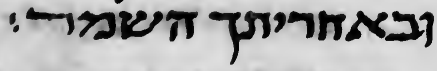

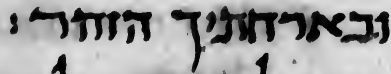

\section{- 1}

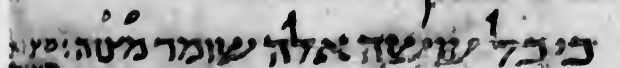

בy:.nos

.

h.

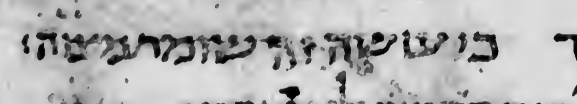

स $\therefore$ : \%

2N1 $4 \ldots . .3$

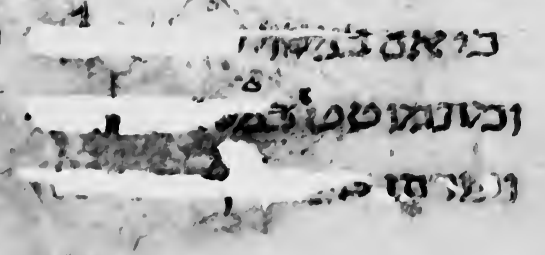

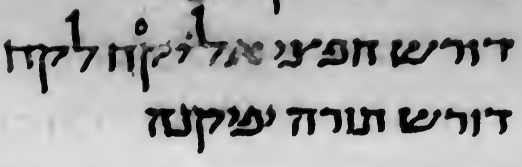

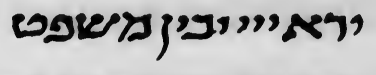

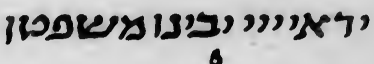

תוחטות

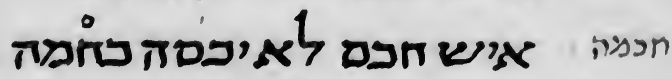
7nשrp's 1 1 1 (1)

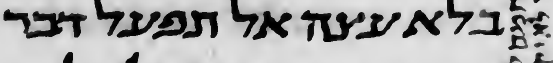

11

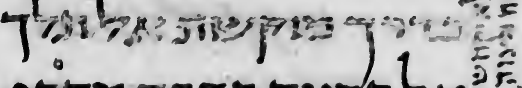

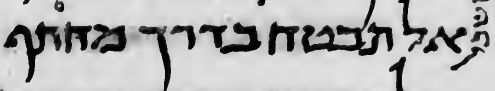

סקטלת

בכלד אלכיך שמכור נפשיך

נקים

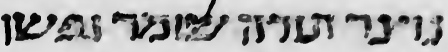

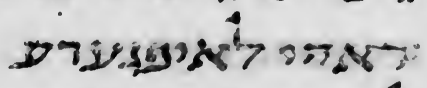

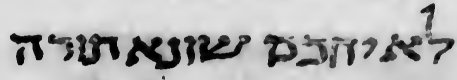

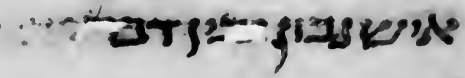





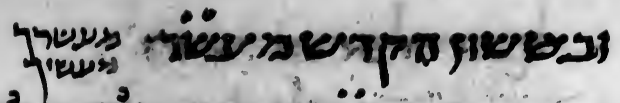

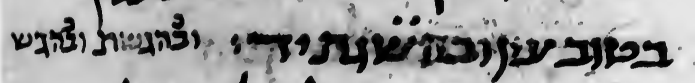
obe : piores perveser?

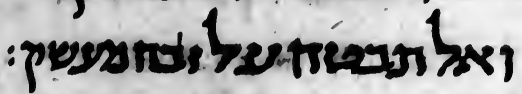

: oraseresa vay jovi

טมנמש

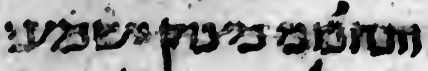

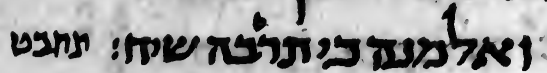

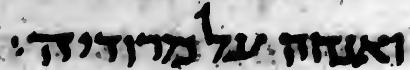

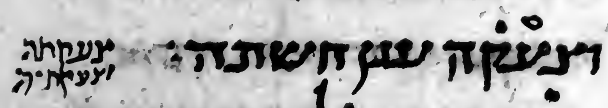

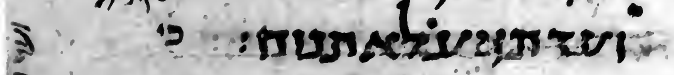

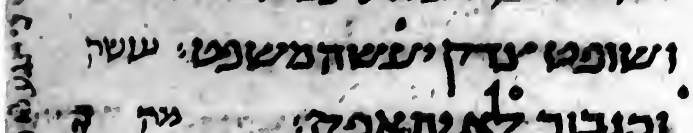

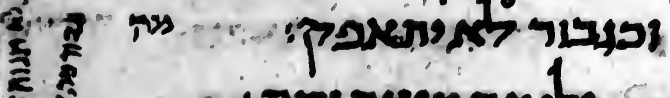

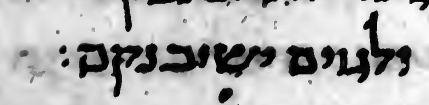

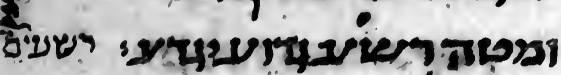

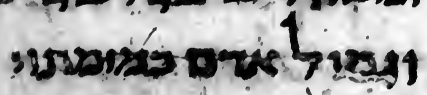

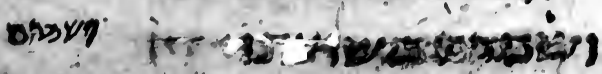
(1) :

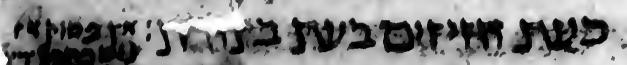

\section{yor}

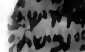

Aresey

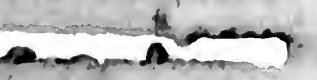

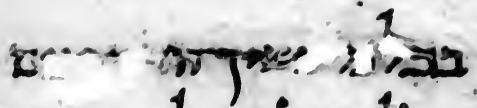

joureine

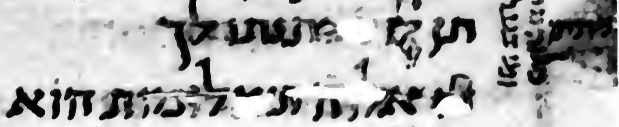

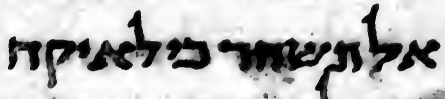

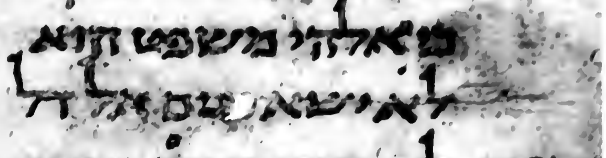

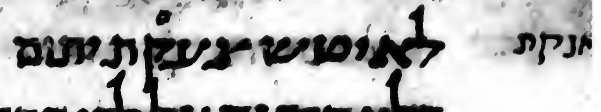

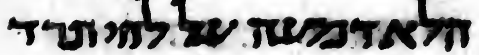

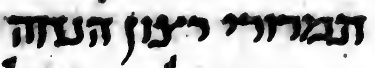

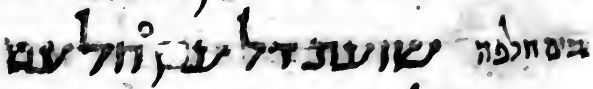

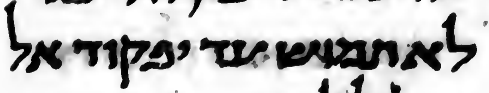

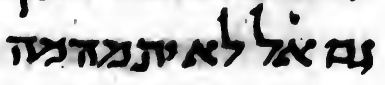

[14]

oravestis projers

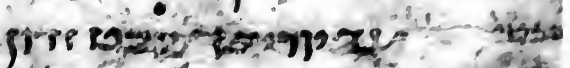
1.100

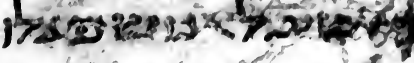

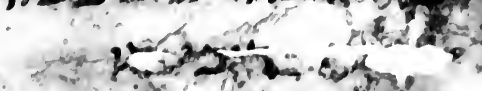

(19) 3

inpiyzart $x$

ip

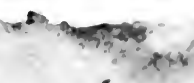


18 is

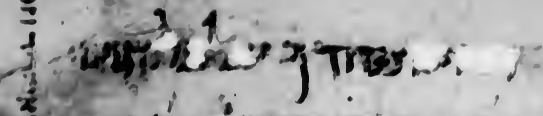

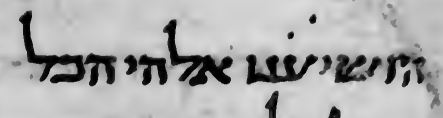

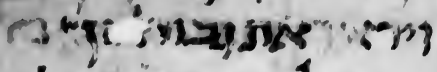

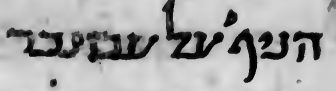

4 ,

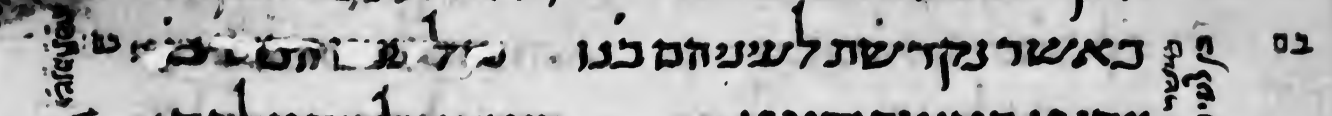

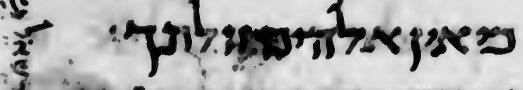

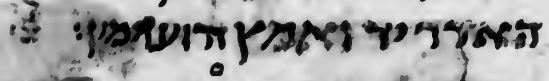

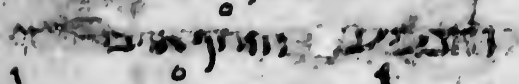

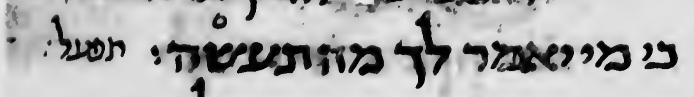

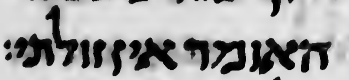

:

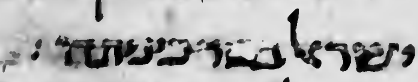

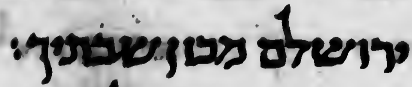

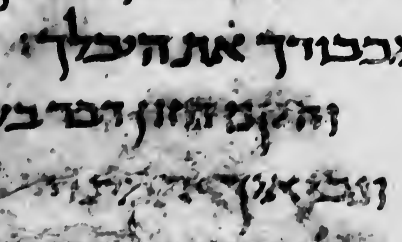

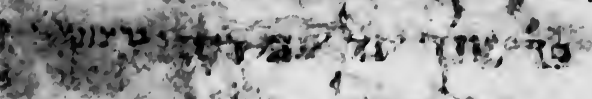

I. $2 i^{2}:-$

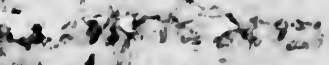

is 8

?

s.

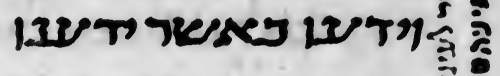

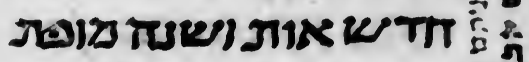

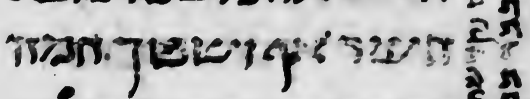

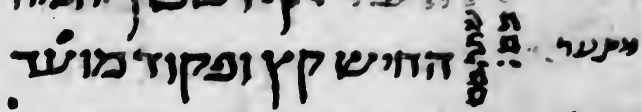

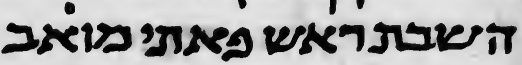
2 'gr

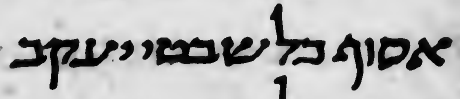

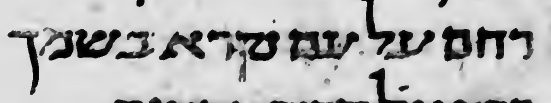
Trenpsprip

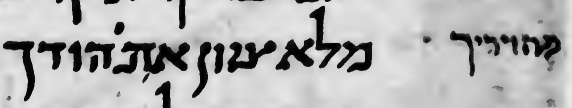

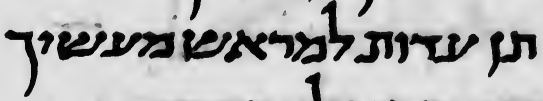

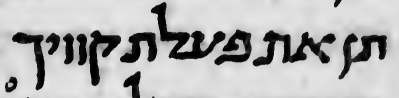

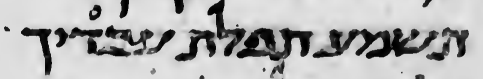

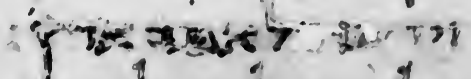
jous:

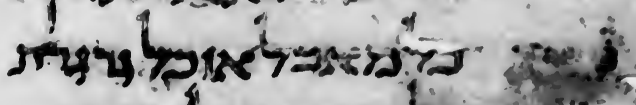

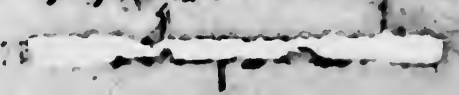




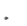




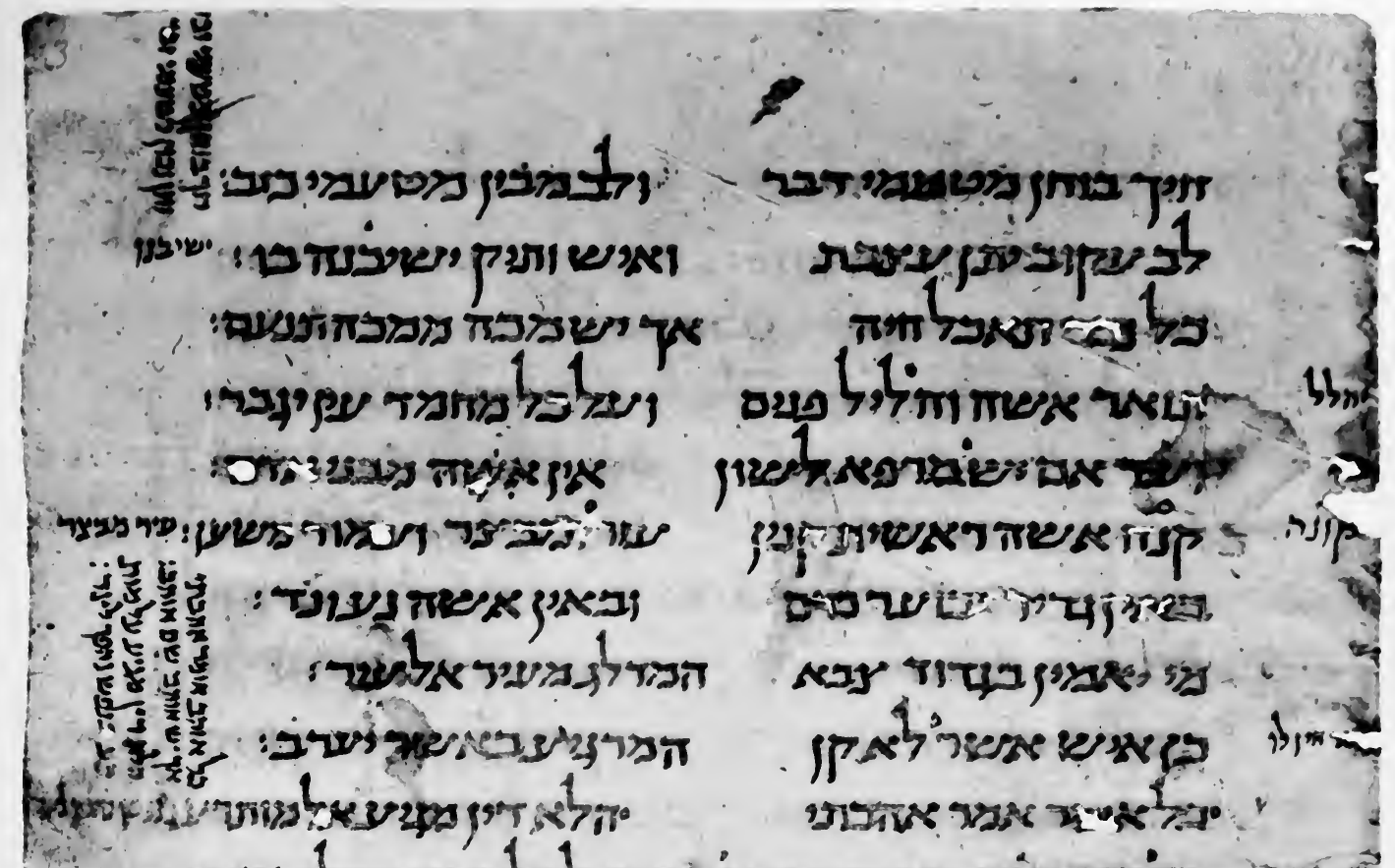

.'.

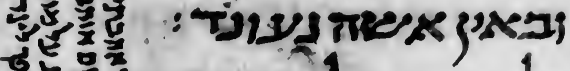

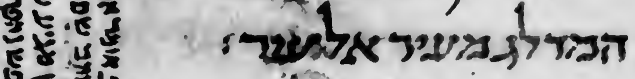

(a)

$x$

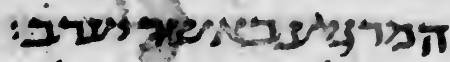

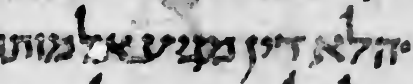

prem sesnaiertax

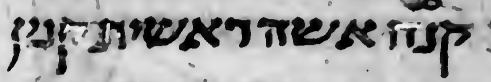

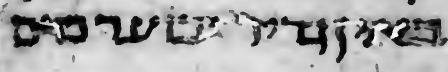

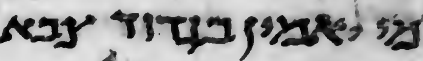

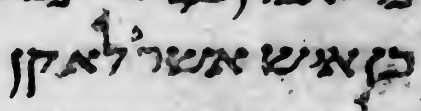

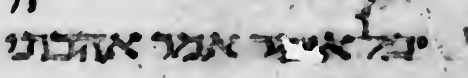

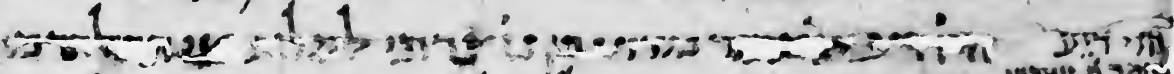

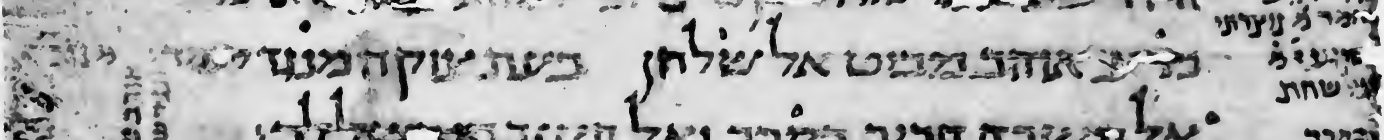
के

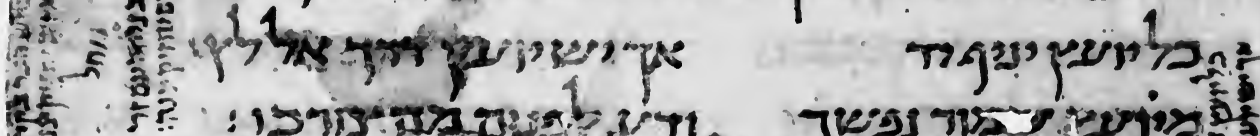

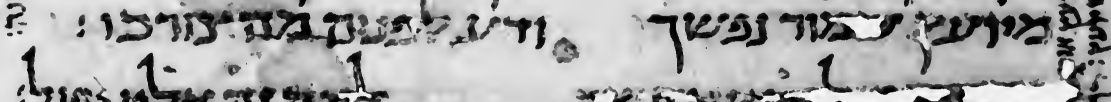

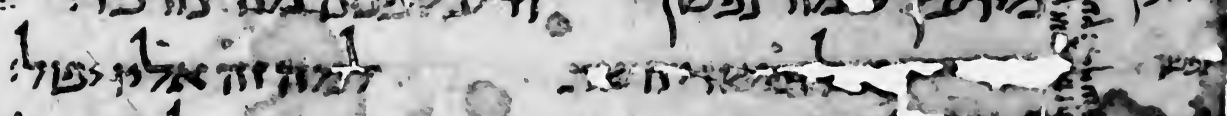
prin q

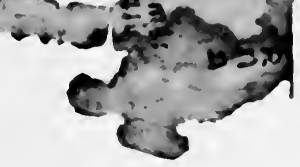

MS. B. Ecclus. xxxvi, $2+-x x x v i i, 9$ 
$-2$

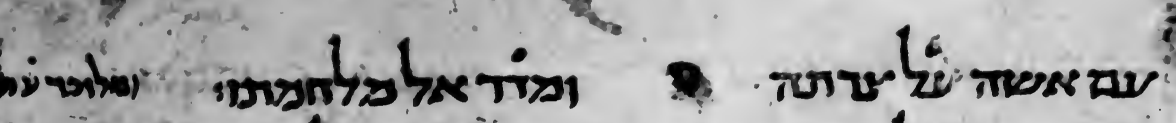

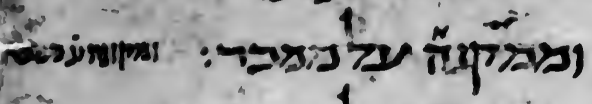

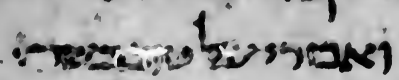

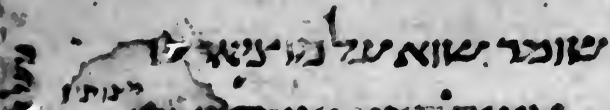

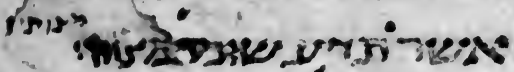

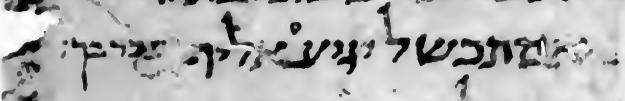

कै

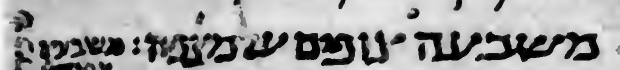
i.t.

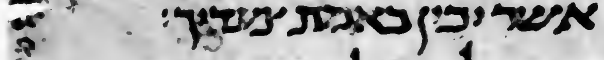

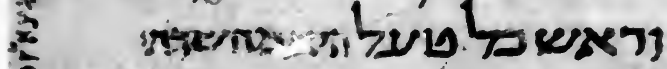

E. axemen

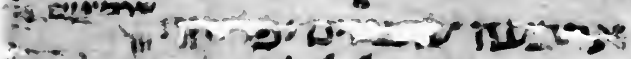

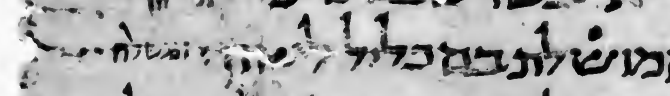

it

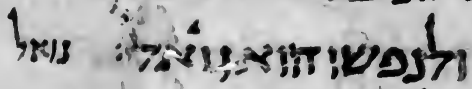

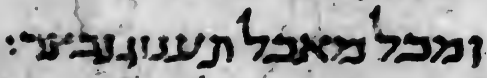

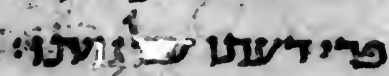

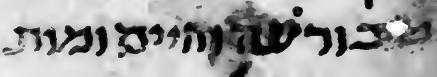

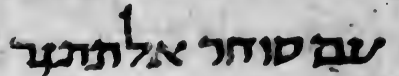

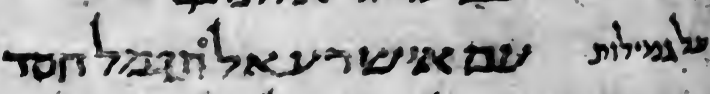

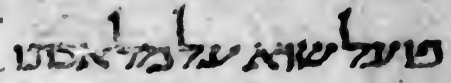

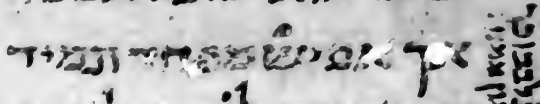

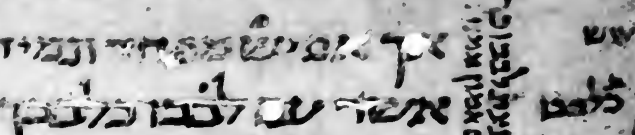

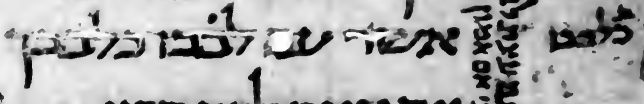

की

หาก 1.5 13)

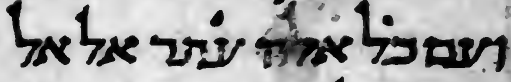

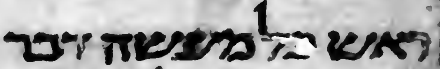

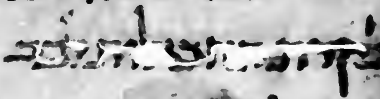
as

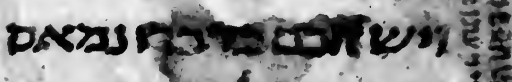

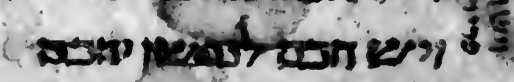

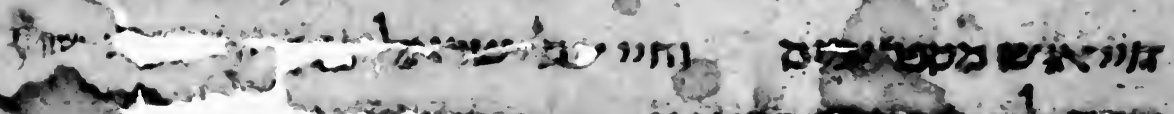

का

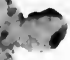

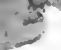

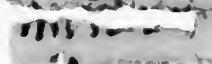

; 1 werde 

th

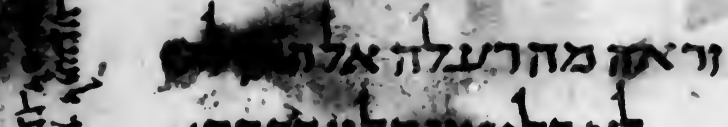

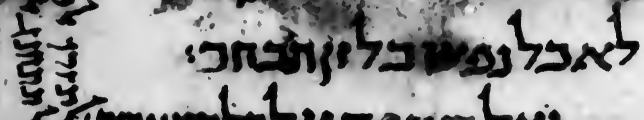

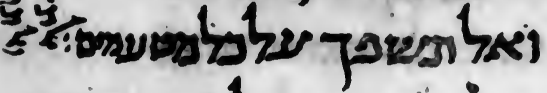

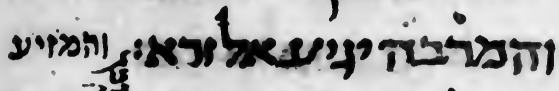

тан)

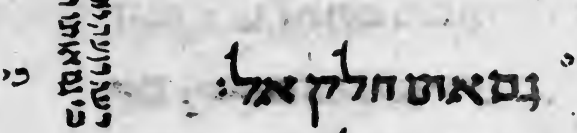

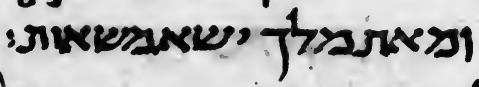

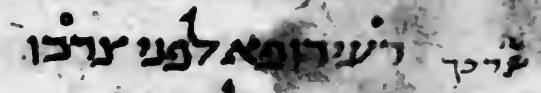

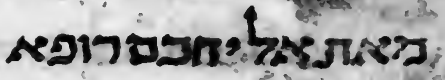

- Destas

jom

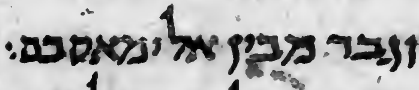

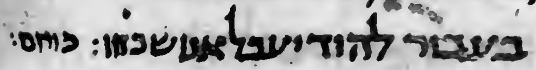

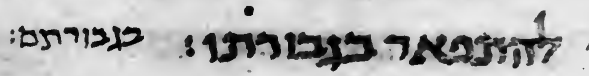

- .

נצ

לो

It isto veveres tas

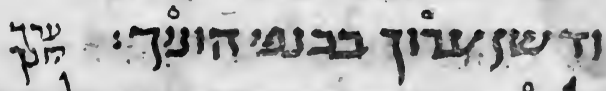

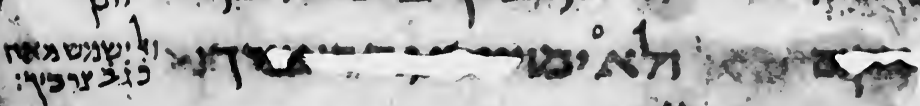

if.

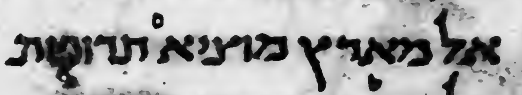

จุเง

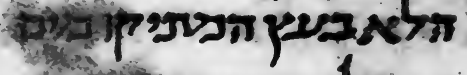

iol:

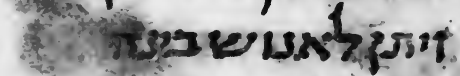

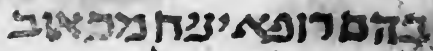

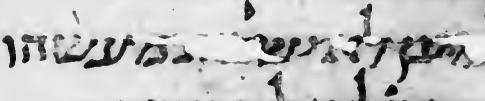

ris.:4

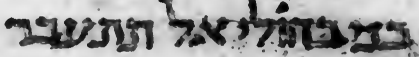

तोosy

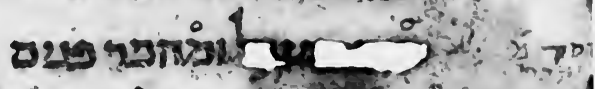

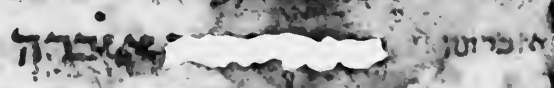
$\lambda \rightarrow$

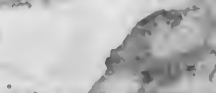





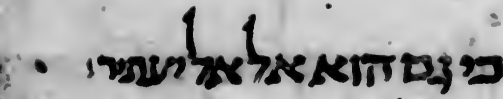

: 17000

'Tund :

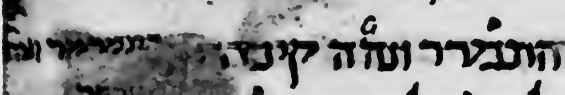

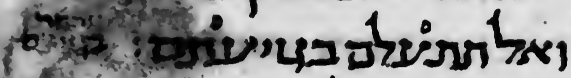

ושית

.

x.

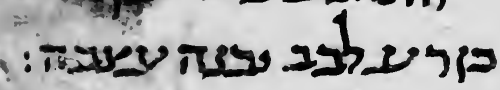

פר :

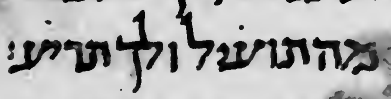
1 sint

1

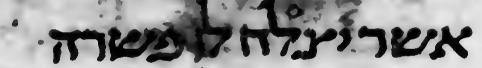
ineriv :3s sist

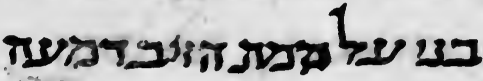

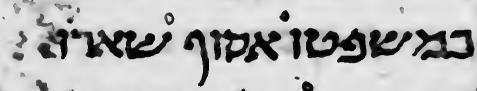

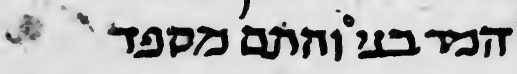

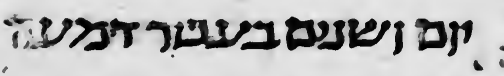

בדיב

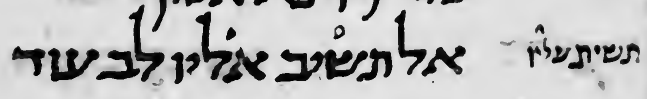

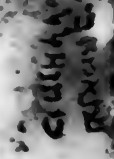

ins.

?

במשרפט:

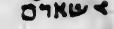
• בפי והרים

MS. B. Ecclus. xxxviii, $13-x \times x v i i i, 27^{\mathrm{h}}$ 


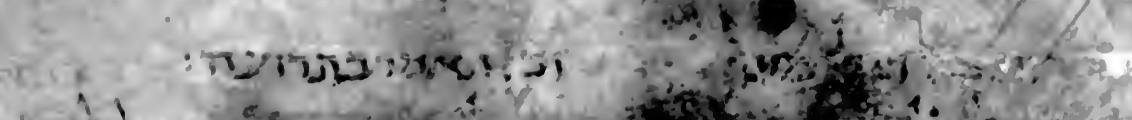

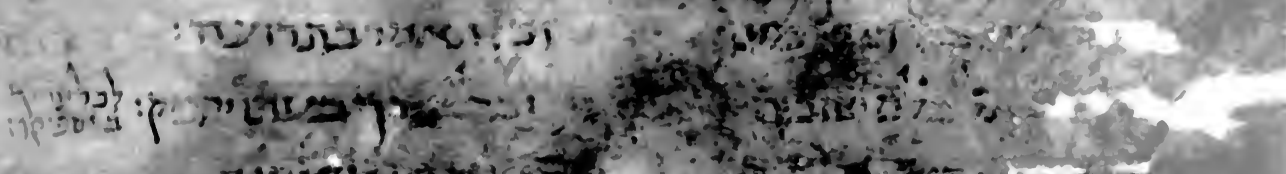

$2 i^{2}$ is

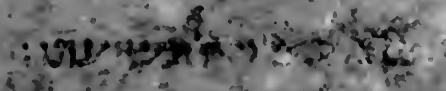

गजin -

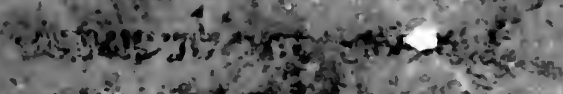

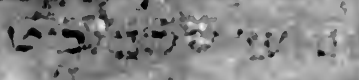

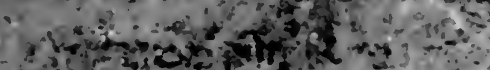

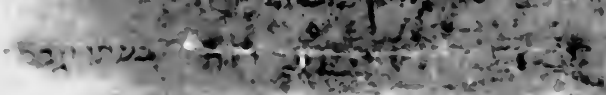

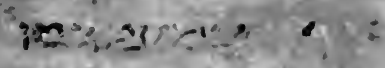

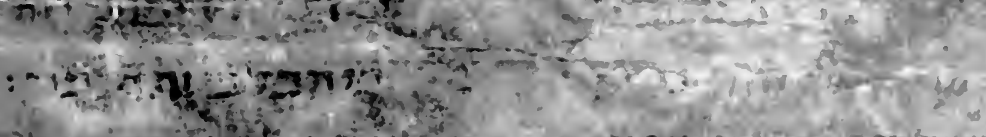

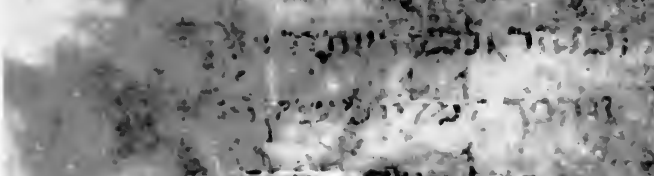

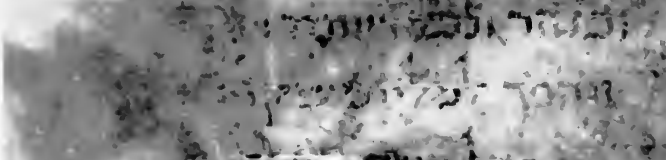

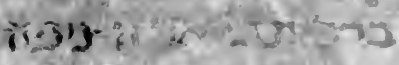

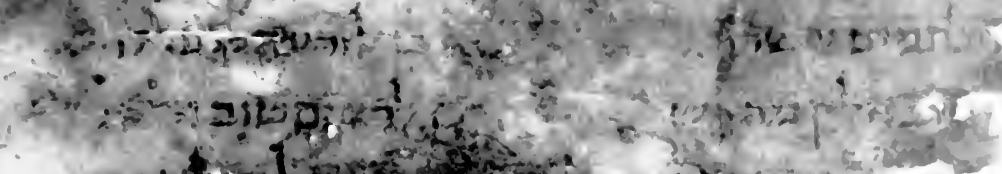

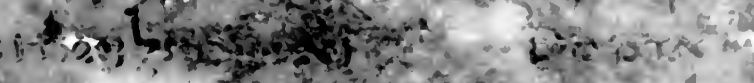

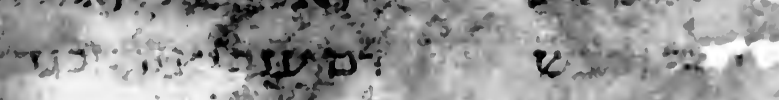

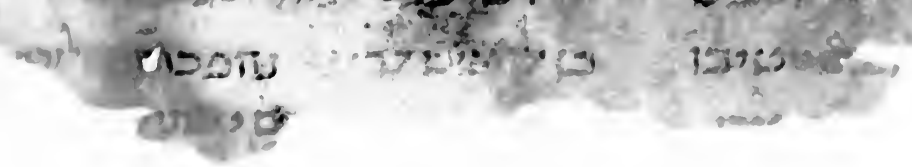

MS. B. Ecclus. $\mathrm{xxxix}, 15^{\mathrm{c}}-\mathrm{xxxix}, 28$ 



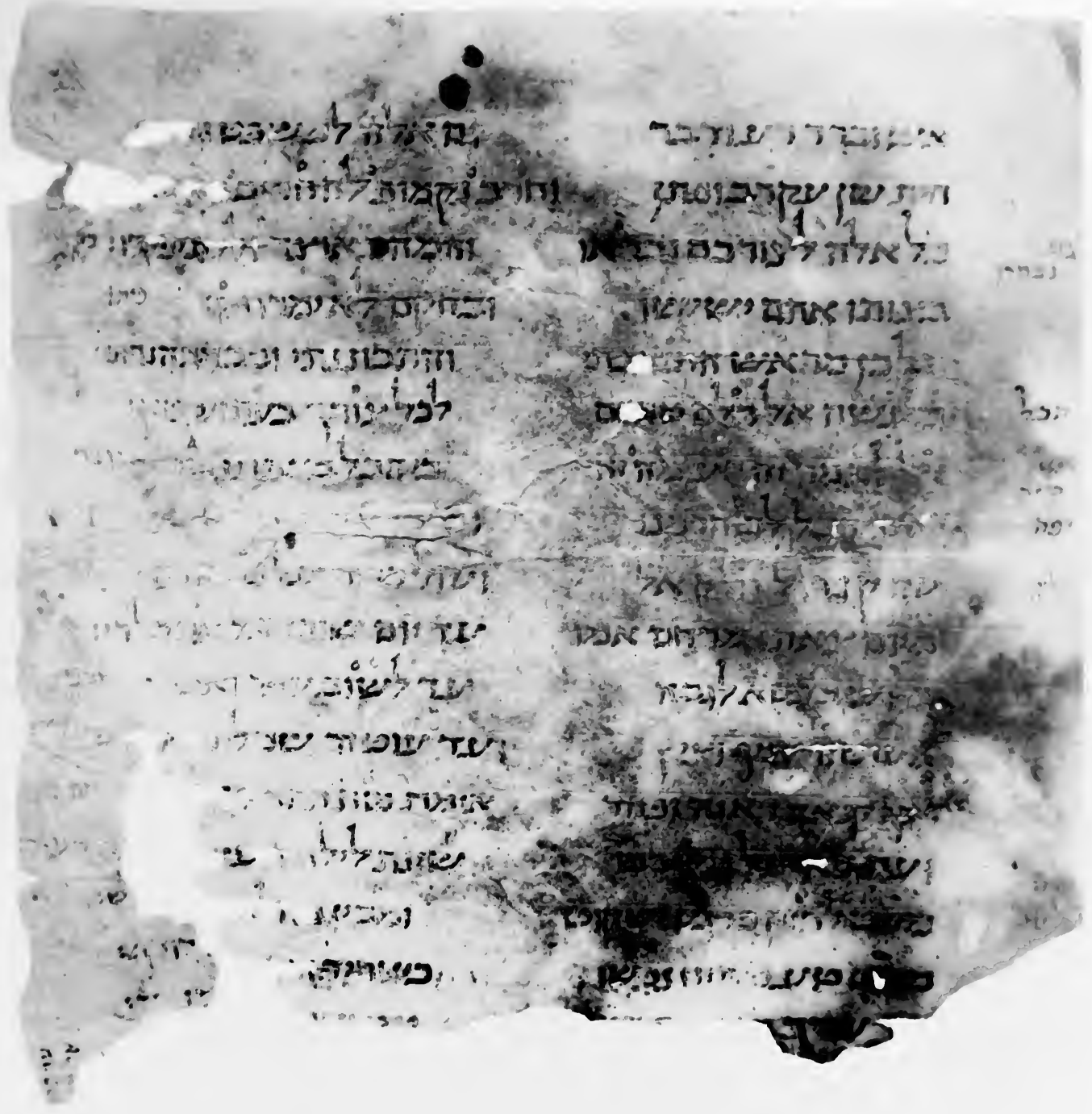

MS. B. Ecclus. $x x x i x, 29-x l, 8$ 


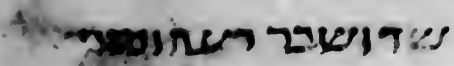

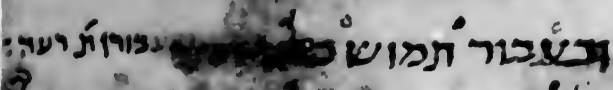

है

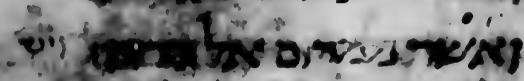

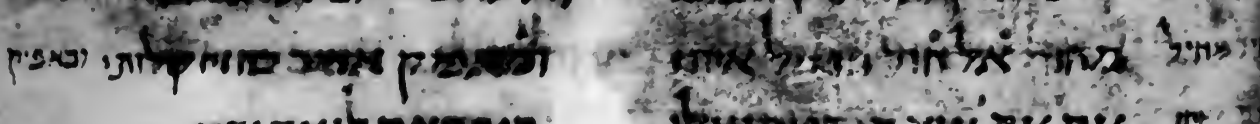

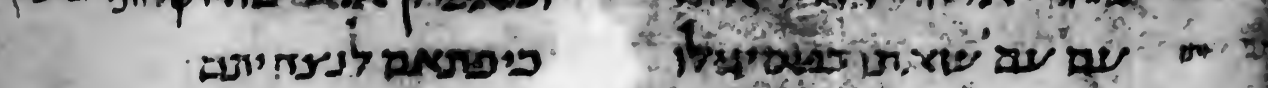

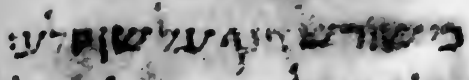
1. 1 . I

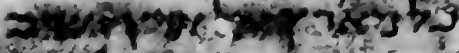
M:

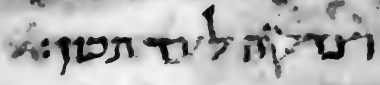

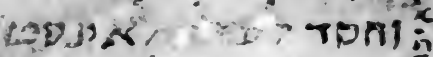

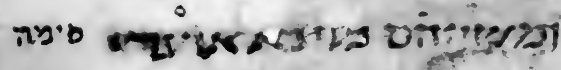

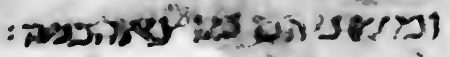

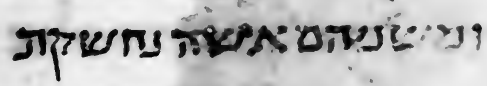

:

: Tาว

:4Y : :

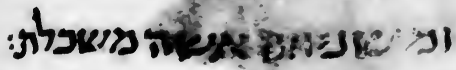

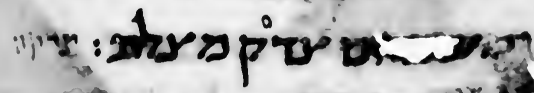

c.. sack

«P 



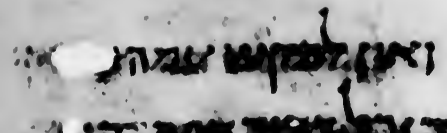

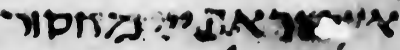

- 978 .

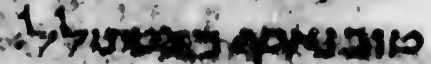

ค. แก,

ענ

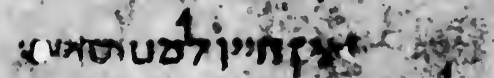

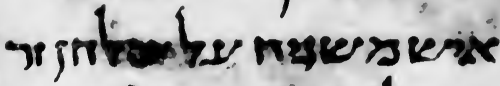
- Moress vaibsiry

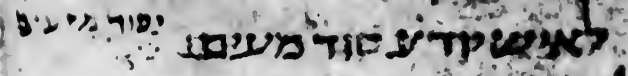

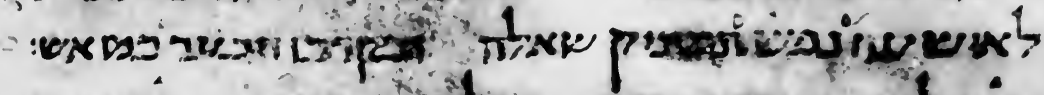
:

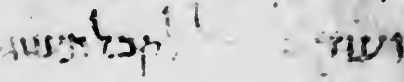

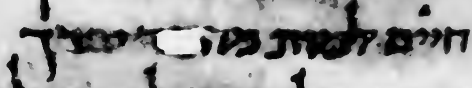

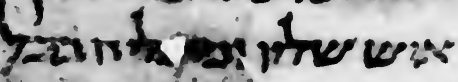

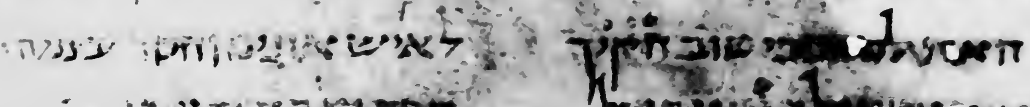

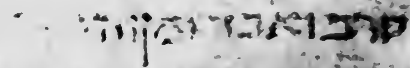

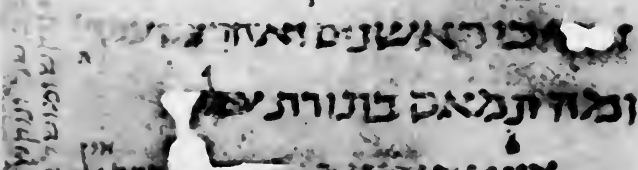

n?

10.0 .3

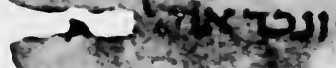

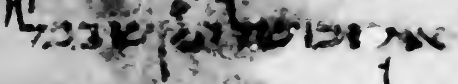

:

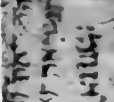
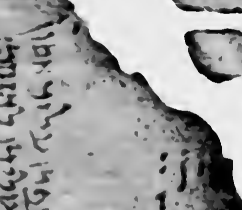

mushm

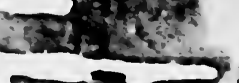

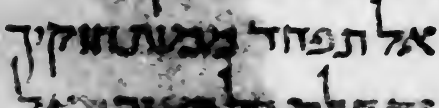

Nics in
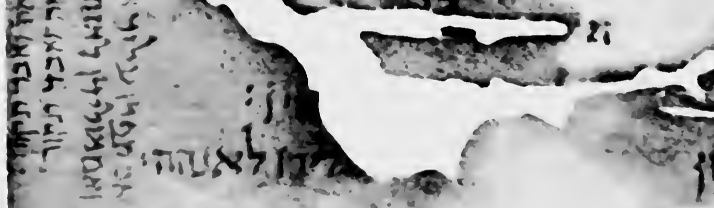

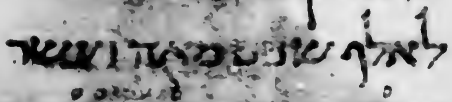

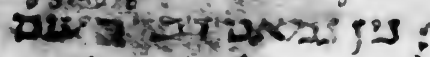

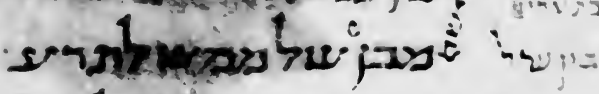
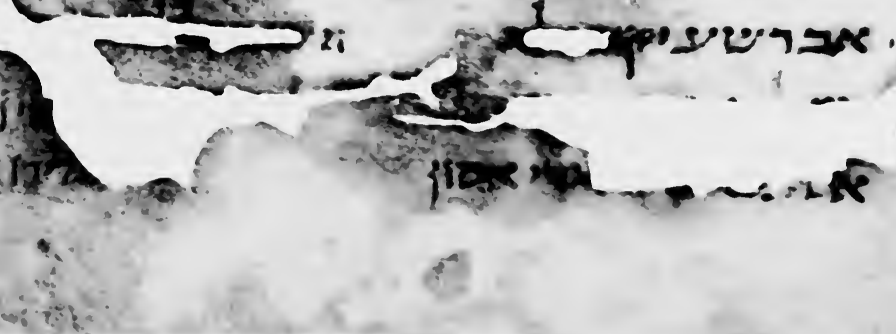

MS. B. Ecclus. $x l, 26^{r}-x l i, 9^{n}$ 
(4) 1112

(2n)

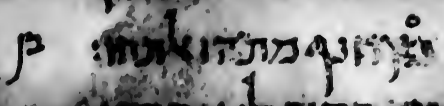

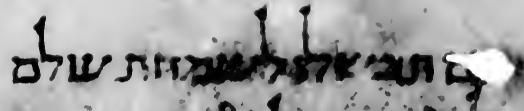

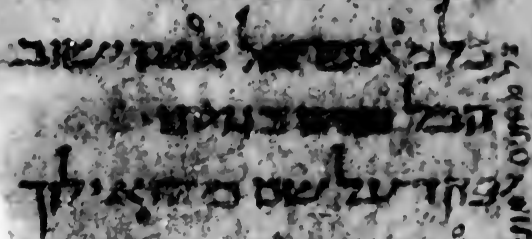

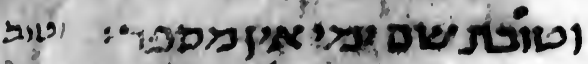

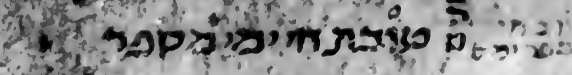

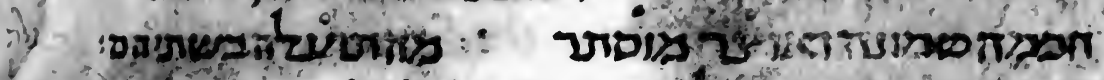

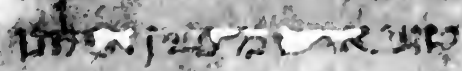

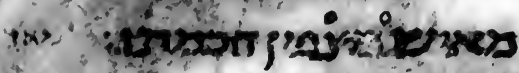

Sorros

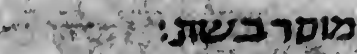

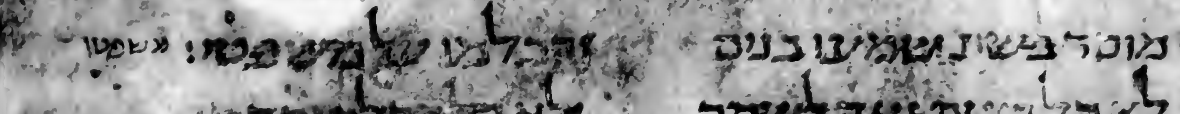

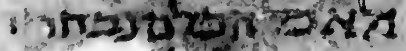

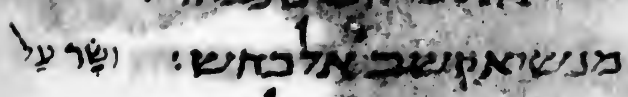

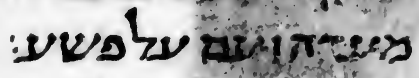

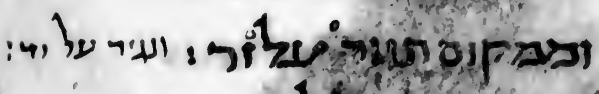

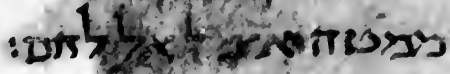

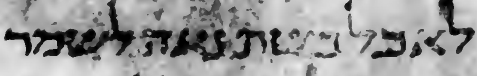

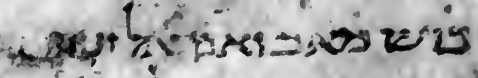
npe tromismos? zastas

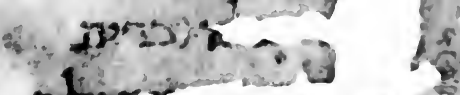

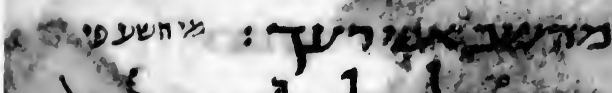

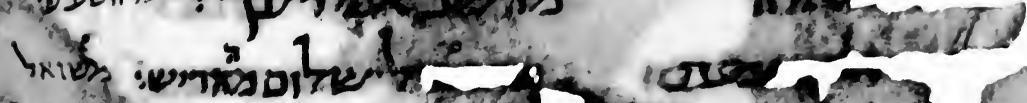

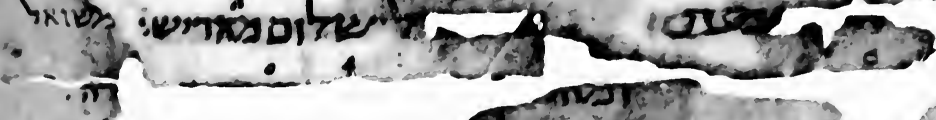

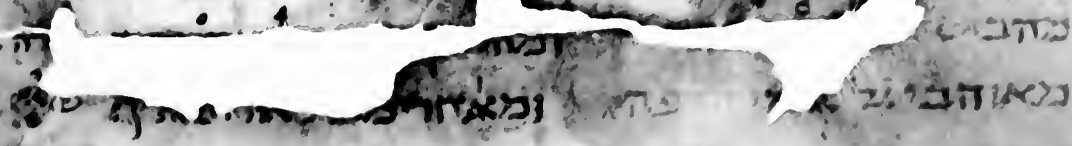

+1
$\therefore$

MS. B. Ecclus, xli, 9-xli, 22 



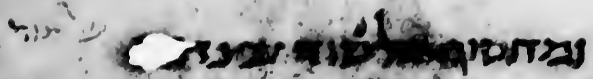

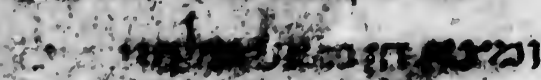

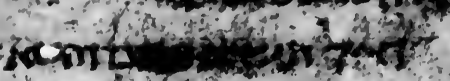

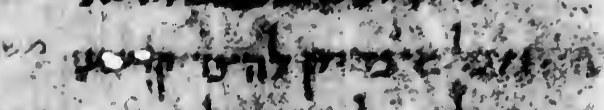

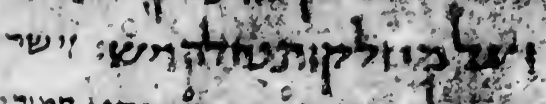

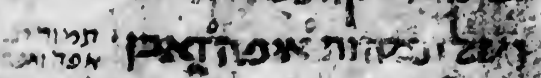

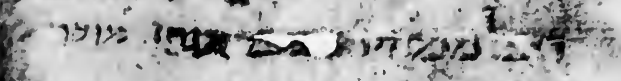
: (U)

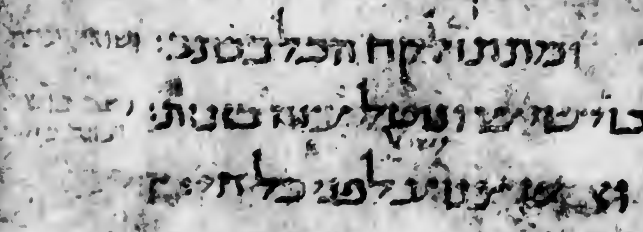

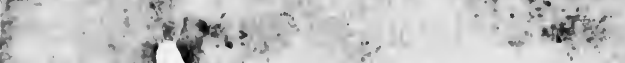

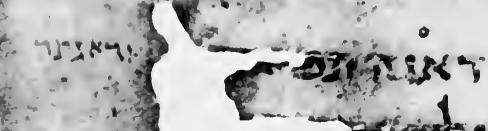

* a

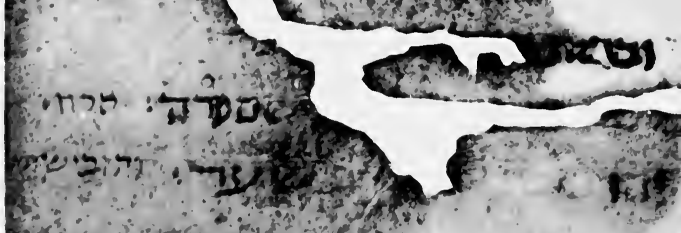
Than -

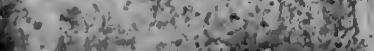

\section{ของ tom

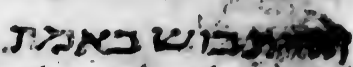

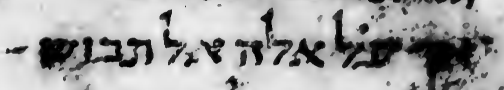

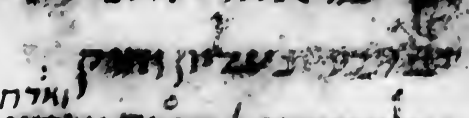

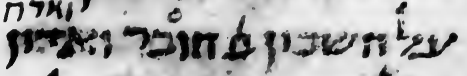

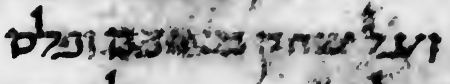

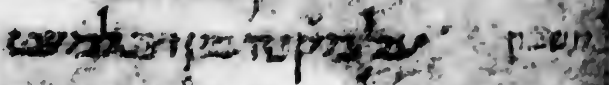

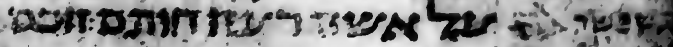

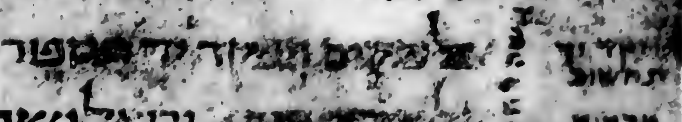

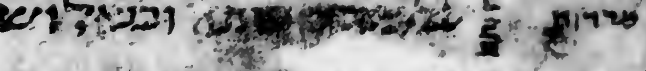

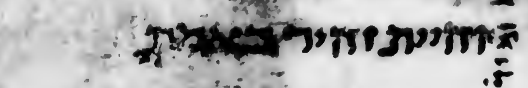

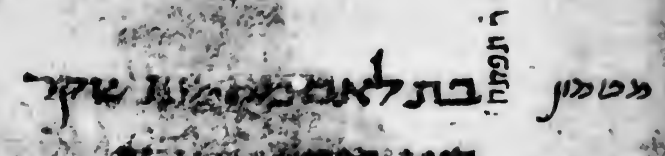

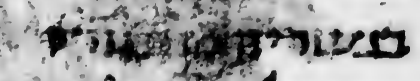

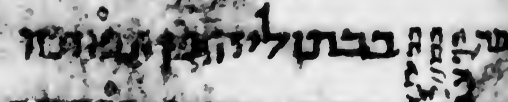
iviting

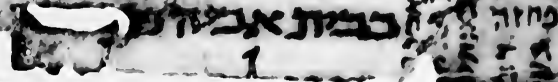

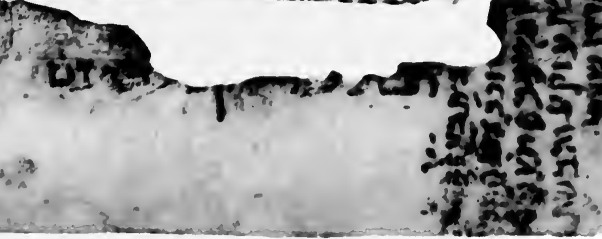




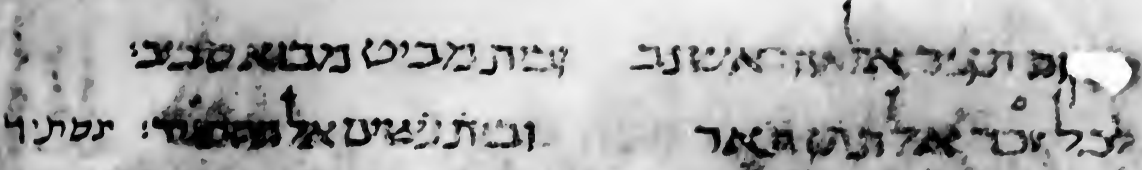

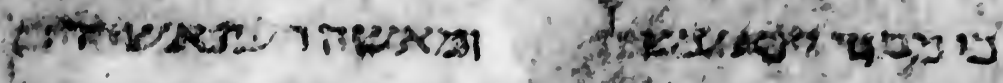

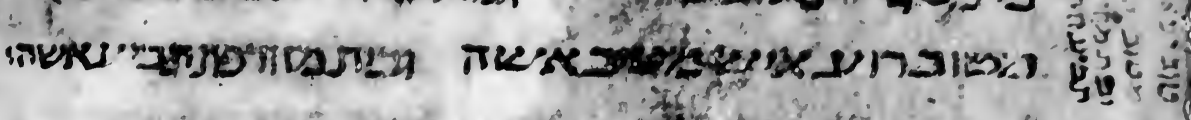

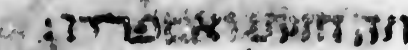

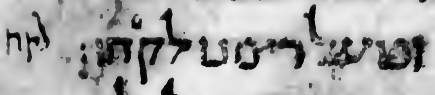

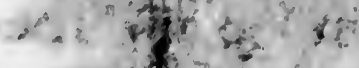

(3.

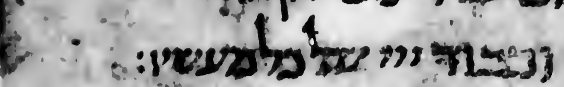

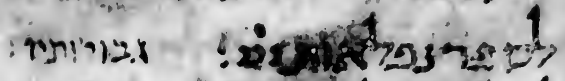

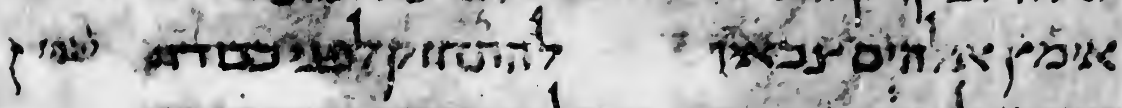

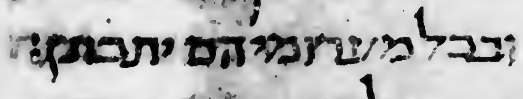

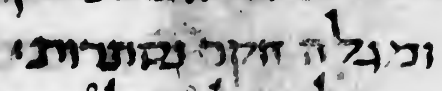

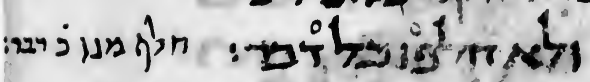

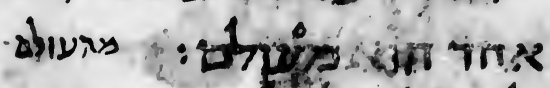

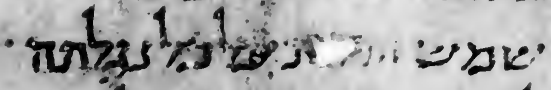

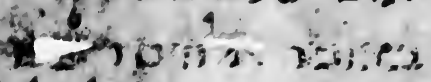

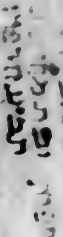

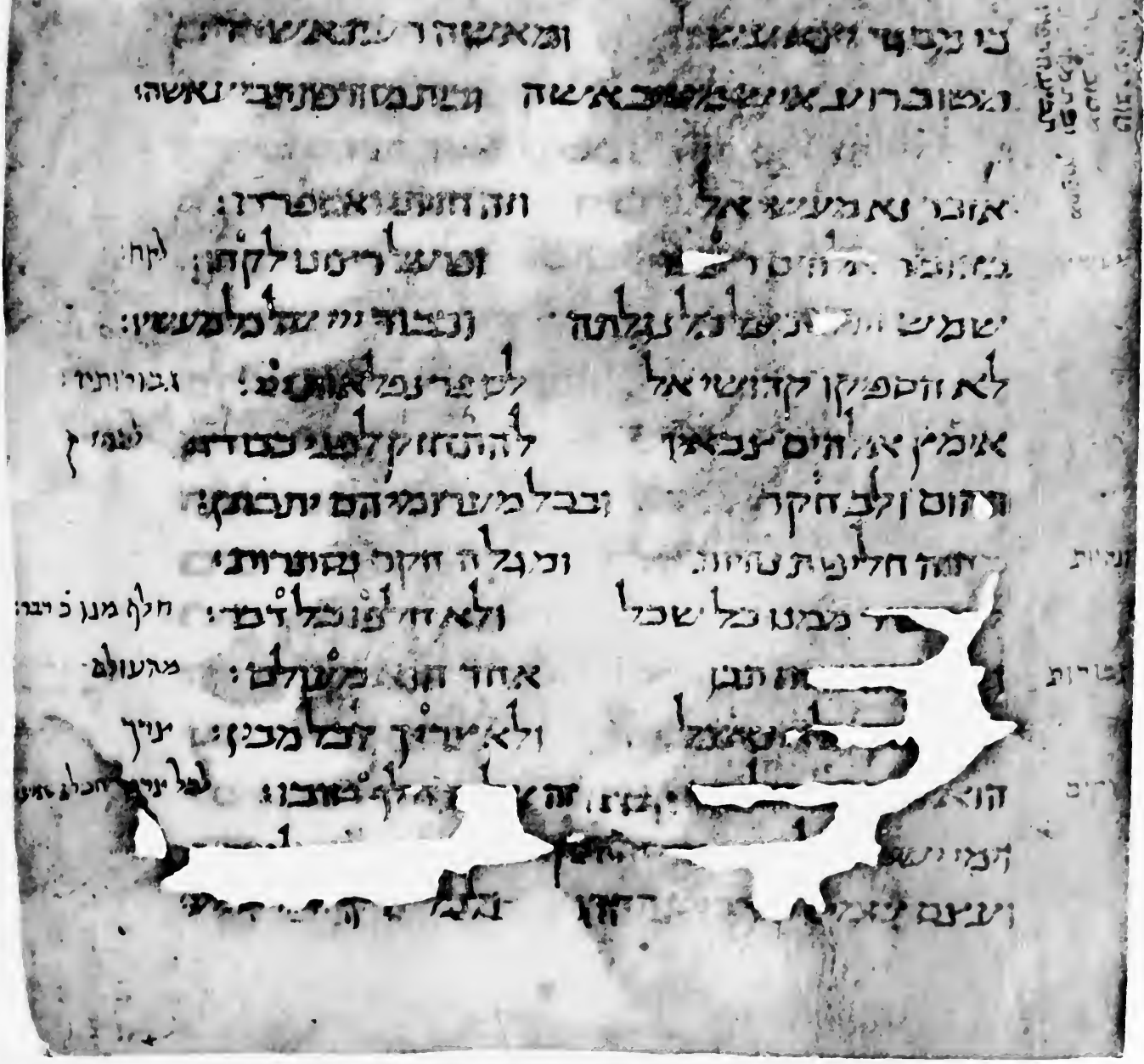

MS. B. Ecclus, xlii, $\mathrm{I}^{\mathrm{e}}-\mathrm{xlii}, 23$ 


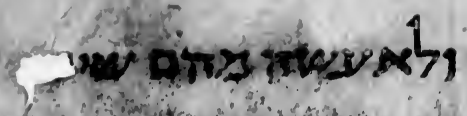

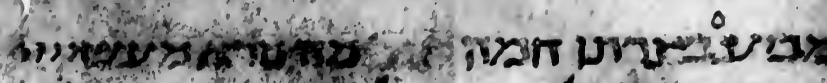

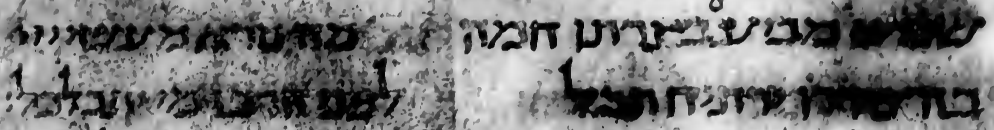

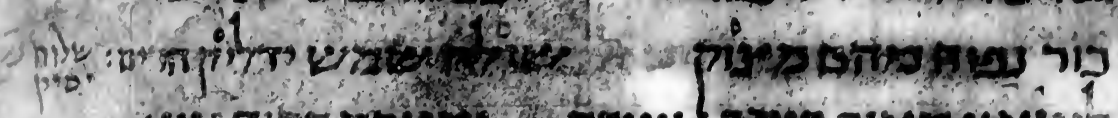

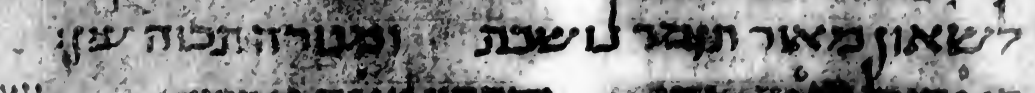
iys:

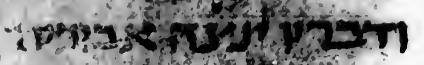
Shwo

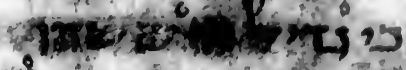

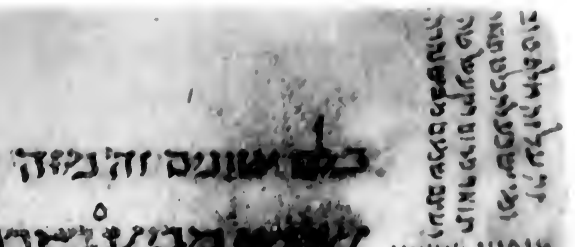

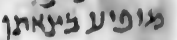

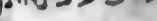

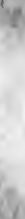

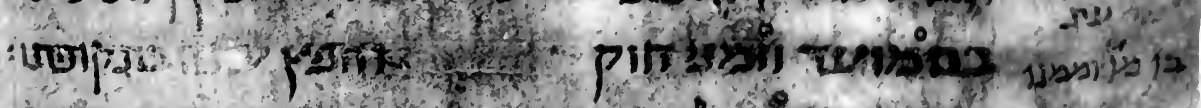

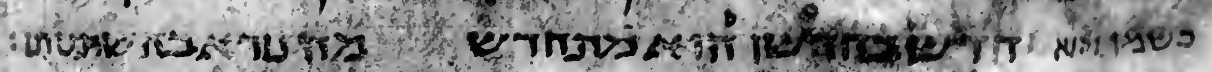

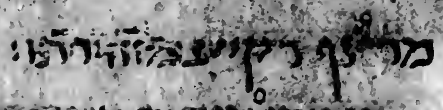

(1)

$\lim _{x \rightarrow 2}=$

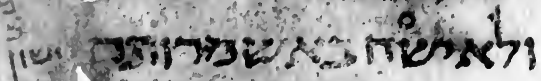

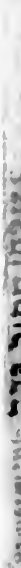

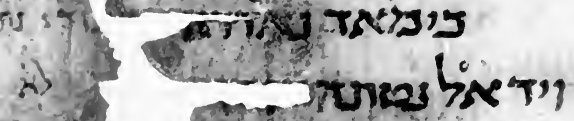

2.

5
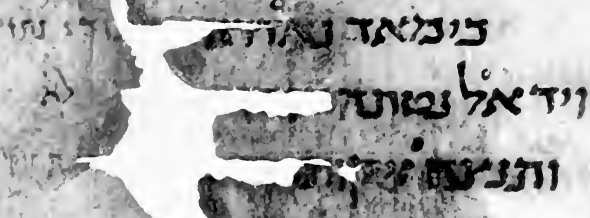

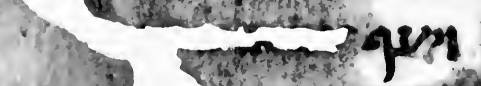

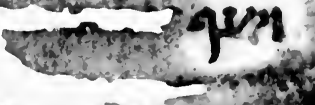

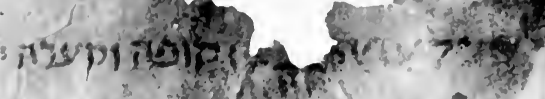
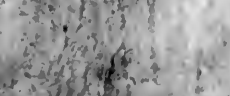

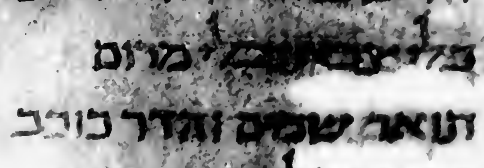

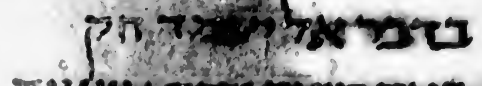

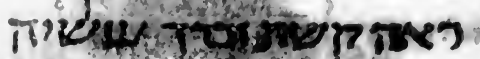

กับข

ก.t

क. I the

3ift's oive pist $x: 1,2,0$ pyis 1) - (f) (1)
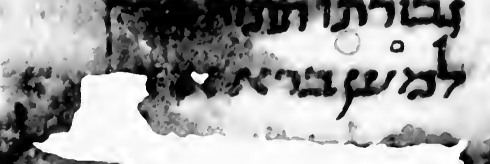

rines

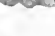

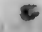

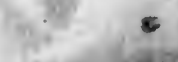

why

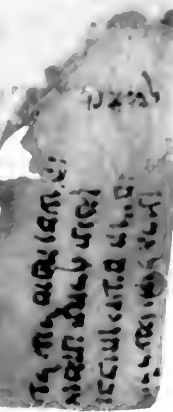

MS. B. Ecclus. xlii, $2+-x l i i i, 17^{\text {h }}$ 

יר

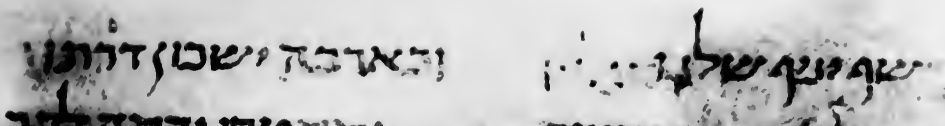

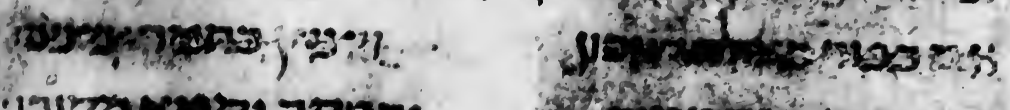

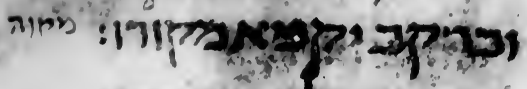

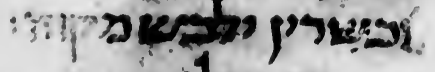

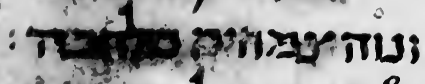

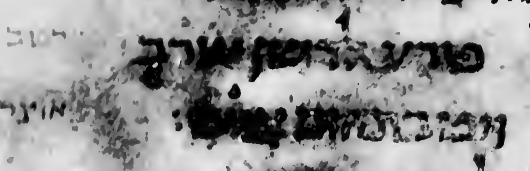

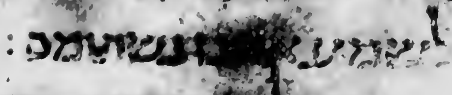

:Tisinenters?

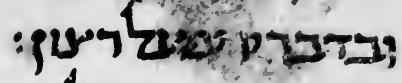

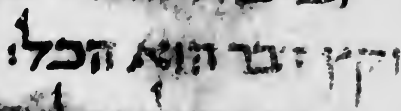

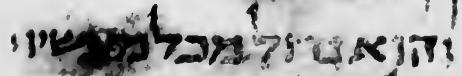

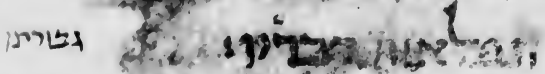

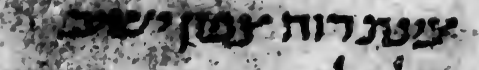

Difors vansts bis

$\circ$

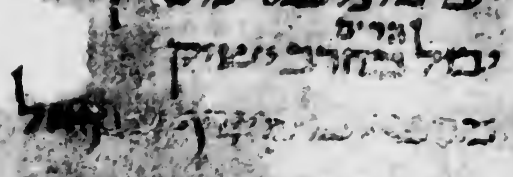

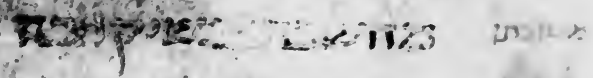

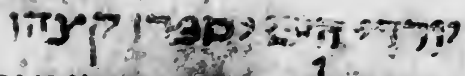

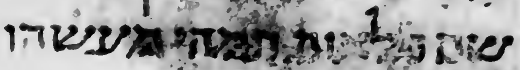

Tolitity sivat

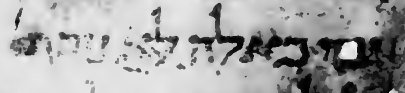

ר?

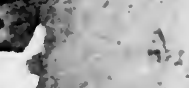

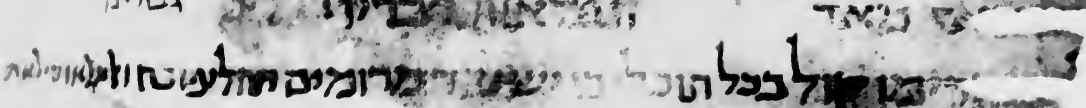

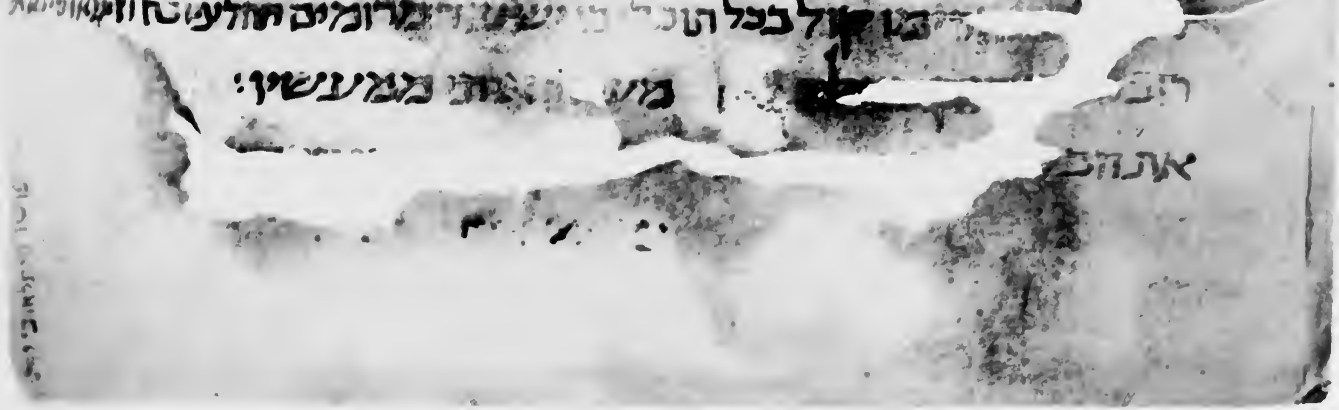

MS. B. Ecclus. xliii, $17^{r}-x$ xliii, 33 



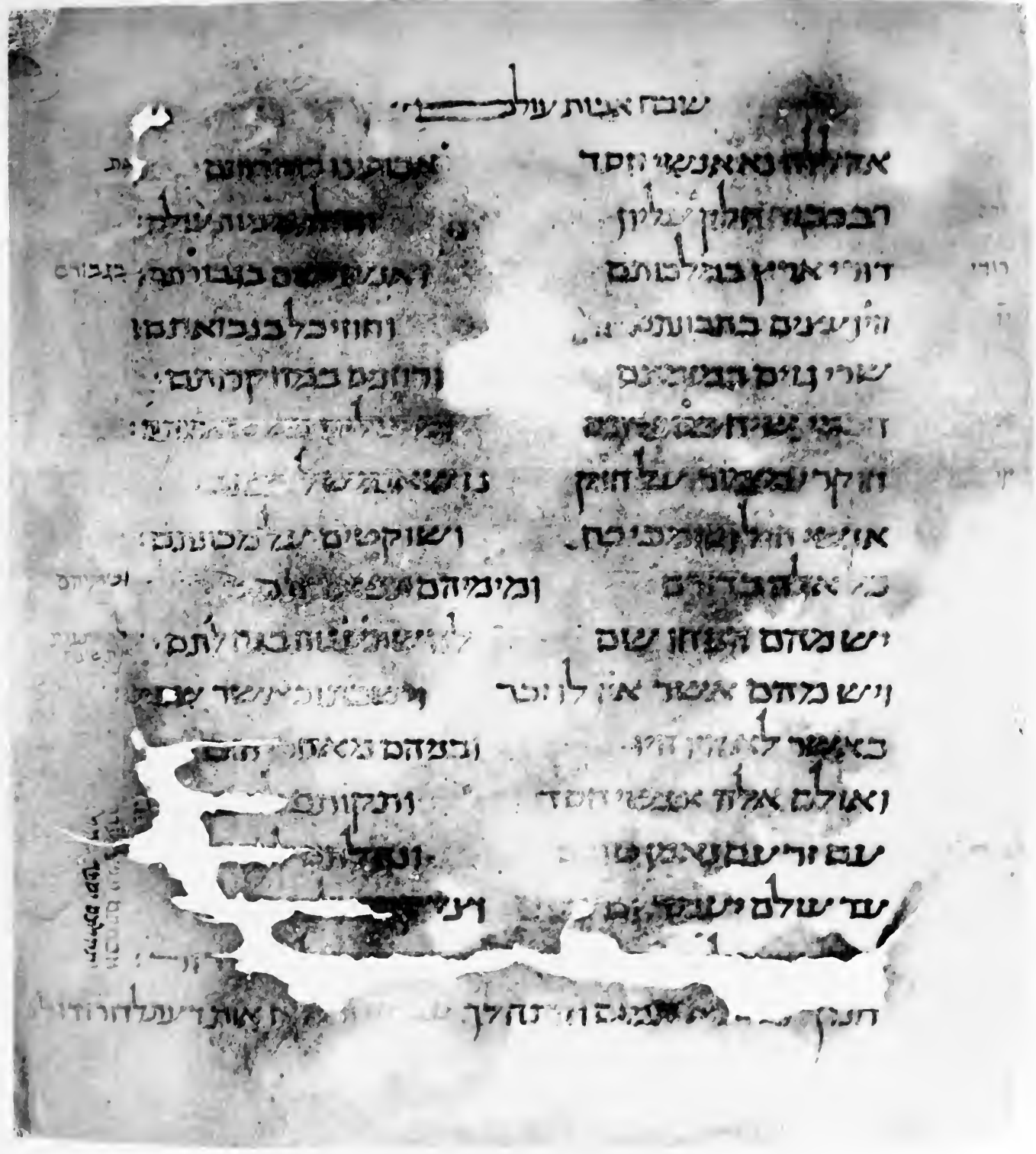



is (2). 1

2.

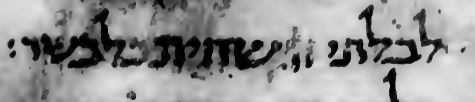

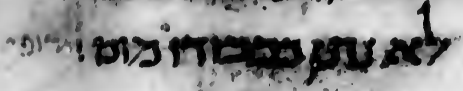

: 13y minapes:

: pass xams

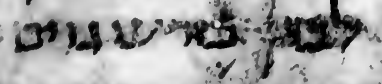

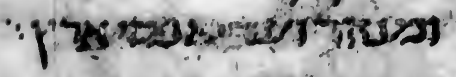

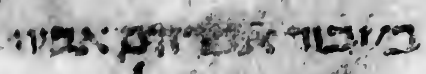

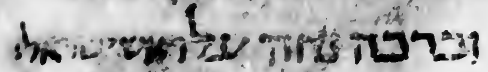

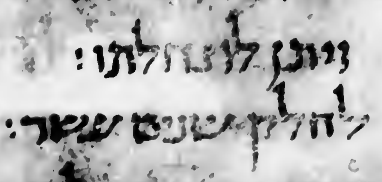

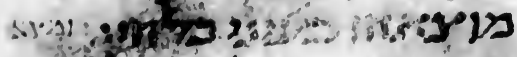

formot was

" ".

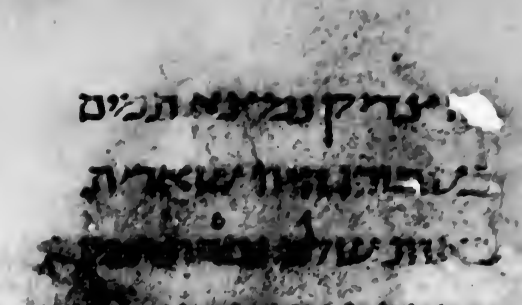

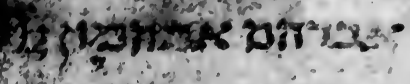

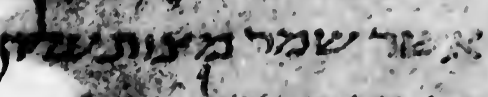

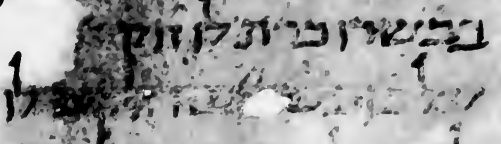

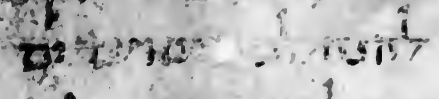

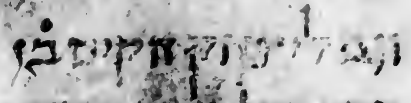
$135 \mathrm{~s} n \mathrm{~m}=\mathrm{N}$ T. T2007issis?

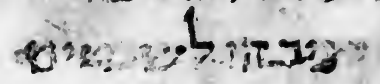

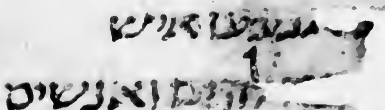
प्र. 0.5

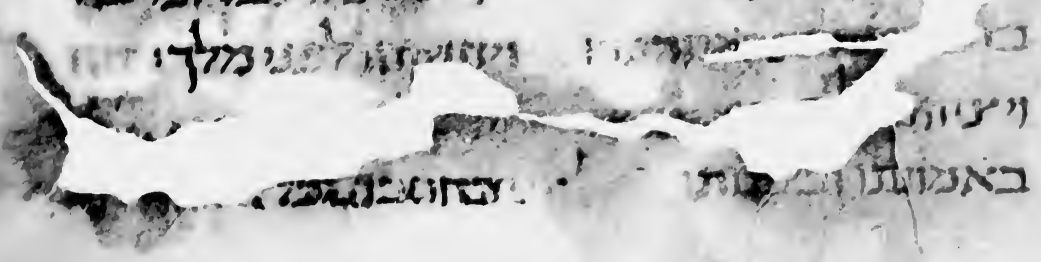





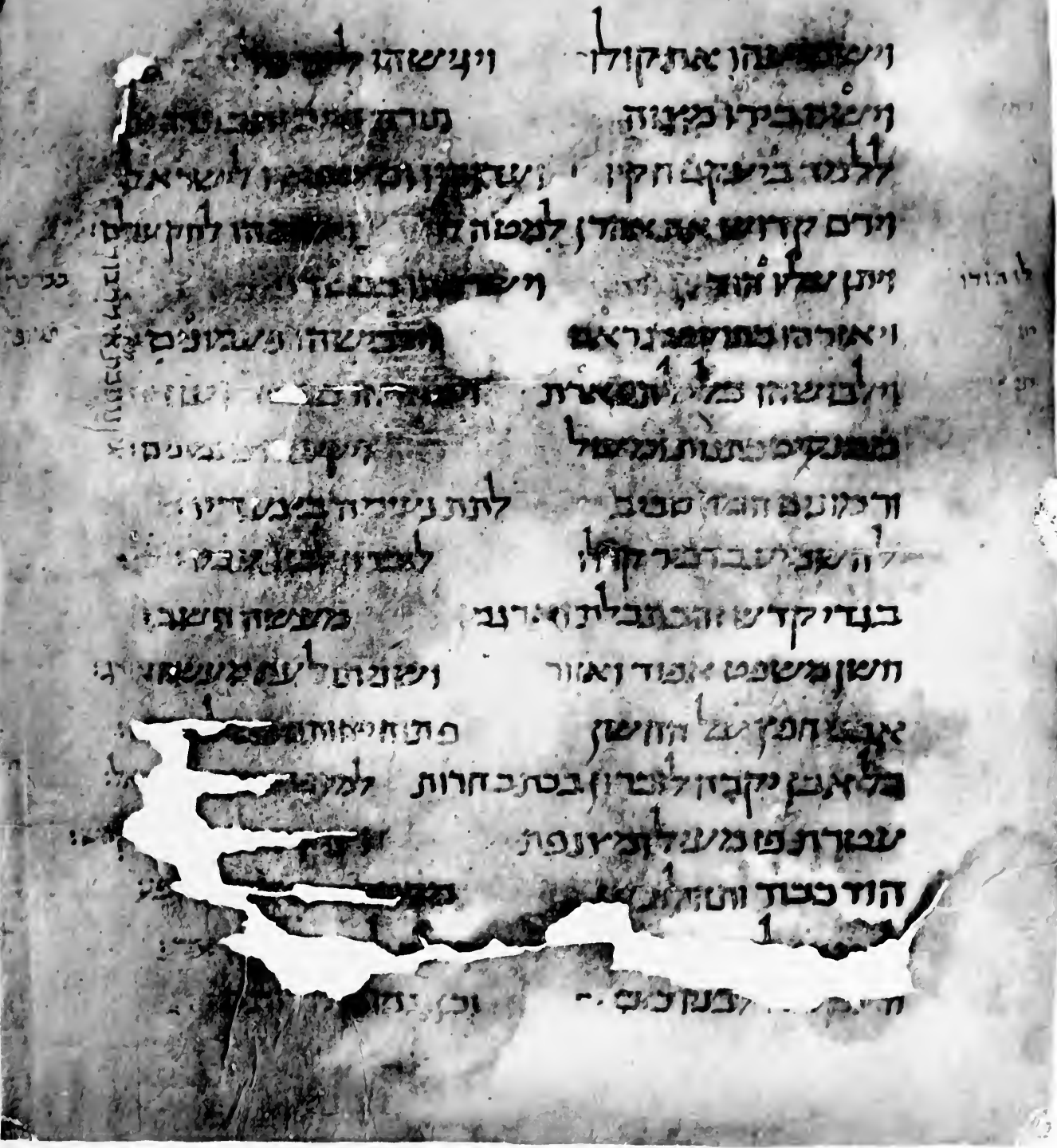

MS. B. Ecclus. xlv, 5-xlv, I3 



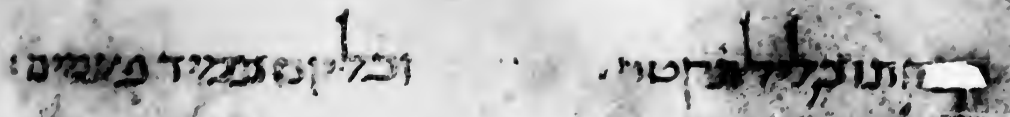

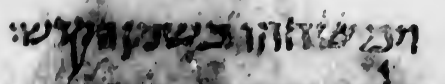

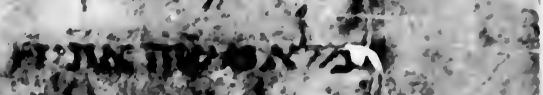

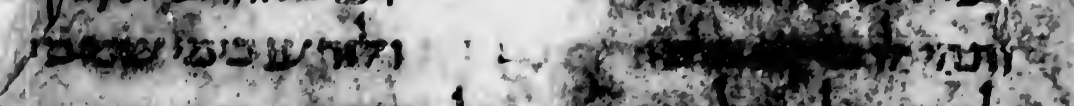

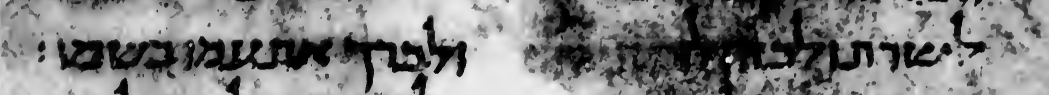

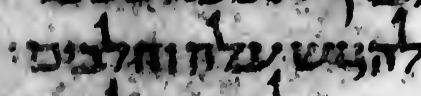

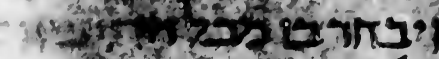

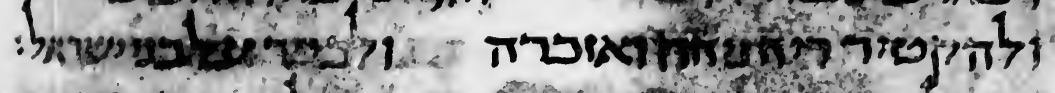

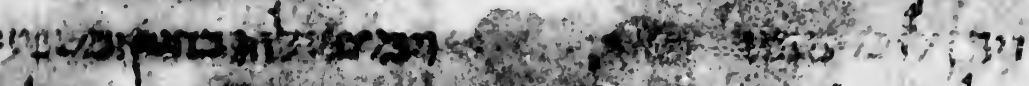

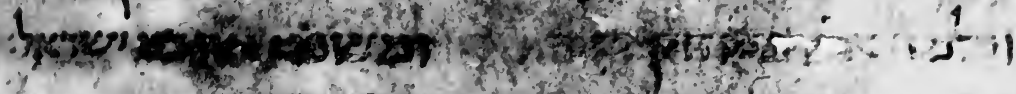

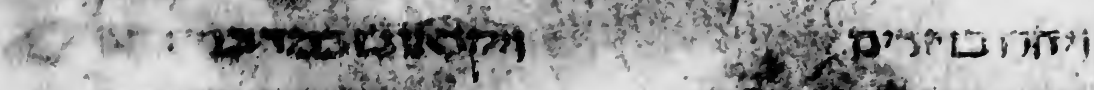

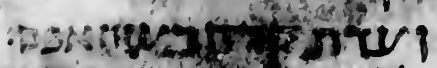

if

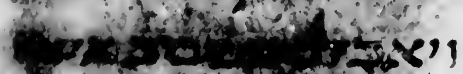

4h

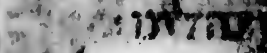

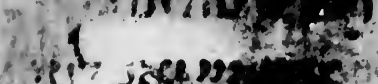

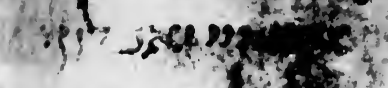

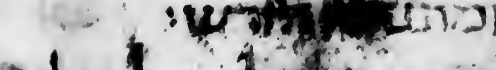

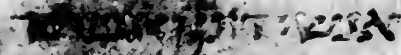
for $x$ ist

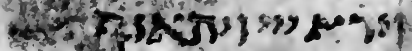

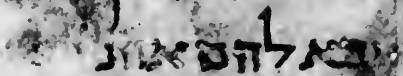

Mign fortan-

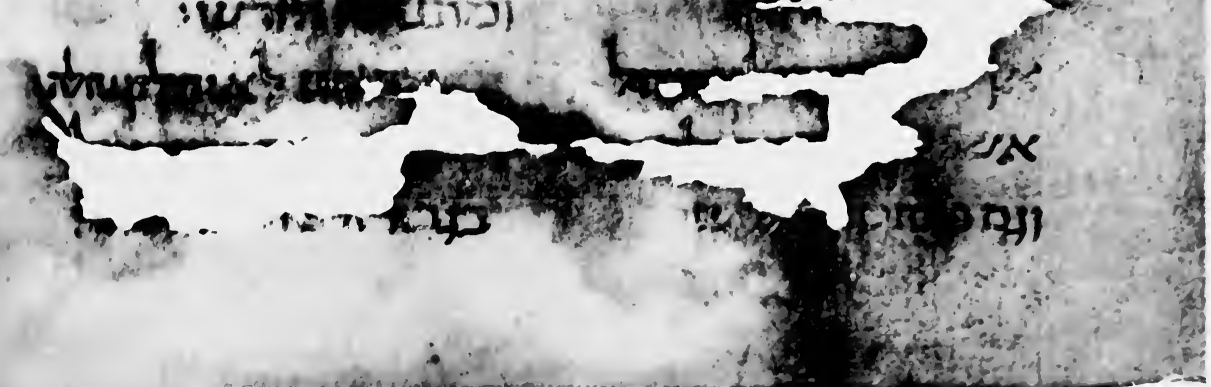

MS. B. Ecclus. $x l v, 1+-x l v, 23^{n}$ 



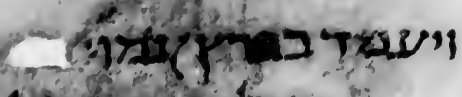

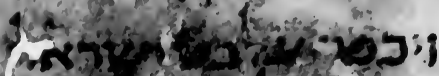

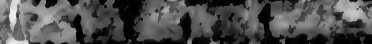

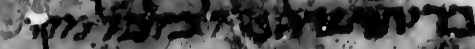

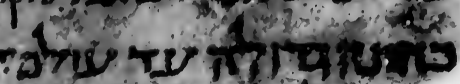

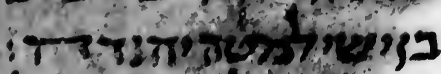

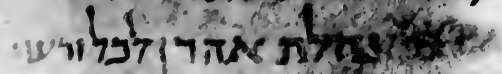

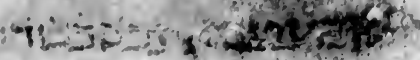

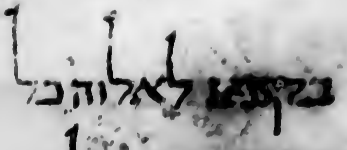

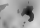

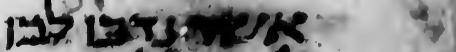

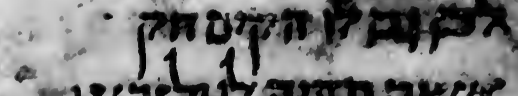
if -

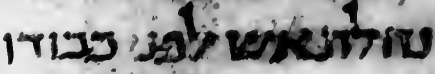

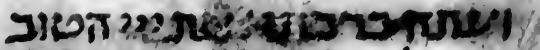

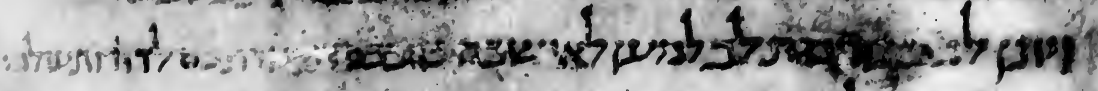

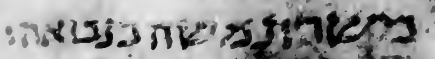

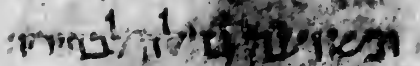

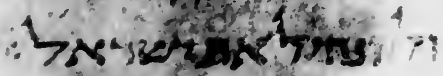
tze phosivists 1.
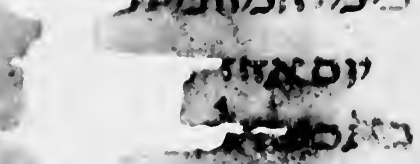

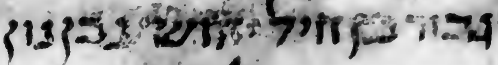

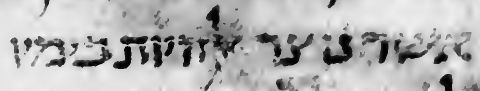
surviptoput

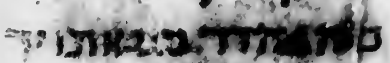

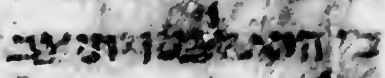

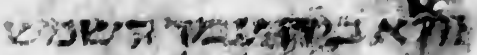

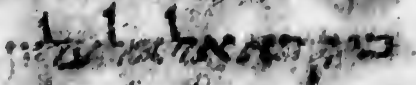

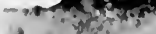

s.

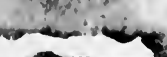

29

4. of 2 ats?

when?

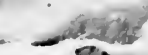
Ren

: PJ

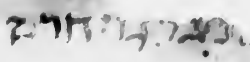
if -1

MS. B. Ecclus. xlv, $23^{\mathrm{b}}-\mathrm{xlvi}, 6^{1}$ 


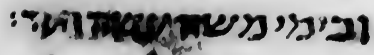

-)

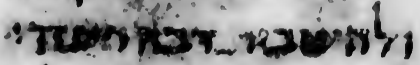

itumatrinos visurs:

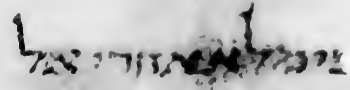

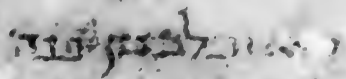

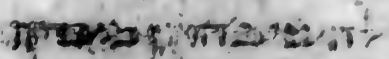

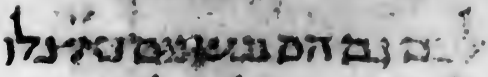

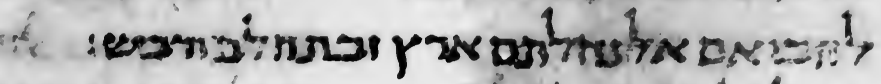

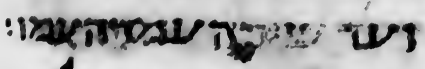

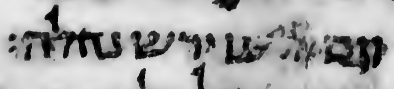

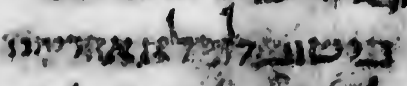

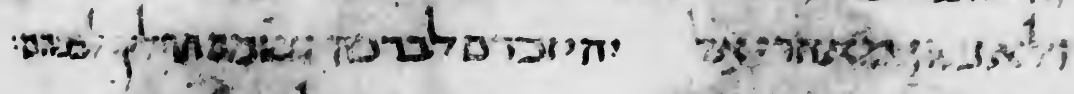

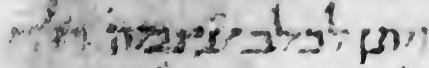

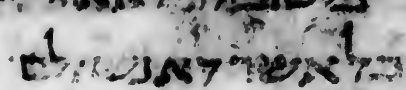

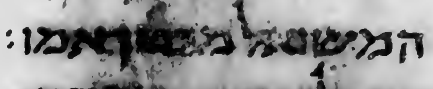
4ากั

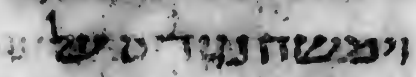

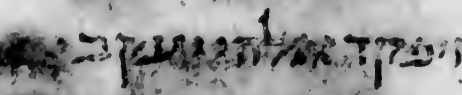
(a) aidas 2 ,

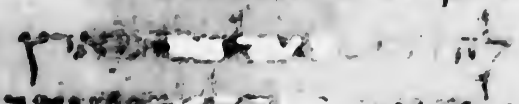
sperstar co c.t.

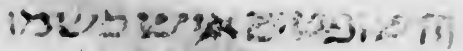

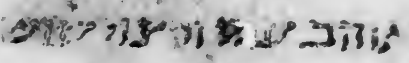

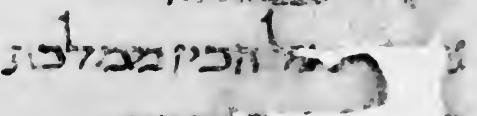
1.นข ต Trtatin = 



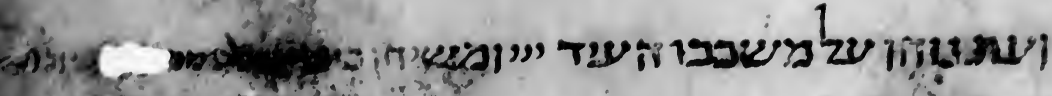

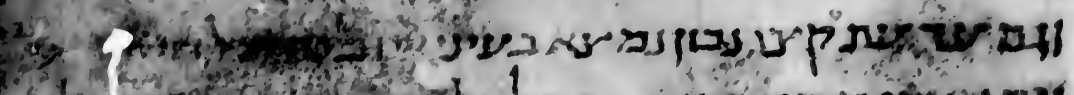

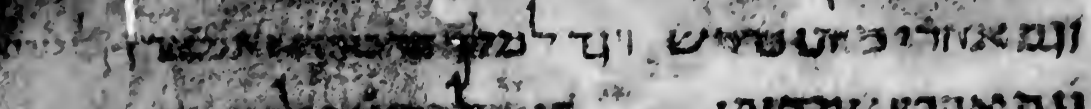

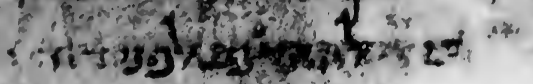

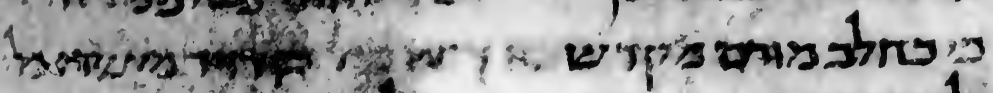

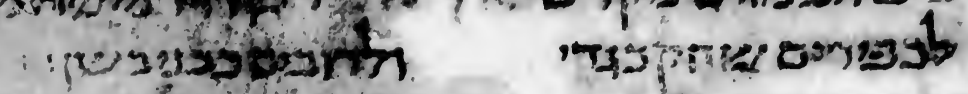

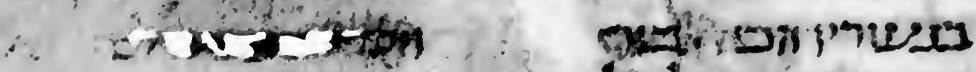

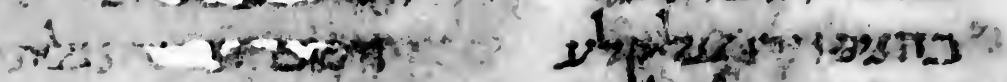

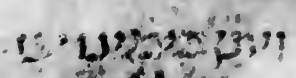

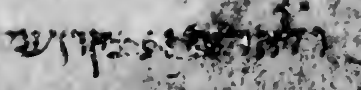

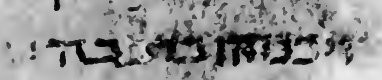

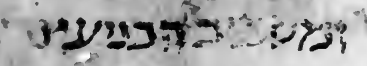

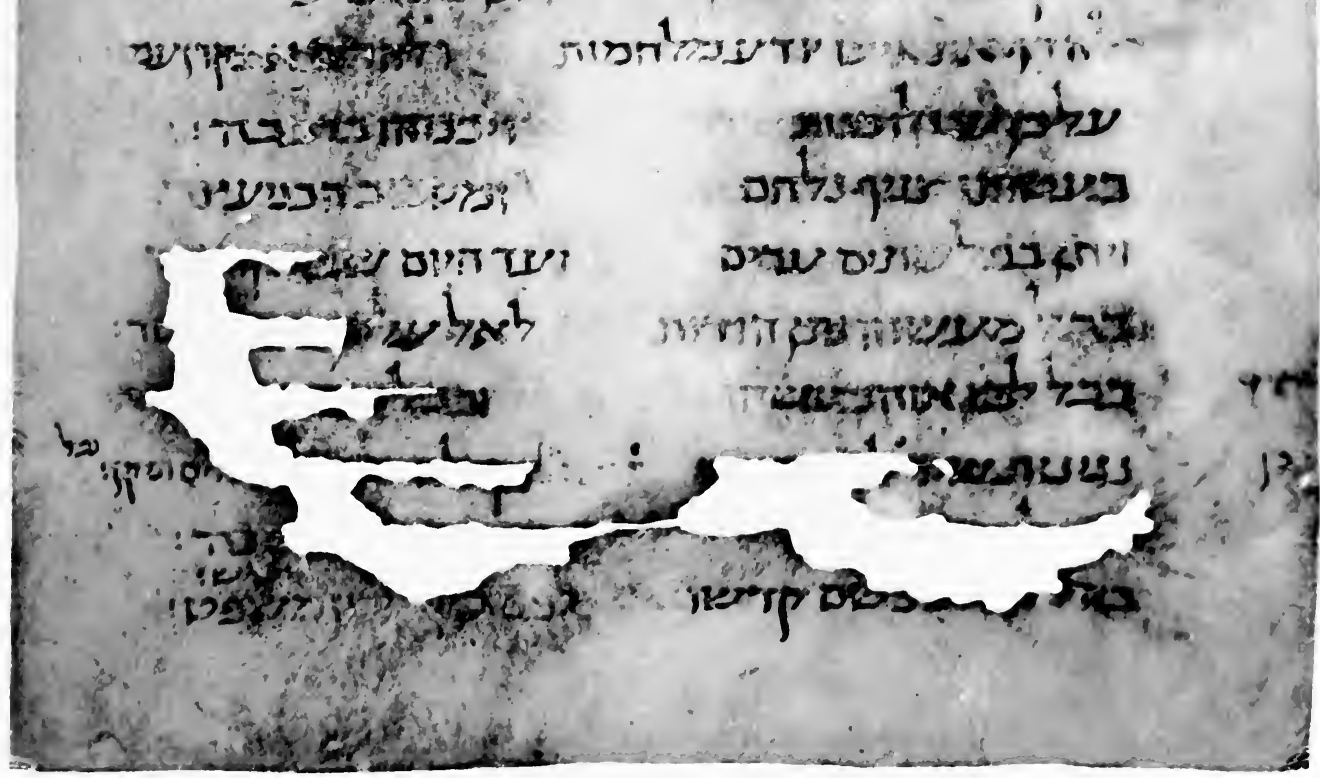

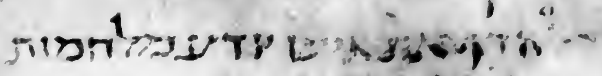

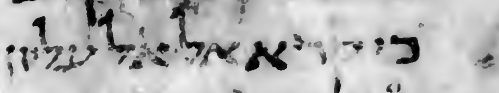

MS. B. Ecclus. xlvi, 19-xlvii, ro 
. 


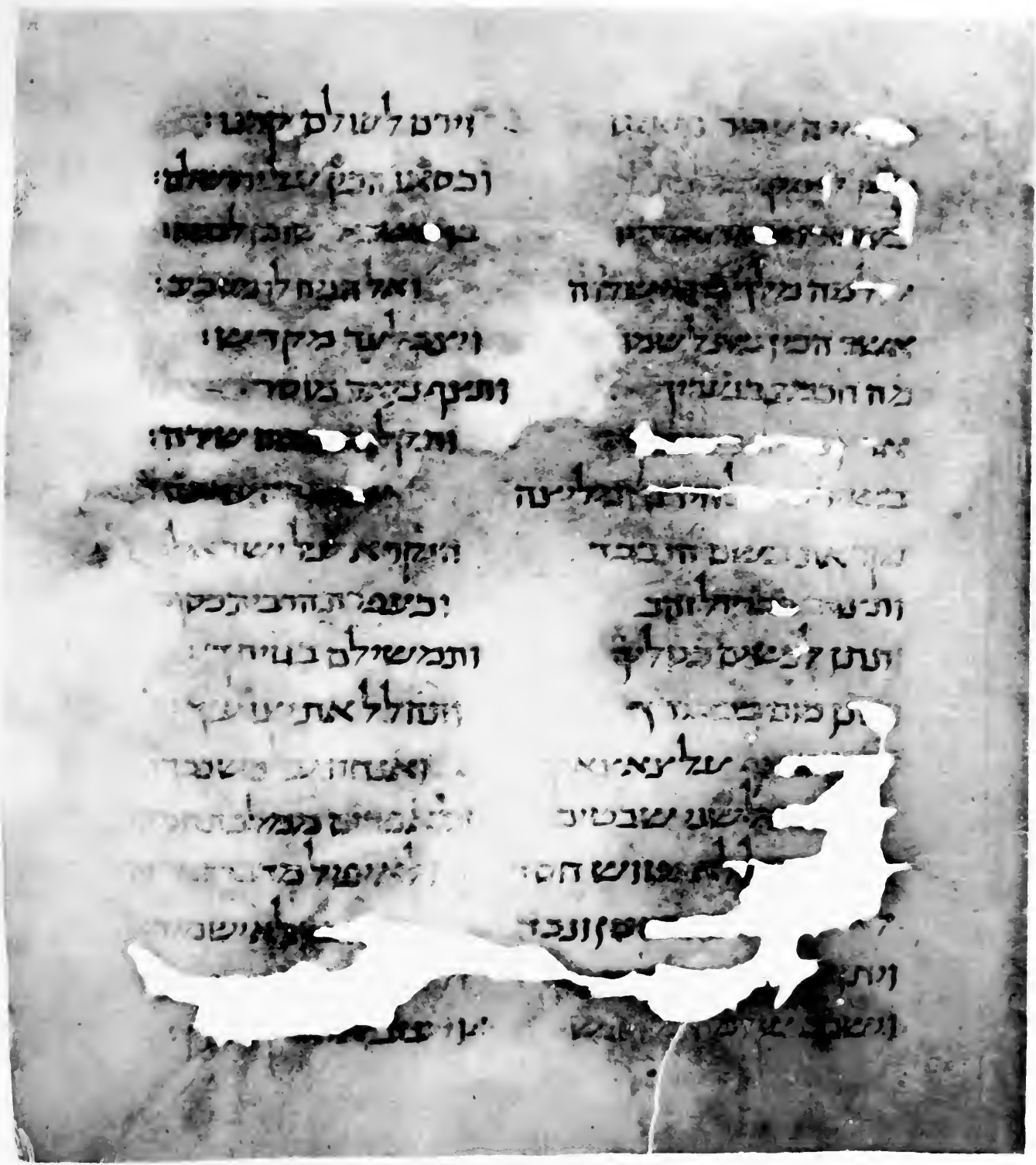

MS. B. Ecclus. xlvii, I $1-x l v i i, 23^{b}$ 


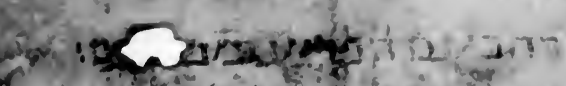
es 79 .

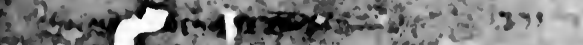
o. 5 C

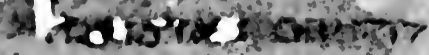

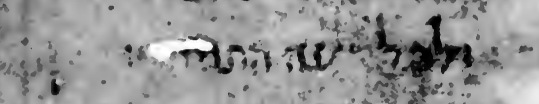

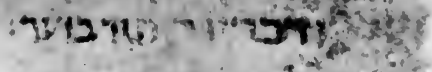

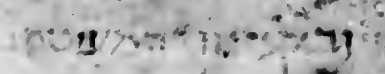

$$
\text { Min ir max } 2
$$

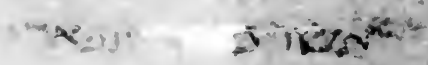

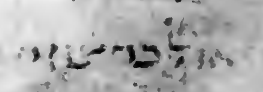

:Dris - motxat

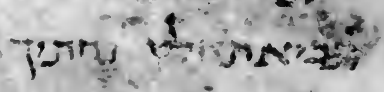

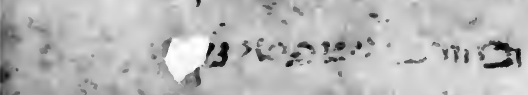

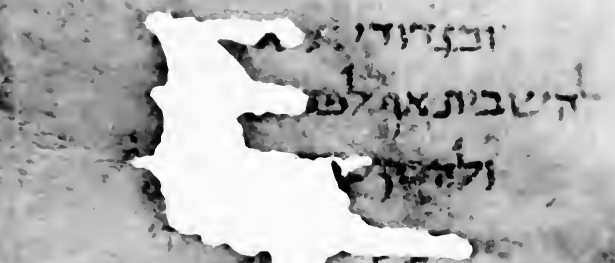

TI:-

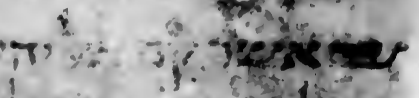

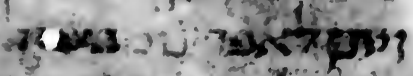

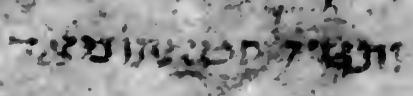

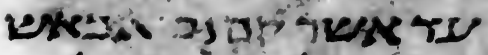

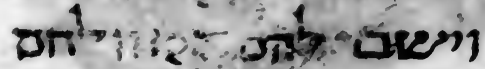

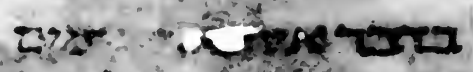

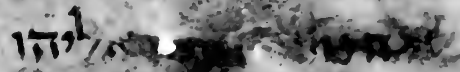
- Ins?

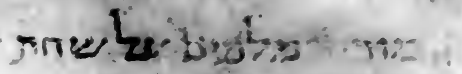

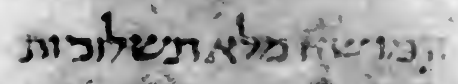

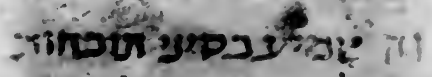
o' 1 ins

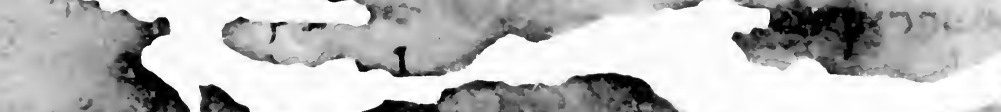

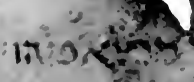
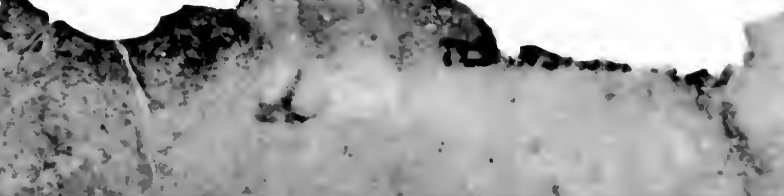

MS. B. Ecclus. xlvii, $23^{c}-x \mid v i i i$, I2 


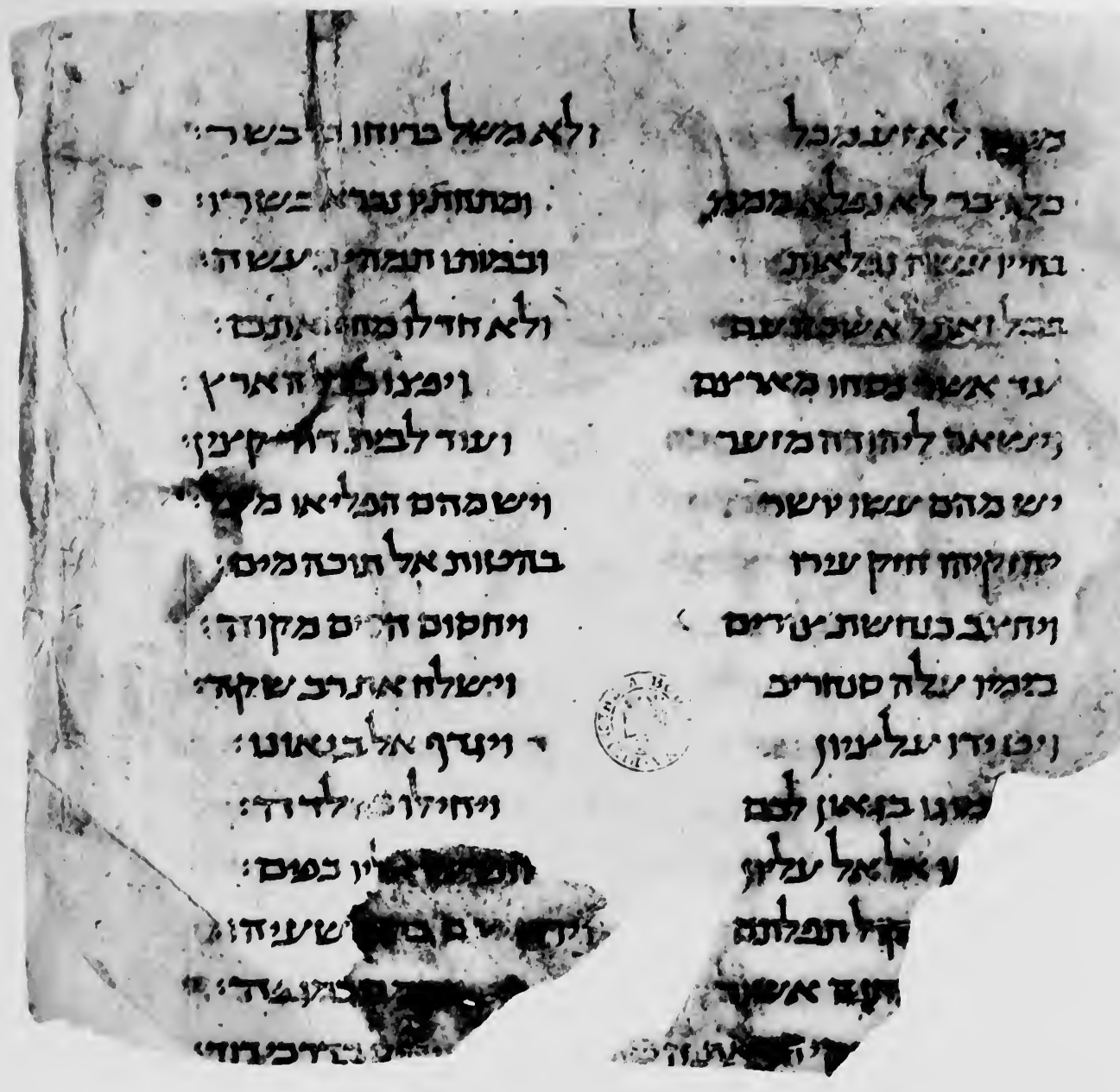

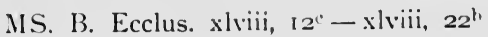




\section{.}




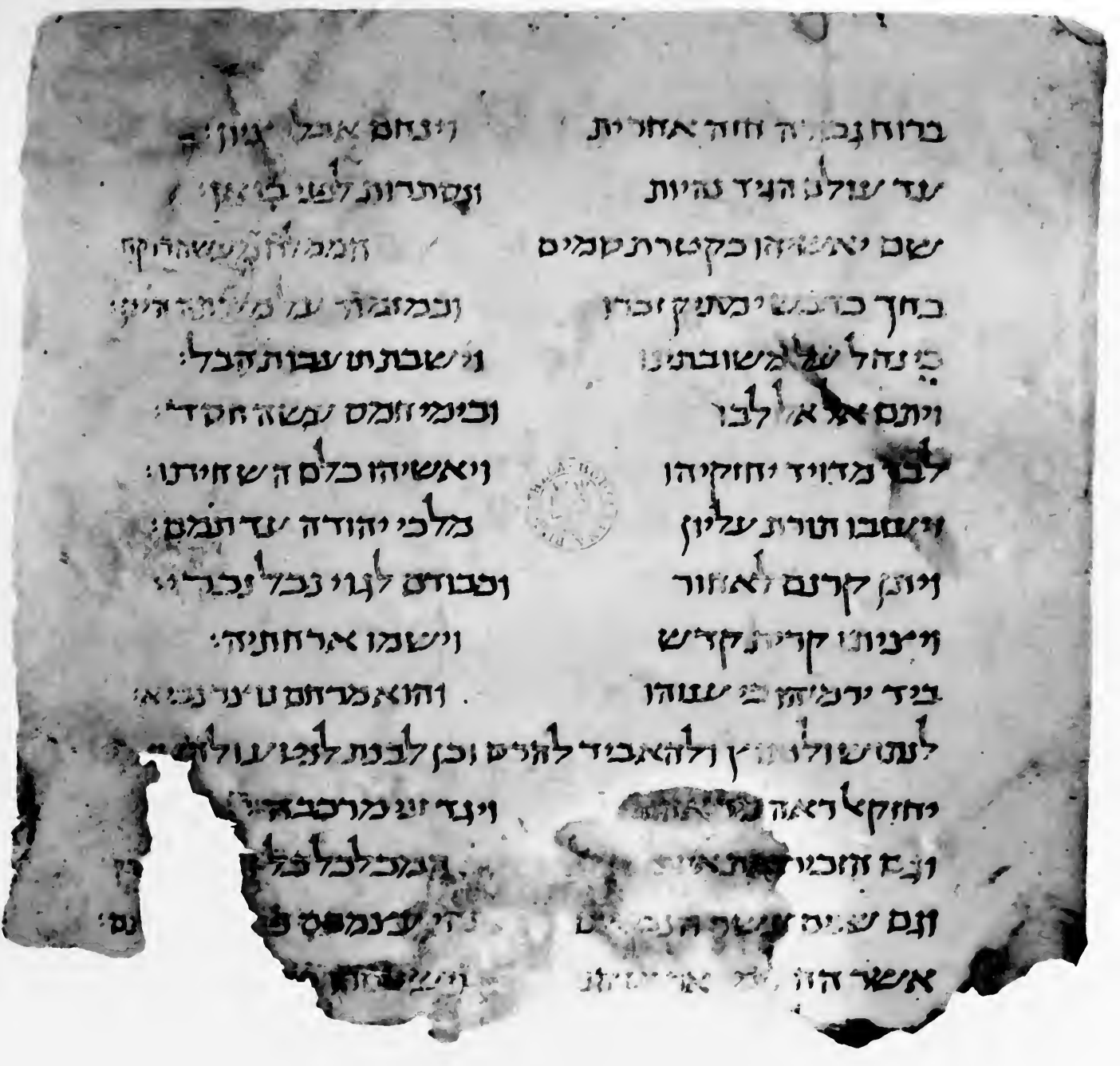

MS. B. Ecclus. xlviii, $2+-x \operatorname{lix}$, I 


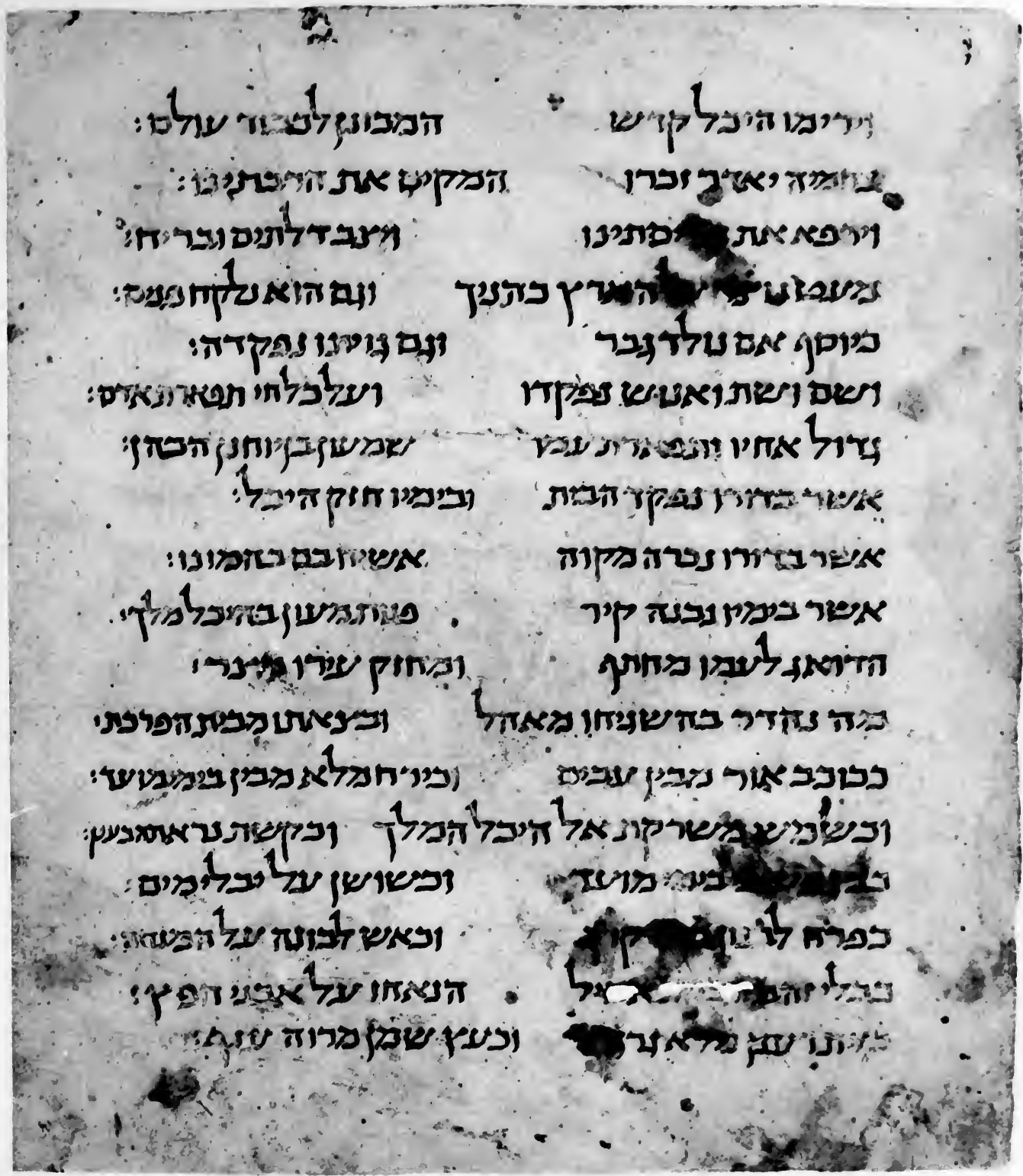

MS. B. Ecclus. xlix, $12^{c}-1$, 10 


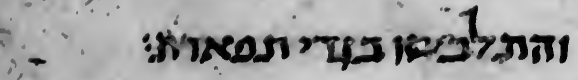

- : "2

ทv丶

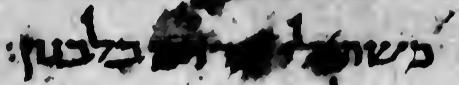

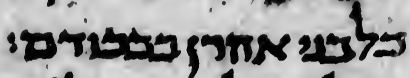

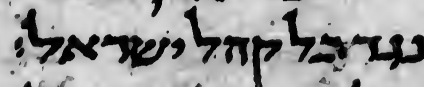

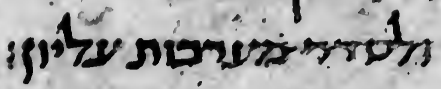

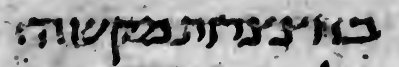

intzes rest mont?

1.

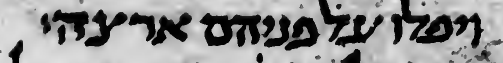

:

: Dוח

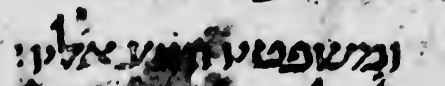

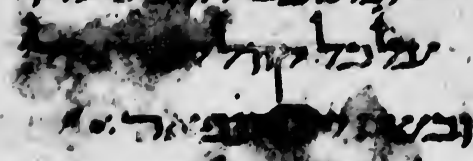

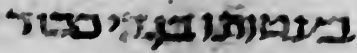

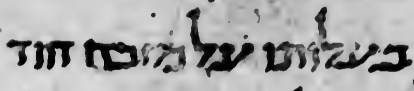
".

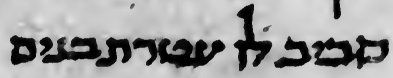
brosusmiapes vory" rese! numpism

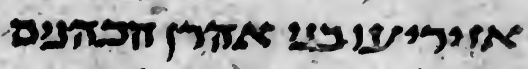
raship winem ien'y . ח

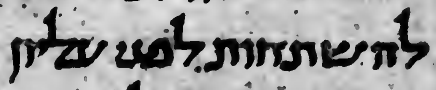

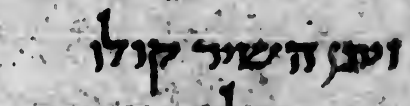

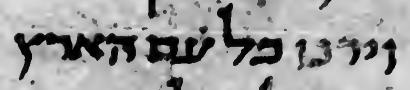
nsias rues ints re MTNReA TISR mores Hasis? suse hsot? isen? 130

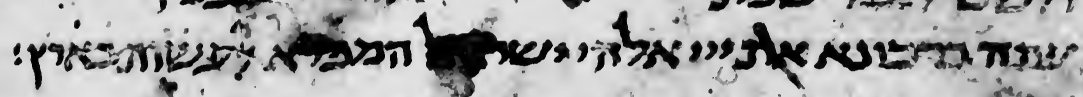

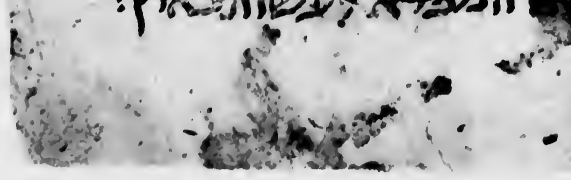





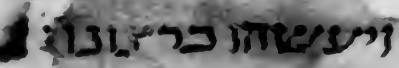

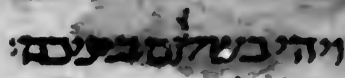

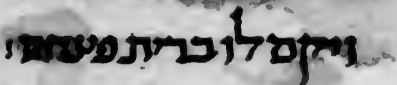

כימיומי

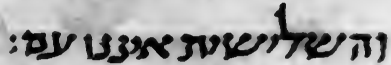

: : 1)

:

:

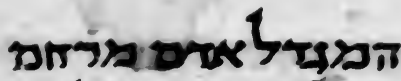

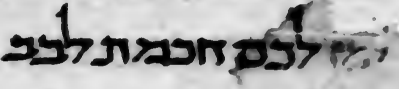

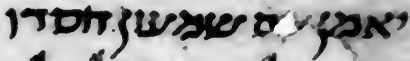

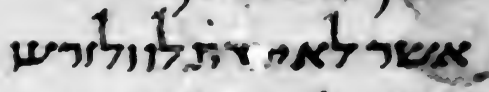

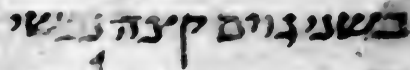

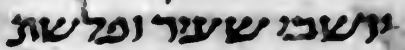

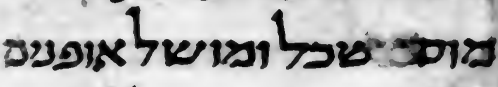

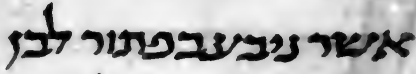
תיה - את

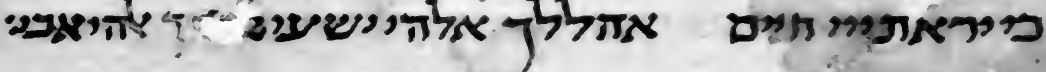
ביפדית מבותנפטיט

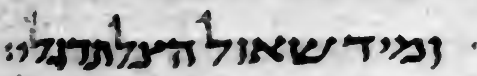

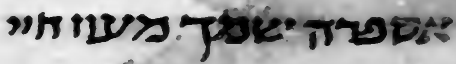

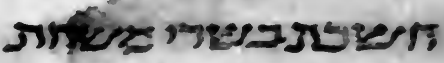

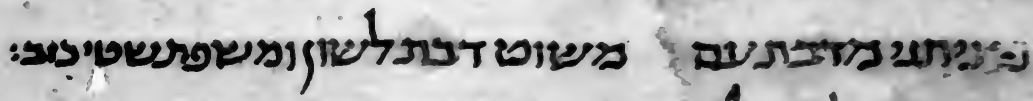
:

: obe $\pi$ iा

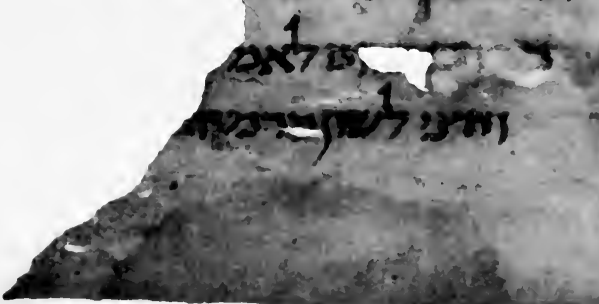

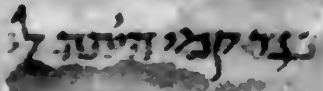
Itemis serpisas 7ร กับ

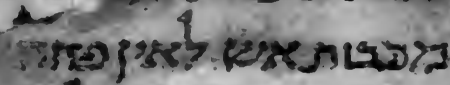
1

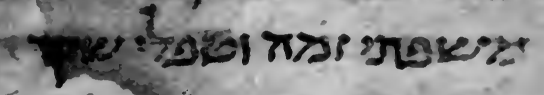

MS. B. Ecclus. $1,22^{r}-1 i, 5$ 


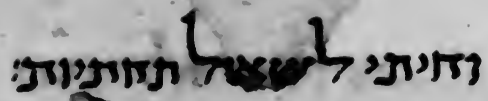

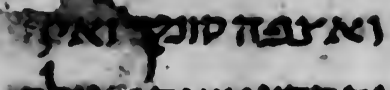

gotur YTENITDMI

uמ

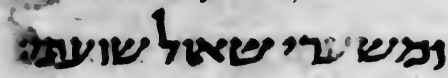

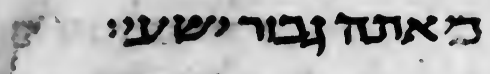

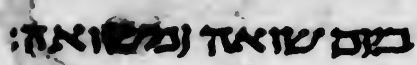

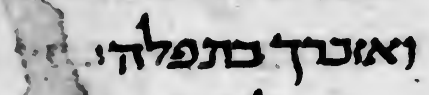

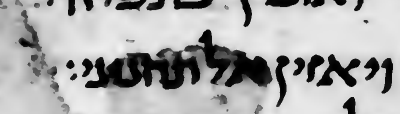

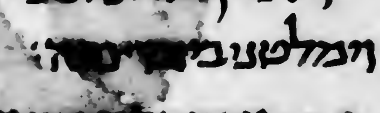

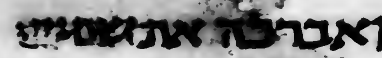

us ras abiefar

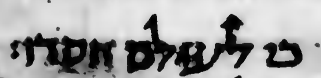

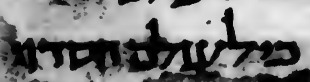

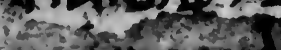

astrondersy

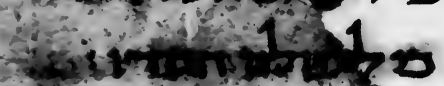

$1+1,150$

supm

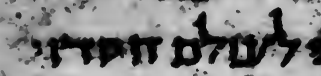

1) מאו

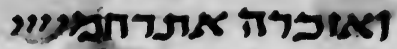

המקציל אתחחוטיבו

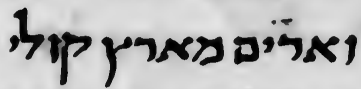

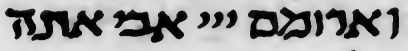

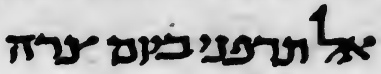

אהללולה שמנק תמכיד

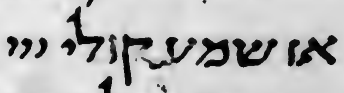

111

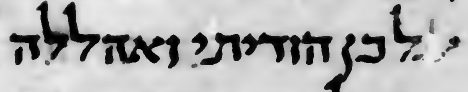

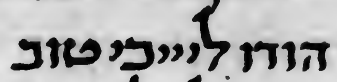

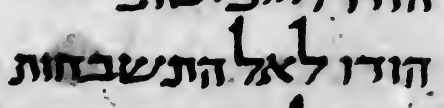

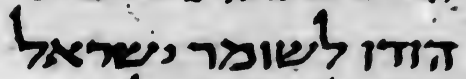
1

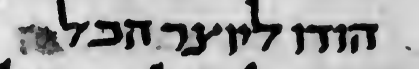

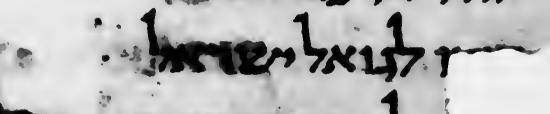

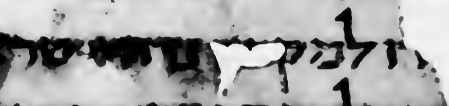

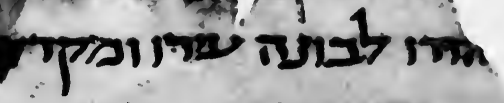

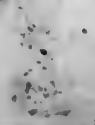
$x$ 



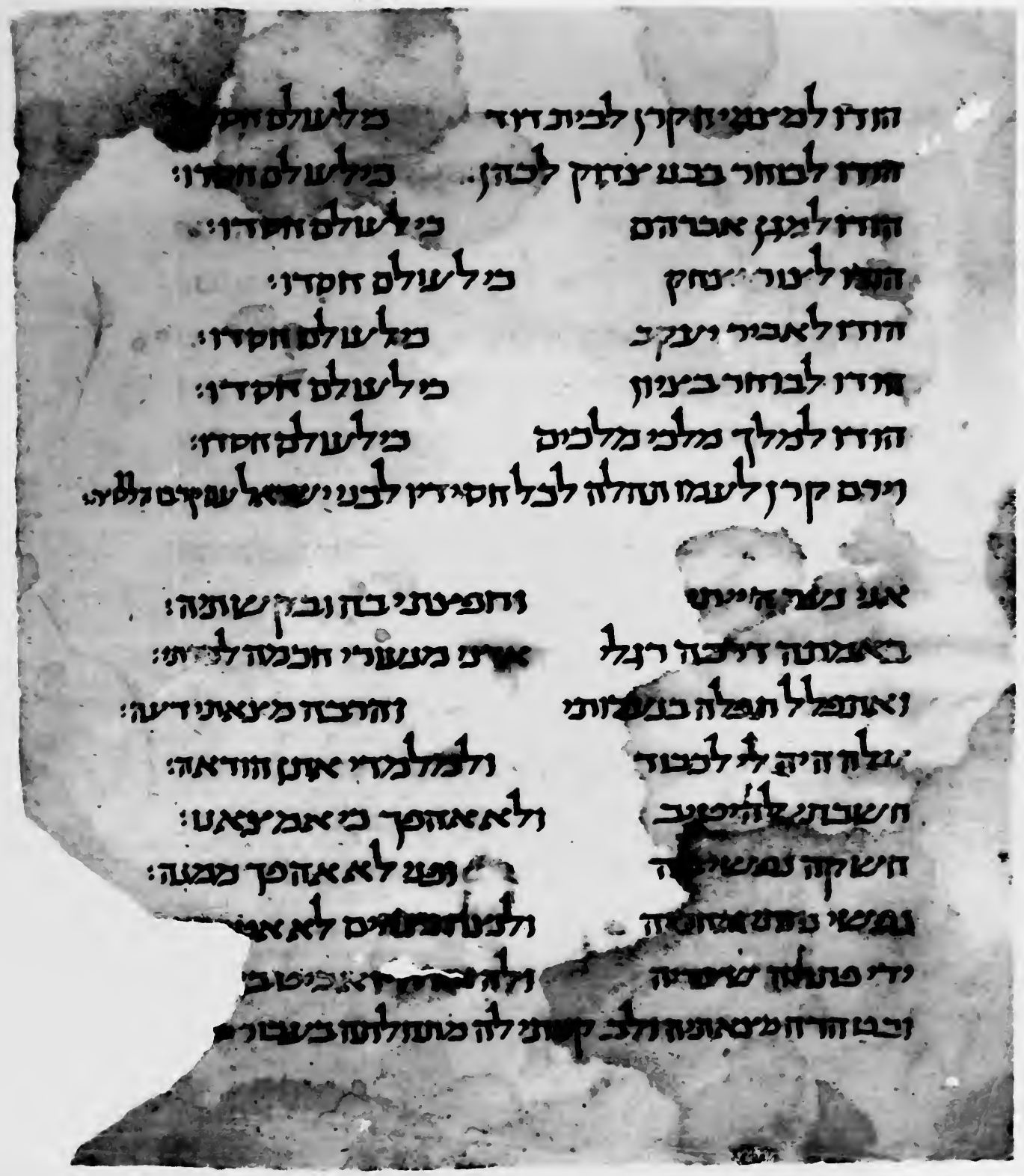

MS. B. Ecclus. li, $12+-\mathrm{li}, 20$ 


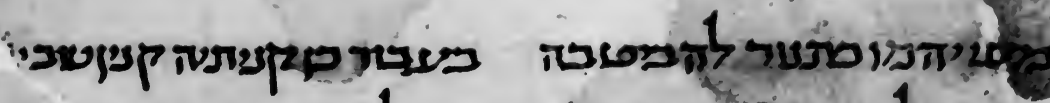

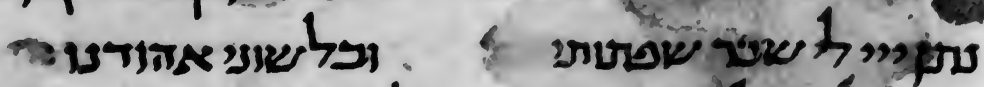

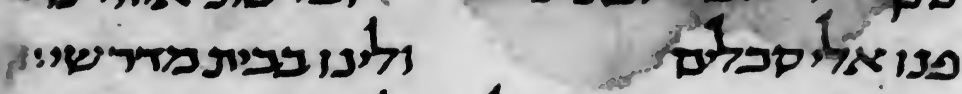

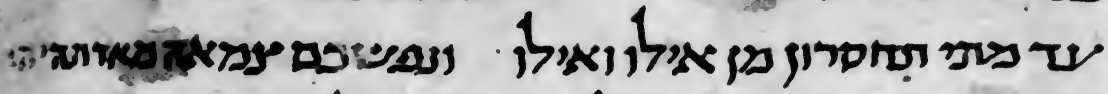

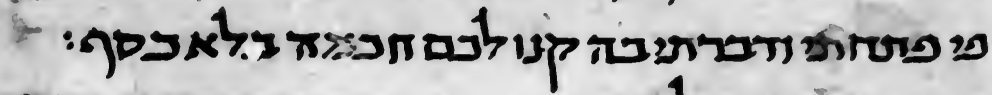
:

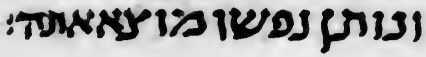

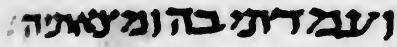

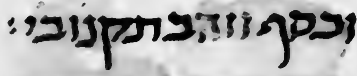

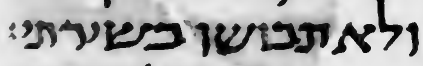

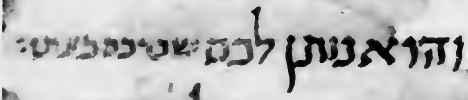

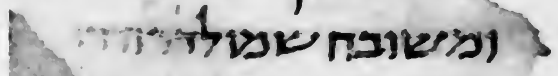

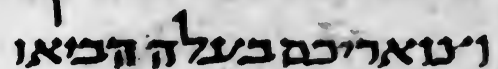

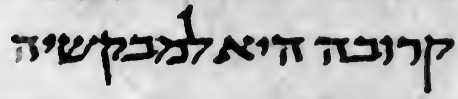
ניאוביצזיכס ביקטן הייתי

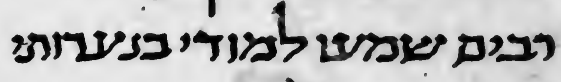
ט

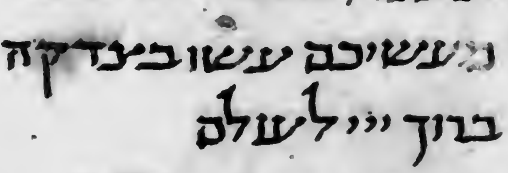

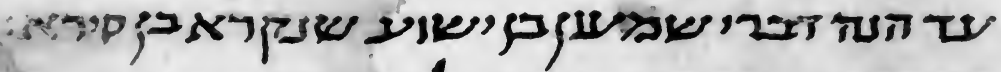

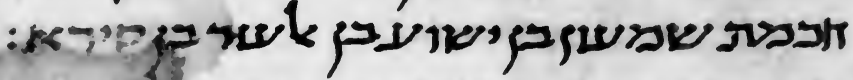

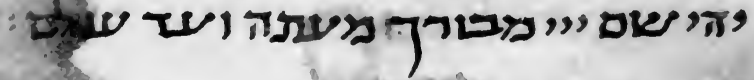

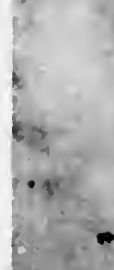

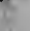

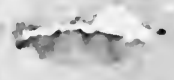





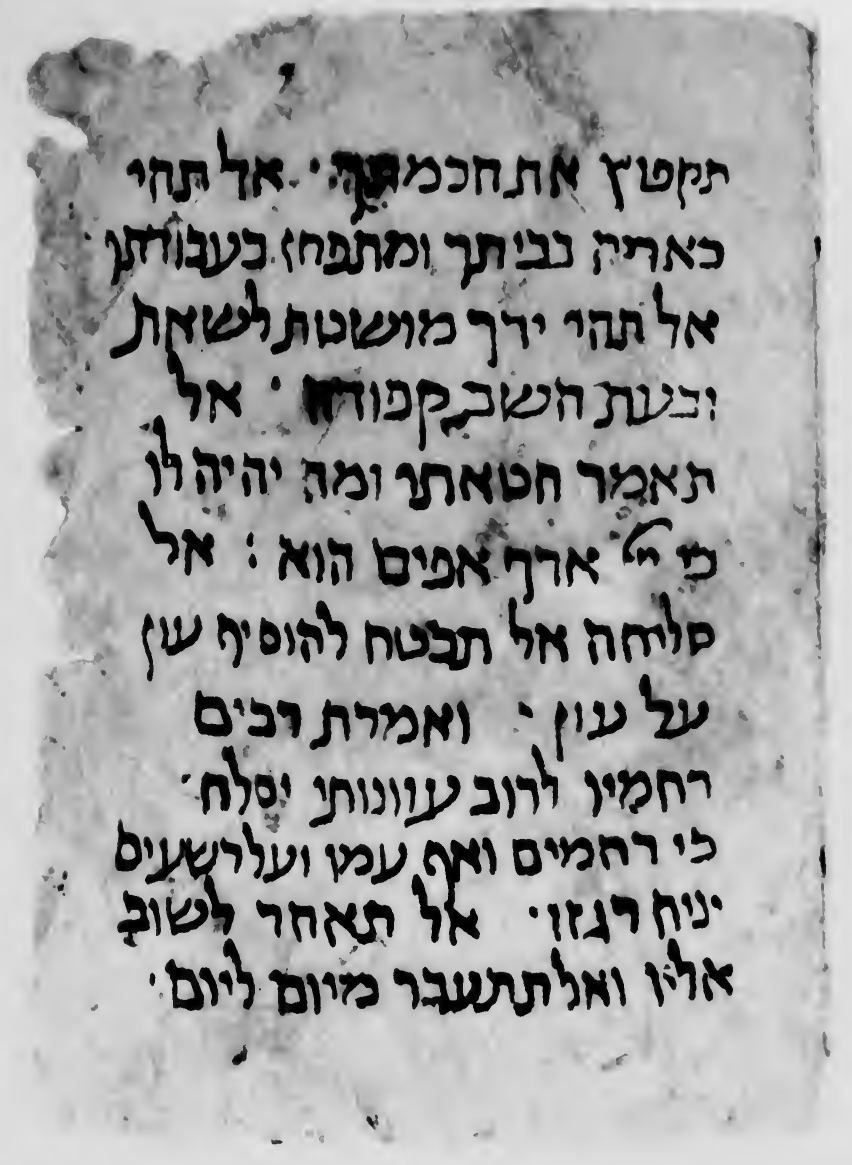

MS. C. Ecclus. iv, 23, 30, $3^{1} ; v,+-v, 7^{b}$ 
. 


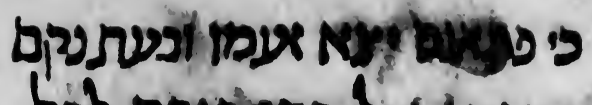

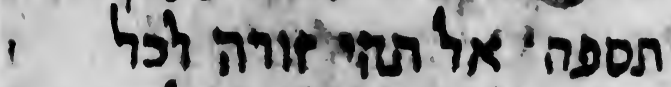

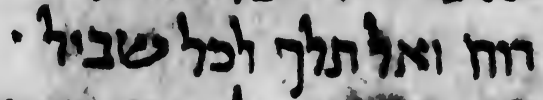

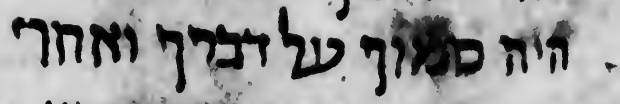

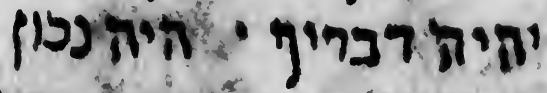

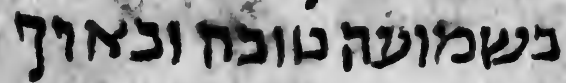

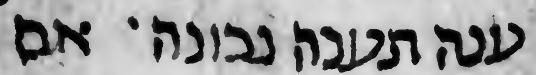

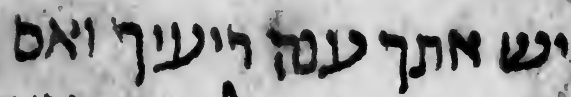

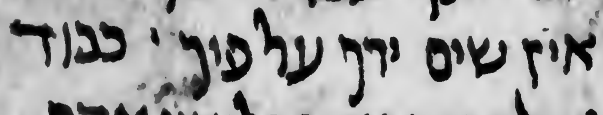

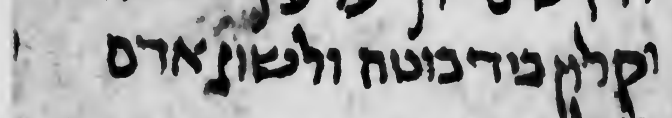

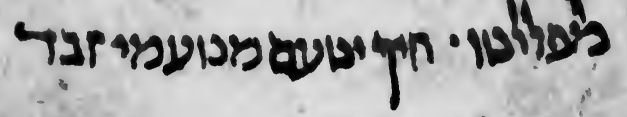

MS. C. Ecclus. v, $7^{\prime \prime} ; r, 9-v, 13+$ 

7rips win:- mosn divgr

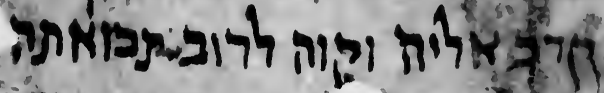

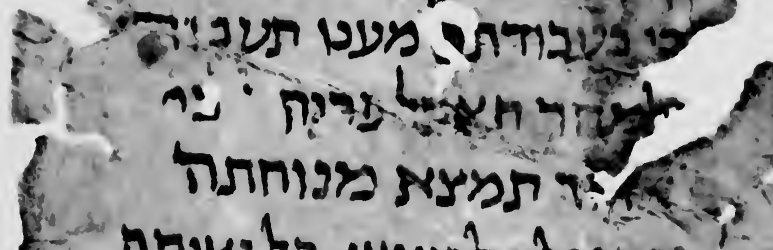

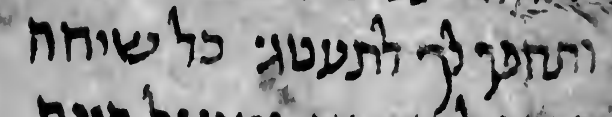

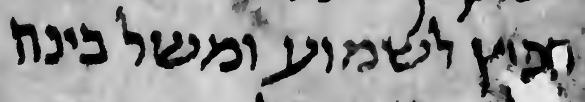

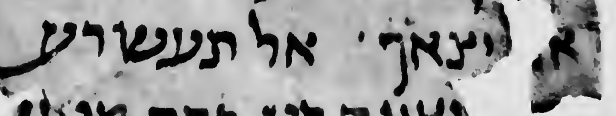
plios pris yy jive. Nowgris

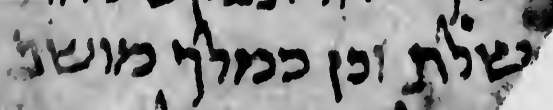

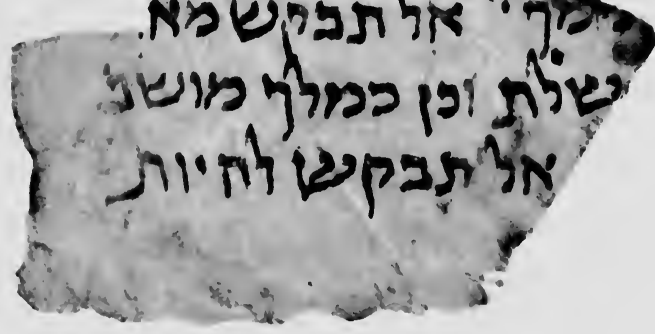

MS. C. Ecclus. vi, $18^{h}, 19,28,35$; vii, $1,4,6^{\text {n }}$ 



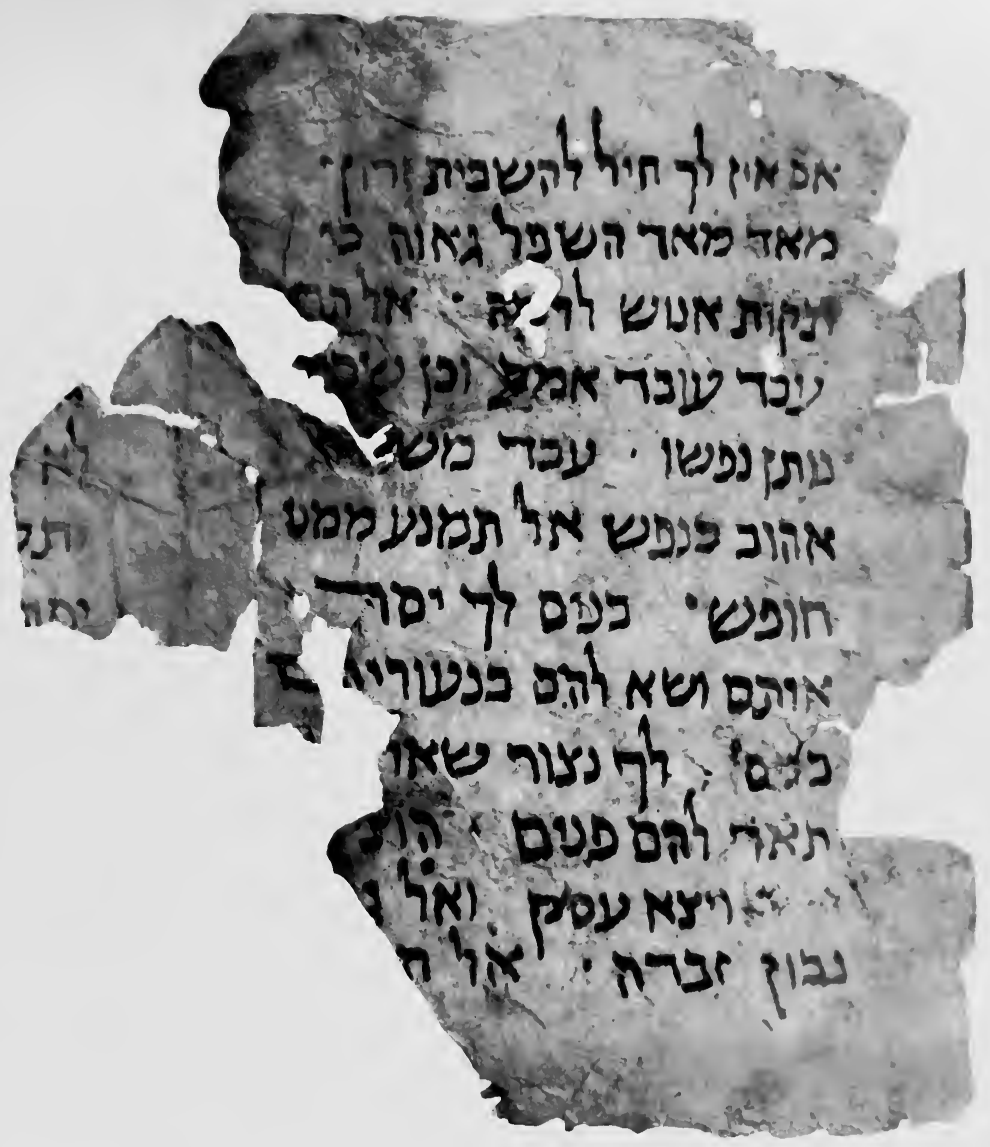

MS. C. Ecclus. vii, 6', 1 7, 20, 21, 23-25 


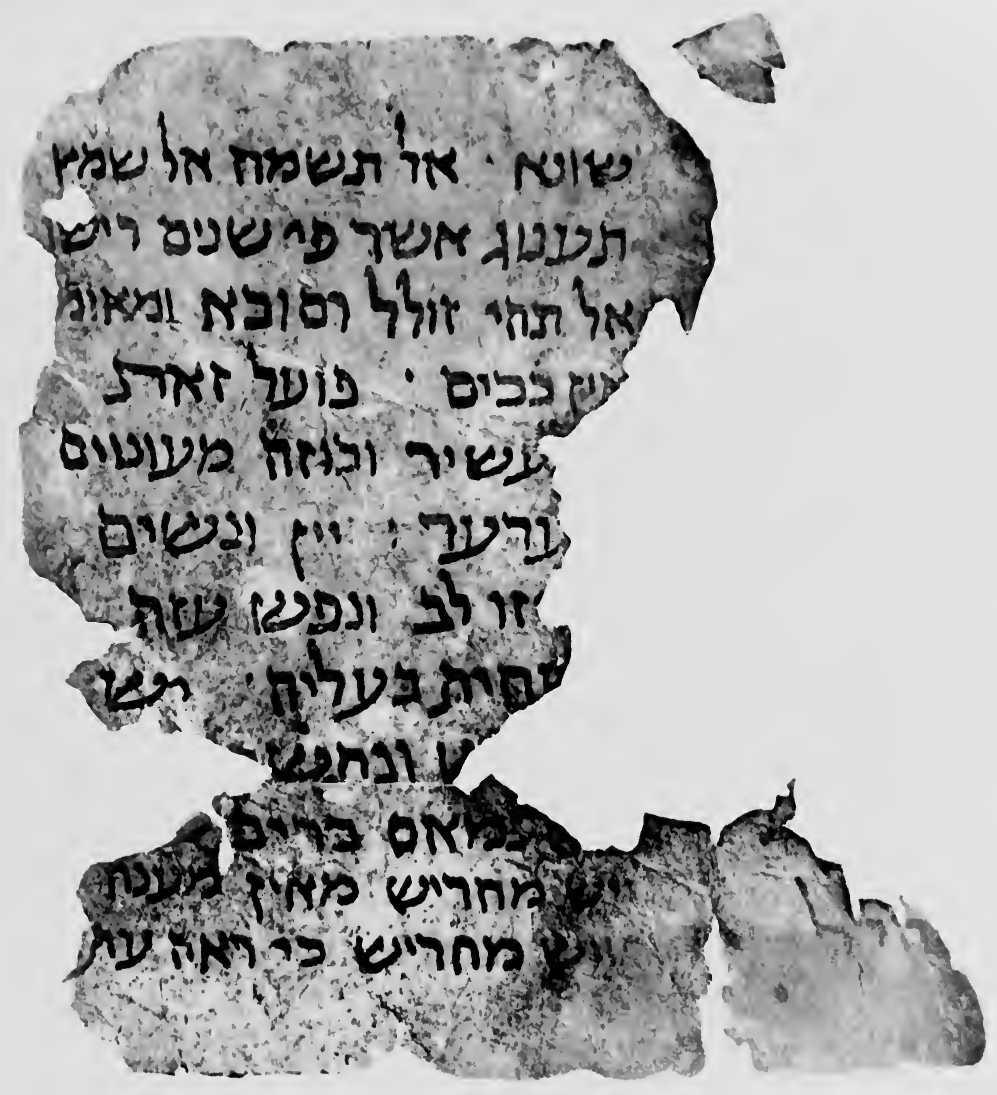

MS. C. Ecclus. xviii, $3^{1}-x i x, 3^{b} ; x x, 5,6$ 



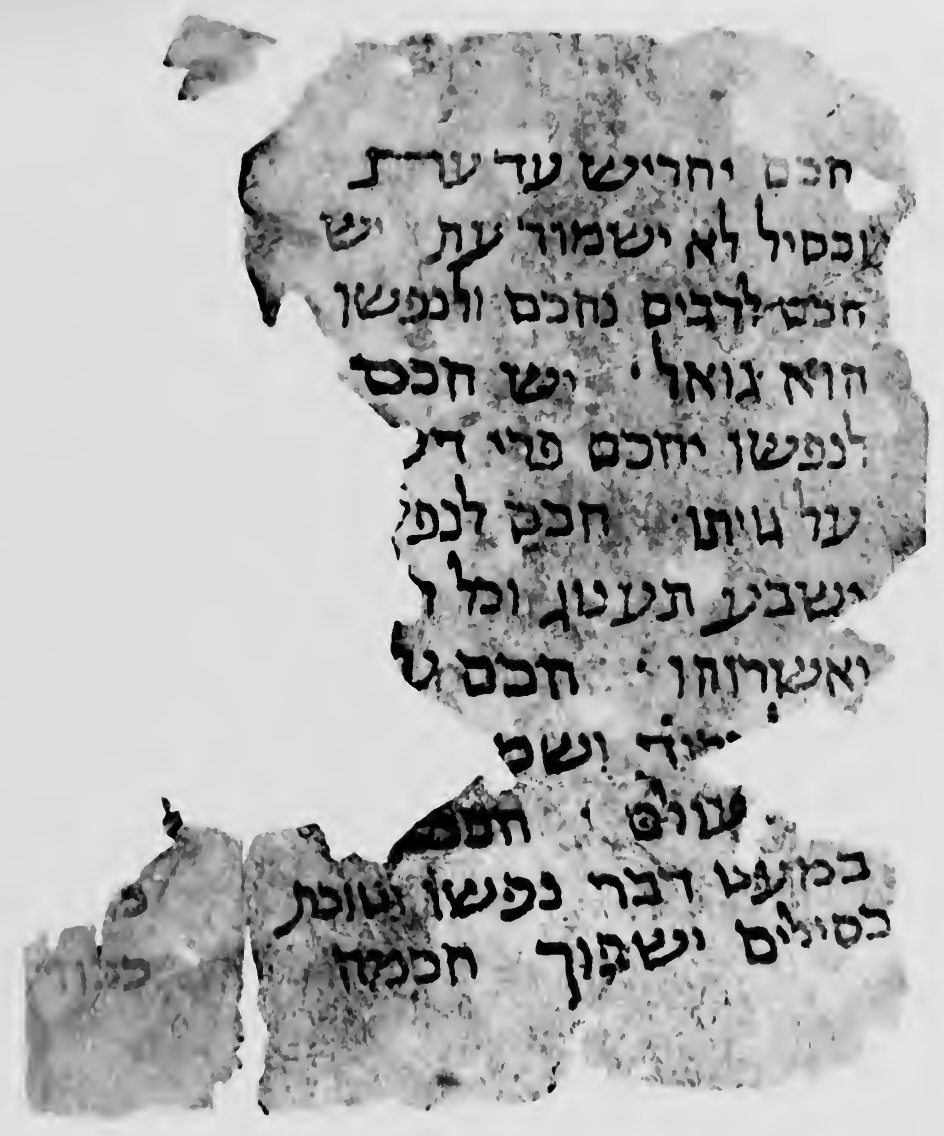

MS. C. Ecclus. $x x, 7 ; x x x v i i, 19,22,24,26 ; x x, 13$ 



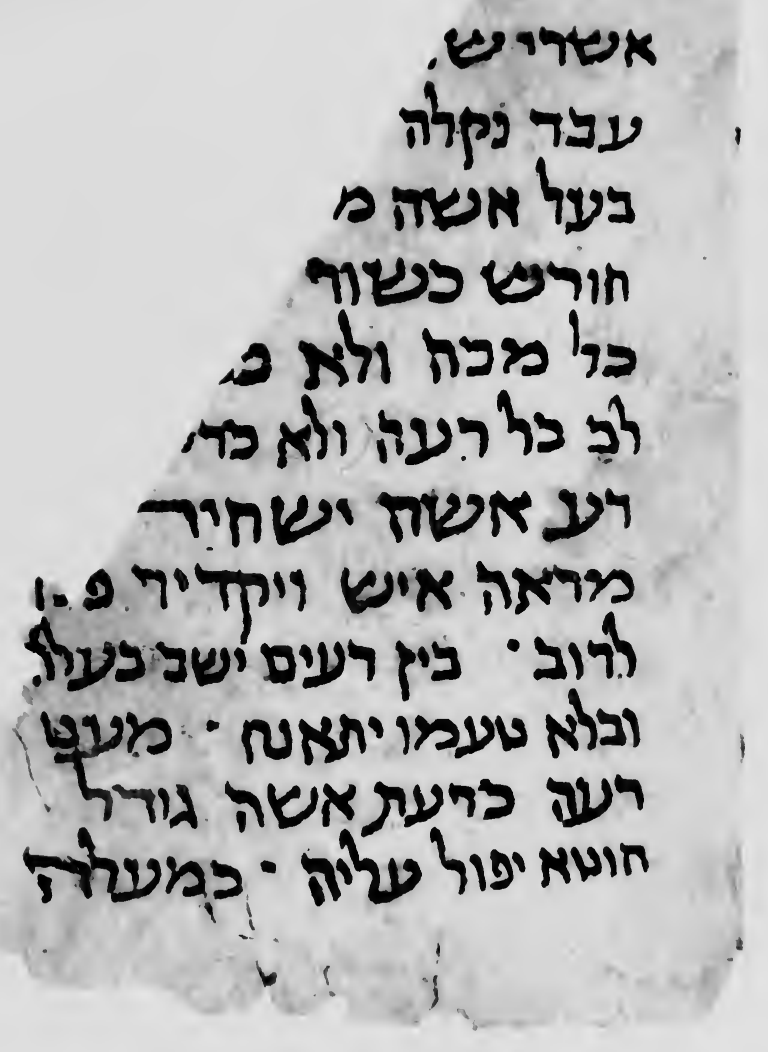

MS. C. Ecclus. xxv, 8, $13,17-20^{2}$ 

hies.

או דתמור

הiterier

tomes 0 : 9

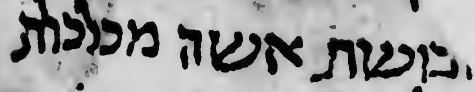

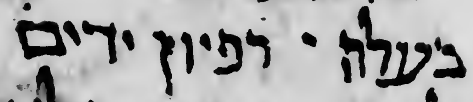

लीpres

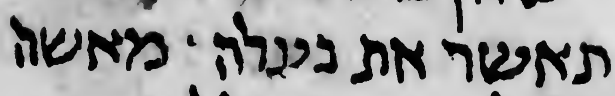

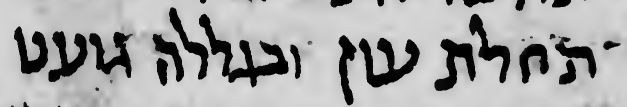

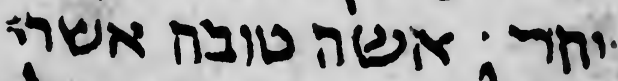

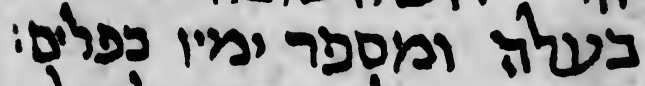

ה)y

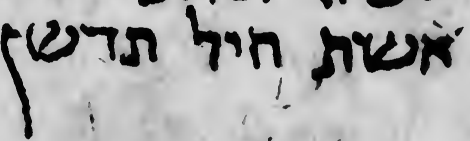

MS. C. Ecclus. $x x i, 20^{1,-2+;} x x v i, 1,2^{4}$ 


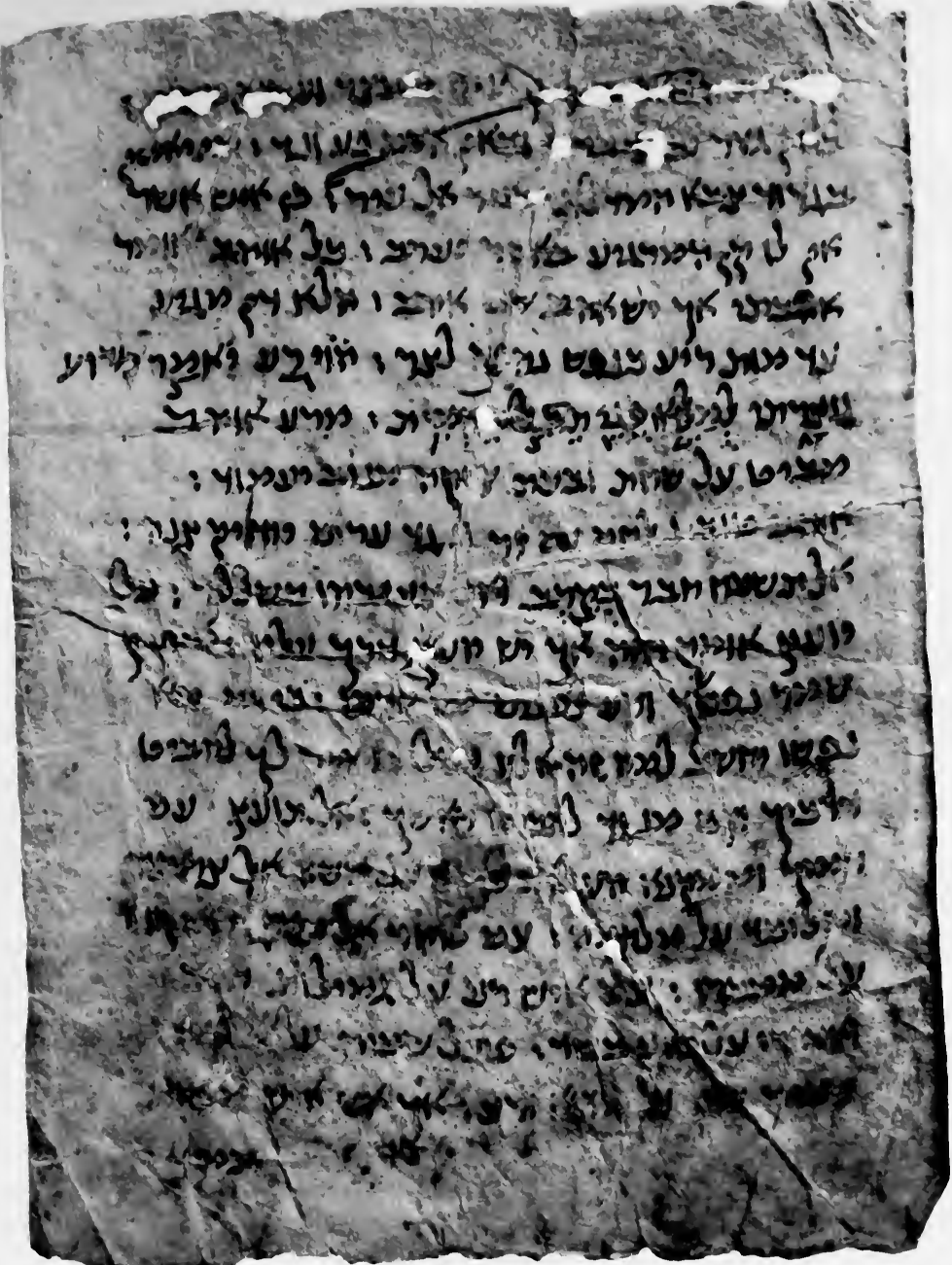

MS, D. Ecclus, xxxvi, 29-xxxvii, $12^{n}$ 
. 


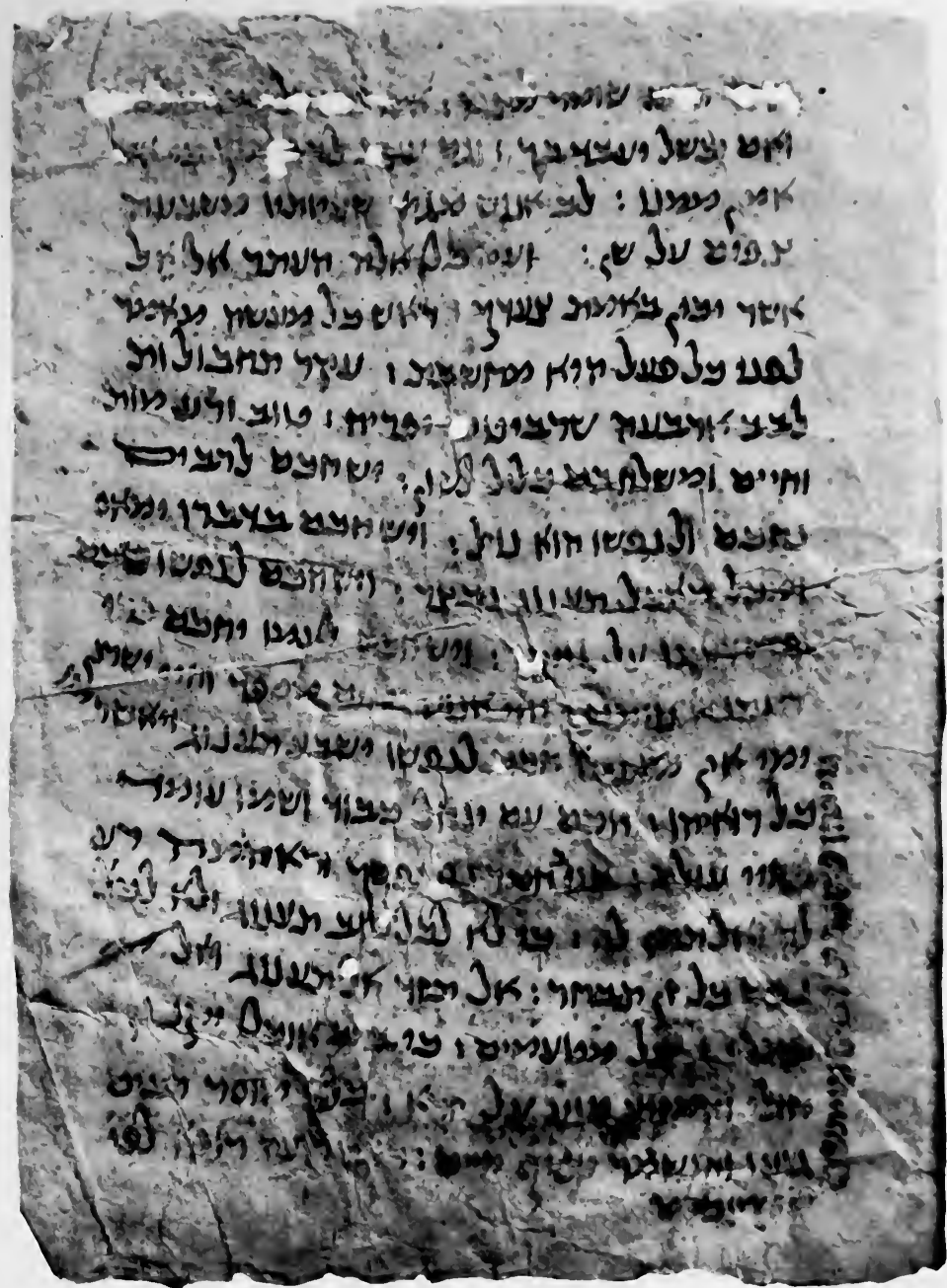

MS. D. Ecclus. $x x x v i i, 12^{b}-x x x v^{2 i i i,} I^{n}$ 


\section{-}




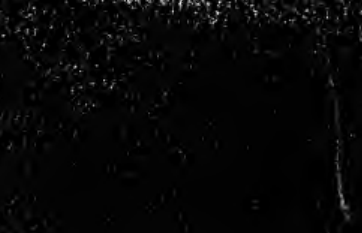

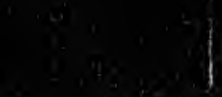

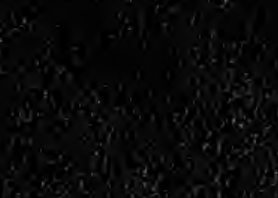

+

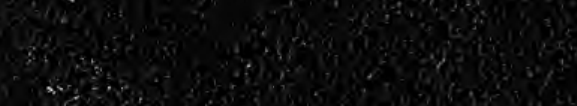
8 